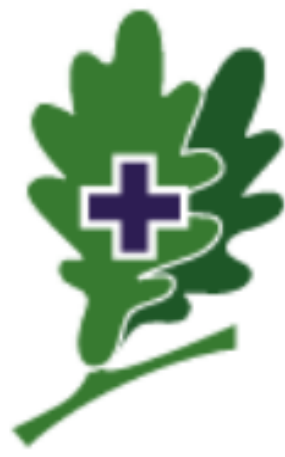

FACULTAD DE CIENCIAS VETERINARIAS UNIVERSIDAD NACIONAL DE LA PLATA

TESIS DOCTORAL

MV. FLORENCIA ALINA D'FRANCISCO

2021 


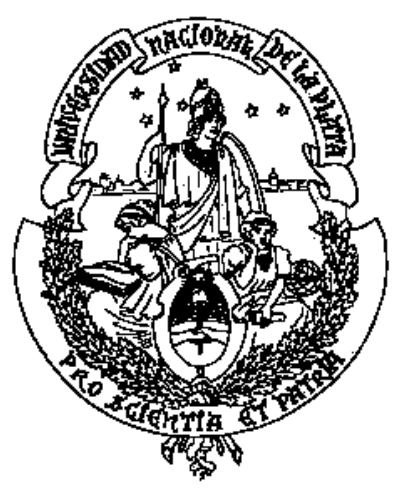

UNIVERSIDAD NACIONAL DE LA PLATA

FACULTAD DE CIENCIAS VETERINARIAS

Trabajo de Tesis realizado como requisito para optar al título de DOCTOR EN CIENCIAS VETERINARIAS

EFECTOS DE UN DERIVADO DE INDENOPIRIDINA, RTI-4587-073 (L), EN LA REPRODUCCIÓN DEL GATO DOMÉSTICO (FELIS CATUS)

AUTOR: Méd. Vet. D'FRANCISCO, Florencia A.

DIRECTOR: Dra. GOBELLO, Cristina, DECAR

LUGAR DE TRABAJO: Centro de Fisiología Reproductiva, Facultad de Ciencias Veterinarias, UNLP

MIEMBROS DE JURADO: Dra. De Palma, Viviana

Dr. Ortega, Hugo

Dra. Yaful, Graciela

Año 2021 
A mi familia. A mis amigos. A mis animalitos.

Y a todos aquellos que me acompañaron en este camino.

"Hagas lo que hagas, ámalo. Como amabas la cabina del Paradiso cuando eras niño”

Giuseppe Tornatore, “Cinema Paradiso” 


\section{AGRADECIMIENTOS}

A mi directora, la Doctora Cristina Gobello, por abrirme las puertas al mundo de la investigación y guiarme en todo momento con gran compromiso, dedicación y responsabilidad.

A mi familia, por ser ejemplo de esfuerzo, honestidad y dignidad. Por inculcarme siempre la importancia de la educación y brindarme las herramientas necesarias para transitar la vida, tratando siempre de hacer el bien. Pero sobre todo gracias por ser incondicionales y estar en todo momento.

A mis amigos, parte fundamental de mi vida. Gracias por su incondicional apoyo y cariño.

A Nacho, que me acompañó en el tramo final. Gracias por su compañía, apoyo, paciencia y especialmente por todo su amor.

A mis compañeras de trabajo Mari y Cami, por su invalorable colaboración, dedicación y buena predisposición en todo momento. Gracias por los momentos, mates y risas compartidos, y por hacer que todo sea mucho más fácil y ameno.

A los Servicios de Cardiología y Ultrasonografía, por brindarme el espacio para desarrollar parte de este trabajo.

A mi país, Argentina, que me dio la posibilidad de acceder a una formación académica de excelencia gracias a su educación pública, y que a través del Consejo Nacional de 
Investigaciones Científicas y Tecnológicas (CONICET), me otorgó la beca que me permitió dedicarme de manera exclusiva a mis estudios de doctorado.

Al Research Triangle Institute, Research Triangle Park, North Carolina, USA, por la provision del RTI-4587-073 (L) y al Contraception \& Reproductive Health Branch Center for Population Research, National Institute of Child Health \& Human Development, National Institutes of Health, USA, por la provision del acyline.

Finalmente, a todos los animales que participaron de este trabajo, porque fueron mucho más que participantes, brindando amor y compañía. Especialmente Raúl, que se volvió miembro de mi familia. 
PUBLICACIONES PARCIALES DEL PRESENTE TRABAJO DE TESIS

\section{Publicaciones en revistas internacionales}

D'Francisco F, López Merlo M, Vercellini R, Blanco P, Barbeito C, Gobello C. Effect of the Indenopyridine RTI-4587-073 (L) on Feline Testicle. Anim Reprod Sci. 2019; 205:10-17.

D’Francisco F, Lapuente C, López Merlo M, Barbeito C, Gobello C. Feline testicular ultrasonogram differentiates pre vs. postpubertal and normal vs. disrupted spermatogenesis. Theriogenology. 2020; 153:503-507.

\section{Presentaciones en congresos nacionales e internacionales}

D’Francisco F, López Merlo M, Vercellini R, Blanco P, Arias D; Gobello C. Evaluación histológica de testículos felinos expuestos a un protocolo contraceptivo de RTI-4587-073 (L). X Jornadas Internacionales de Veterinaria Práctica, 2017, Mar del Plata, Argentina.

D’Francisco F, López Merlo M, Vercellini R, Blanco P, Barbeito C, Gobello C. Efecto de la indenopiridina RTI-4587-073 (l) en el testículo felino. VIII Jornadas de Jóvenes Investigadores. Facultad de Ciencias Veterinarias, Universidad de Buenos Aires, 2018, Capital Federal, Argentina. 
D'Francisco F, López Merlo M, Verellini R, Blanco P, Barbeito C, Gobello C. Effect of the indenopyridine RTI-4587-073 (1) on feline testicle. 6th International Symposium on Non-Surgical Contraceptive Methods of Pet Population Control, 2018, Boston, USA.

D’Francisco F, López Merlo M, Lapuente C, Blasco A, Gobello C. Ultrasonograma testicular en el gato doméstico durante el arresto espermatogénico. IX Jornadas de Jóvenes Investigadores. Facultad de Ciencias Veterinarias, Universidad de Buenos Aires, 2019, Capital Federal, Argentina.

D’Francisco F, López Merlo M, Lapuente C, Blanco P, Gobello C. Feline testicular ultrasonogram before and after spermatogenic arrest. XXIInd International Congress of the European Veterinary Society for Small Animal Reproduction (EVSSAR), 2019, Berlin, Alemania.

D’Francisco F, Lapuente C, López Merlo M, Lantermino A, Gobello C. Testicular ultrasound differences in pre vs. postpubertal male cats. XXIIIrd International Congress of the European Veterinary Society for Small Animal Reproduction (EVSSAR), 2020, Milán, Italia (aceptado) 


\section{ÍNDCE DE CONTENIDOS}

\section{ABREVIATURAS}

RESUMEN

\section{CAPÍTULO I}

Efecto del derivado de indenopiridina RTI-4587-073 (L) en el testículo felino

\section{CAPÍTULO II}

Análisis digital ultrasonográfico de testículos felinos normales y anormales

\section{CAPÍTULO III}

Análisis digital ultrasonográfico durante el desarrollo testicular felino 
ABREVIATURAS

T: testosterona

LH: hormona luteinizante

FSH: horomona folículoestimulante

GnRH: hormona liberadora de gonadotrofinas

PO: per os

ml: mililitro

MHz: mega Hertz

ng: nanogramo

SC: subcutánea

IM: intramuscular

IV: intravenosa

Kg: kilogramo

g: gramo

$\mu \mathrm{m}:$ micrómetro

H\&E: hematoxilina y eosina

SEM: error estándar de la media

$\boldsymbol{\mu g}$ : microgramo

RDI: región de interés

IMP: intensidad media de pixeles

ANOVA: análisis de varianza 


\section{EFECTOS DE UN DERIVADO DE INDENOPIRIDINA, RTI-4587-073 (L), EN LA REPRODUCCIÓN DEL GATO DOMÉSTICO (FELIS CATUS)}

Palabras claves: felino, contracepción, reproducción, indenopiridina, ultrasonografía

\section{Resumen}

Con el objetivo de contribuir al control y mejora de la reproducción de felinos domésticos, este Trabajo de Tesis se planteó como objetivos: 1) evaluar el efecto de la indenopiridina RTI-4587-073 (1) en la espermatogénesis; 2) describir y comparar la ecogenicidad y heterogeneidad testicular mediante análisis digital de imágenes ultrasonográficas en: a) testículos normales y con alteraciones en la espermatogénesis y b) gatos prepuberales, peripuberales y adultos. En el primer capítulo, 30 gatos machos adultos, se trataron (día 0) con $12,5 \mathrm{mg} / \mathrm{kg}$ PO de RTI-4587-073 (L) y se hemiorquiectomizaron a los -14 días, 6 horas, 12 horas, 1 día, 7 días, 14 días, 21 días, 35 días o 42 días. Previamente, se tomaron muestras para determinación de testosterona (T) fecal. Los testículos se evaluaron macro y microscópicamente. El RTI-4587-073 (L) no provocó cambios en: parámetros macroscópicos testiculares $(\mathrm{P}>0,1)$, concentraciones de $\mathrm{T}$ fecal $(\mathrm{P}>0,1)$ ni aparición de efectos secundarios. Histológicamente, a partir de las 6 horas, se observó desorganización de la citoarquitectura del epitelio seminífero y disminución del volumen de todos sus componentes, excepto las espermatogonias. Estos cambios desaparecieron gradualmente hacia el final del estudio. Así, el RTI-4587-073 (L) provoca rápida interrupción de la espermatogénesis con retorno a la normalidad en aproximadamente un ciclo espermático, sin efectos secundarios. En el segundo capítulo, se incluyeron 7 gatos machos adultos en un modelo experimental de daño 
espermatogénico, mediante administraciones sucesivas de un antagonista de GnRH. Previa y posteriormente, los testículos se evaluaron mediante ultrasonografía modo B. La ecogenicidad y heterogeneidad se analizaron digitalmente, cuantificándolas como la intensidad media de pixeles (IMP) y su desvío standard (DS), respectivamente. Los animales se orquiectomizaron, y los parámetros histomorfométricos testiculares se correlacionaron con las variables ultrasonográficas. La ecogenicidad $(\mathrm{P}<0,05)$ pero no la heterogeneidad $(\mathrm{P}<0,1)$, disminuyó tras el deterioro espermatogénico $(\mathrm{P}>0,1)$. No se halló correlación entre parámetros ecográficos e histológicos. En el tercer capítulo, 14 gatos machos adultos, se evaluaron ultrasonográficamente como en el capítulo anterior. Luego de ser orquiectomizados, se clasificaron histomorfométricamente como Prepuberales, Peripuberales o Pospuberales. La IMP $(\mathrm{P}<0,05)$ y la $\mathrm{SD}(\mathrm{P}<0,05)$ se incrementaron a la pubertad. Los parámetros ultrasonográficos e histomorfométricos mostraron estar fuertemente correlacionados. El análisis digital de imágenes ultrasonográficas modo B podría convertirse en una herramienta diagnóstica útil en la evaluación de la funcionalidad reproductiva del gato doméstico. 


\section{EFFECTS OF AN INDENOPIRIDINE DERIVATE IN THE DOMESTIC CAT REPRODUCTION}

Key words: feline, contraception, indenopiridine, ultrasonography

\section{Summary}

To contribuite to the improvement and control of feline reproduction, the aims of this Thesis were 1) to evaluate the effect of the indenopiridine RTI-4587-073 (1) on spermatogenesis; 2) to describe and compare testicular echogenicity and heterogeneity assessed through digital ultrasound images of a) normal and abnormal testicles b) prepubertal, peribupertal and adult cats. In the first chapter, 30 adult male cats were treated (d 0) with RTI-4587-073(l) $12.5 \mathrm{mg} / \mathrm{kg}$ PO and randomly hemiorchiectomized on: day $-14,6$ h, 12 h, 24 h, day 7, day 14, day 21, day 35 or day 42. Fecal samples for testosterone ( $\mathrm{T}$ ) measurement were collected and the testes were gross and microscopically examined. RTI-4587-073 (L) did not cause clinical side effects nor changes in neither gross testicular parameters $(\mathrm{P}>0.1)$ nor fecal $\mathrm{T}$ concentrations $(\mathrm{P}>$ 0.1). Severe disorganization of the cytoarchitecture of the seminiferous epithelium and decrease in all its components volumes, except spermatogonias, were found at $6 \mathrm{~h}$ to progressively decrease up the end of the study. RTI-4587-073 (L) rapidly disrupted spermatogenesis, returning to normality in approximately one spermatic cycle without clinical side effects. On the second chapter, a pharmacological model of spermatogenic impairment was used where 7 adult male cats were administered a GnRH antagonist. Testicles were evaluated by mode B ultrasonograpy before and after the antagonist, and echogenicity and heterogeneity were digitally analyzed and measured as mean pixel 
intensity (MPI) and its standard deviation (SD), respectively. The animals were orquiectomized and the correlation among histomorfometric and ultrasonographic parameters was calculated. Testicular echogenicity $(\mathrm{P}<0.05)$ but not its heterogeneity $(\mathrm{P}>0.1)$ diminished after spermatogenic damage. No correlation between histologic and ecographic parameters was found. On the third chapter, 14 male cats were ultrasonographically evaluated as previously described. The animals were orquiectomized and classified as Prepubertal, Peribupertal or Pospubertal. The MPI $(\mathrm{P}<0.05)$ and the SD $(\mathrm{P}<0.05)$ increased at puberty. Ultrasonographic and histomorfometric parameters had shown to be strongly correlated. Digital analysis of B Mode ultrasound images could be a useful tool in the feline breeding soundness examination. 


\section{INTRODUCCIÓN GENERAL}

Desde hace décadas, el gato doméstico viene experimentando un incremento notable en su popularidad como animal de compañía, tendencia observada a nivel mundial y nacional (Zasloff, 1996). En muchos países la población felina ha superado ampliamente a la canina. A medida que aumenta la urbanización y el nivel de desarrollo, el gato es preferido detrimento del perro, debido a su tamaño más pequeño y la menor necesidad de espacio, lo que le permite adaptarse fácilmente a las largas jornadas laborales de sus propietarios (Bernstein, 2007). Se estima que en el mundo existen más de 300 millones de gatos mantenidos como animales de compañía (Statista, 2018) y más de 3 millones en nuestro país (Pet Secure, 2020). Como consecuencia, el interés en la cría de gatos de raza se ha incrementado notablemente (Axner, 1996), existiendo en la actualidad más de 60 razas (O’Brien, 2008). Esta tendencia también se observa en nuestro país, donde actualmente son reconocidas más de 20 razas por la Federación Felina Argentina. Todo esto genera una importante actividad económica, promoviendo no sólo el comercio de alimento balanceado y sanitarios, sino también de medicamentos y servicios veterinarios. Sumado a esto, el gato doméstico es un excelente modelo experimental para el estudio de disfunciones genéticas, enfermedades infecciosas e infertilidad en humanos (Pukazhenthi y col., 2001), así como también para el desarrollo de biotecnologías reproductivas para la conservación y preservación de felinos silvestres, los cuales, en su gran mayoría, se encuentran amenazados, son vulnerables o están en peligro de extinción de (Axnér y Forsberg, 2007; O’Brien y col., 2008). 


\section{Anatomía y fisiología del gato doméstico}

El tracto reproductivo del gato consiste en el pene, el escroto, testículos, próstata, glándulas bulbouretrales o de Cowper, epdídimos, conductos deferentes, cordón espermático y uretra.

El pene está localizado ventralmente al escroto. Es una estructura muy vascularizada, compuesto por dos cuerpos cavernosos y un cuerpo esponjoso. En el gato adulto, la porción final, el glande, es una estructura cónica de 5-10 mm, orientado caudalmente, cubierto por 100-200 espículas cornificadas y curvas, de $1 \mathrm{~mm}$ de largo, que se dirigen hacia la base del pene, cuyo desarrollo es andrógeno dependiente (Feldman y Nelson, 1996). Estas espículas se desarrollan en la peripubertad y estimulan la liberación de la hormona luteinizante (LH) en la hembra (Aronson y Cooper, 1967). En los machos de esta especie la separación balano prepucial y la presencia de espículas demuestran el grado de desarrollo sexual (Johnston y col., 2001).

El escroto está localizado ventral al ano y dorsal al pene, y es no pendular. Su piel es fina, y está cubierta por un pelo denso. Un fino tabique de tejido conectivo lo divide en dos cavidades, cada una ocupada por un testículo, epidídimo y el inicio del cordón espermático. Los testículos, que normalmente se encuentran descendidos en la bolsa escrotal al momento del nacimiento (Davidson y Baker, 2009) están localizados en el saco escrotal.

Histológicamente, están compuestos por túbulos seminíferos densamente agrupados, separados por tejido intersticial, que contiene principalmente células de Leydig. Los tres principales tipos celulares testiculares son las células intersticiales de Leydig, que secretan testosterona $(\mathrm{T})$, las células de Sertoli, que secretan estrógenos e inhibina y actúan como soporte estructural y funcional para las células germinales; y las células germinales: espermatogonias, espermatocitos primarios y secundarios, espermátides redondas y elongadas y espermatozoides, que constituyen el epitelio germinal. La barrera hematotesticular y las células de Leydig se encuentran completamente desarrolladas al 
alcanzar la pubertad (Sanchez y col., 1994). La duración de cada ciclo espermático es de 10,4 días, y la duración total de la espermatogénesis es de 46,8 días (França y Godinho, 2003).

La función testicular es doble: producción de gametas y secreción de hormonas sexuales. Es mediada por las hormonas LH y folículoestimulante (FSH) secretadas por la hipófisis anterior, en respuesta a la hormona liberadora de gonadotrofina $(\mathrm{GnRH})$ hipotalámica. La LH estimula la secreción de testosterona por las células de Leydig y su secreción se ve inhibida por un mecanismo de retroalimentación negativa en respuesta a altos niveles de testosterona y LH. La FSH estimula la secreción de estradiol e inhibina por las células de Sertoli, las cuales, a su vez, por retroalimentación negativa, inhiben la liberación de FSH (Jhonston y col., 2001). Al igual que en el resto de las especies, la testosterona presenta un patrón de liberación pulsátil (Carter y col., 1984; Johnstone y col., 1984). En muchos gatos, las concentraciones de esta hormona disminuyen durante la realización de maniobras semiológicas o bajo el efecto de agentes anestésicos (Johnstone y Bancroft, 1988; Tsutsi y col., 1990).

El epidídimo está fuertemente adherido al testículo, y es el sitio de maduración y reserva extragonadal de espermatozoides. La cabeza y la cola están localizadas en el polo craneal y caudal, respectivamente, y el cuerpo discurre dorsolateralmente.

El conducto deferente es un tubo muscular fino, que inicia en la cola del epidídimo, se extiende a lo largo del borde del testículo y luego hacia la porción caudal del abdomen, donde atraviesa la próstata y desemboca en la uretra, sin formar, como en otras especies, ampolla del conducto deferente.

El cordón espermático está compuesto por el conducto deferente y los vasos y nervios testiculares, cubiertos por una fina membrana. Se origina en la cola del epidídimo y se extiende a través del canal inguinal. La uretra se extiende desde la vejiga urinaria hasta el extremo del pene, siendo estrecha y de corta longitud (Davidson y Baker, 2009) 
La próstata es muy pequeña, de relativamente poca importancia en esta especie (Davidson y Baker, 2009). Está compuesta por cuatro lóbulos esféricos aplanados, dos craneales y dos ventrales, que cubren el nacimiento de la uretra dorsolaterlamente y la porción distal de los conductos deferentes. Es un órgano andrógeno-dependiente, que sufre atrofia luego de la castración. Las glándulas bulbouretrales son dos pequeñas glándulas piriformes, localizadas dorsolateralmente en el bulbo del pene, en inmediaciones de la sínfisis pubiana, y drenan su secreción en la uretra a través de un único conducto (Jhonston y col., 2001).

El gato macho alcanza la pubertad entre los 8 y 10 meses de edad, con aproximadamente un $80 \%$ del peso adulto (Root Kustritz, 2014). Si bien son fértiles durante todo el año, su libido y fertilidad se ven atenuadas durante los meses con menos horas de luz (Schmidt, 1986).

El comportamiento copulatorio normal en el gato es resultado de la recepción sensorial y procesamiento cortical de estímulos visuales, auditivos y olfativos provenientes de una hembra en celo, y de la presencia de testículos funcionales, así como también de un eje hipotalámico-hipófisis-gonadal intacto (Jhonston y col., 2001). El apareamiento es muy rápido. Primero el macho hace un reconocimiento de la hembra olfateando la zona genital, y puede llegar a manifestar el reflejo de Flehmen. Durante este reflejo, el macho abre la boca y cierra los ojos ligeramente mientras olfatea, percibiendo feromonas femeninas por el órgano vómero-nasal (Jhonston y col., 2001). Luego aborda la gata lateralmente y la toma por el cuello con sus dientes. La gata eleva la pelvis, desvía la cola y realiza movimientos de pisoteo con sus patas, emitiendo vocalizaciones y maullidos al tiempo que el macho realiza la penetración y eyaculación. El tiempo que demora el macho desde que sujeta la hembra hasta la penetración es de 0,5 a 5 minutos, y el tiempo de penetración de 1 a 4 segundos. Luego del servicio la hembra rechaza al macho de forma agresiva y comienza a frotarse contra el suelo, a dar vueltas, sacudirse de un lado para el otro y lamerse de forma obsesiva la zona genital. La hembra vuelve a aceptar el macho pasados unos 10 a 60 minutos. La frecuencia de los servicios 
puede variar de 3 a 8 veces en 4 horas dependiendo de la receptividad de la hembra (Gobello, 2019).

\section{Contracepción en gatos domésticos}

Debido a sus características reproductivas, los felinos domésticos son sumamente prolíficos (Grifin, 2001). Una sola pareja de gatos en edad reproductiva, que tenga 3 camadas de 3 o 4 gatitos por año, pueden generar, al cabo de 4 años, una población de aproximadamente 20.700 gatos (Goericke-Pesch y col., 20014). Por este motivo, el control de la reproducción indeseada resulta esencial para la prevención de la sobrepoblación de esta especie. (Goericke-Pesch y col., 2014; Murray y col., 2015).

La gonadectomía ha sido, y es, ampliamente utilizada para el control de la población felina. No obstante, su aplicación masiva para el control poblacional resulta costosa, requiere personal entrenado, así como infraestructura, equipamiento e insumos, y tiene tiempos de ejecución y recuperación prolongados (Levy et al. 2003; Kutzler y Wood 2006; Wallace y Levy 2006). Sumado a esto, su efecto permanente la vuelve inaplicable en animales de raza destinados a la reproducción (Murray y col., 2015), que requieren métodos seguros y reversibles. Además, durante las últimas décadas se ha incrementado el interés sobre el bienestar animal, lo que ha resultado en el interés en la implementación de métodos no invasivos y reversibles (Cechetto y col., 2017; Further y col., 2020). Sin embargo, hasta la fecha, el uso generalizado de contraceptivos es limitado en felinos, debido sobre todo a la falta de opciones eficaces y seguras (Asa, 2018).

Durante décadas se han utilizado progestágenos como una alternativa no quirúrgica para prevenir la reproducción en la hembra felina, con severos efectos secundarios (Johnston et al. 2001; Munson 2006; Greenberg et al. 2013), tales como hiperplasia endometrial, piómetra (Agudelo, 2005), neoplasias mamarios y fibroadenomatosis (Wehrend et al. 2001; Loretti et al. 2005). Otras opciones contraceptivas en la hembra, tales como agonistas y antagonistas de GnRH (Ackermann y col., 2012; Risso y col., 2010) e 
implantes de melatonina (Gimenez et al. 2009; Faya et al. 2011), han mostrado ser efectivas parcialmente.

Por otro lado, al igual que sucede en la mayoría de las especies de mamíferos, la contracepción masculina en felinos ha recibido mucha menor atención que la femenina. Además, suprimir la reproducción en el macho, también contribuiría en gran medida a preservar la salud general y reproductiva de la hembra.

Dentro de los métodos no quirúrgicos que se han estudiado en felinos machos, pueden mencionarse las inyecciones intratesticulares o intraepedidimarias de agentes esclerosantes, tales como gluconato de zinc, cloruro de calcio entre otros. Estos agentes provocan azoospermia asociada a cambios degenerativos testiculares y disminución de los niveles séricos de testosterona (Jana y Samanta, 2011; Oliveira y col., 2013). Sin embargo, el efecto de estas aplicaciones suele ser permanente.

Los agonistas de GnRH han mostrado ser exitosos en suprimir la espermatogénesis y el comportamiento andrógeno dependiente en el gato doméstico (Romagnoli y col., 2017; Munson, 2001; Goericke-Pesch et al., 2011) y en felinos silvestres (Bertschinger et al., 2006). Aunque el uso de este grupo de drogas es seguro y su efecto es reversible, existe una alta variabilidad individual en el comienzo y duración del efecto (Goericke-Pesch, 2014). Por su parte, los antagonistas de GnRH han sido mucho menos estudiados en el macho felino que los agonistas y se ha reportado que provocan un deterioro reversible de la espermatogénesis (García Romero y col., 2012). Así mismo, implantes subcutáneos de melatonina han mostrado provocar disminución en la concentración seminal, pero no azoospermia (Favre y col., 2014). Si bien el uso de estos compuestos ha arrojado resultados prometedores, aún están lejos de ser aplicados masivamente.

También se han probado algunos enfoques inmunológicos contra GnRH (Levy y col., 2004). Sin embargo, las vacunas disponibles hasta el momento han mostrado resultados impredecibles (Goericke-Pesch y col., 2014). 
Por lo expuesto, es necesario el desarrollo de nuevos compuestos que permitan controlar la reproducción indeseada, de forma segura y reversible, en la especie felina.

\section{Examen andrológico}

El examen físico andrológico del macho felino incluye, principalmente, maniobras de inspección y palpación. La inspección del pelaje, por ejemplo, en búsqueda del color naranja con negro, que indica que un macho es quimérico y por ende infértil. (Johnston y col., 2001). La palpación de los testículos debe realizarse para determinar su consistencia, así como también la libre movilidad dentro de la bolsa escrotal. El pene debe protruirse, para evaluar la presencia de un orificio prepucial normal, la ausencia de anillos de pelo que dificultan la protrusión peneana, y la presencia de espículas córneas, indicadoras de testosterona sérica (Johnston y col., 2011). La próstata y las glándulas bulboutretrales no son palpables rectal ni transabdominalmente, y rara vez sufren alteraciones, por lo que no son evaluadas rutinariamente (Root Kustritz, 2014)

Dentro de los métodos complementarios para el examen andrológico, se puede mencionar el análisis seminal. Los métodos de recolección aplicables en el gato doméstico incluyen la vagina artificial, electroeyaculación, cateterización uretral y recuperación de espermatozoides epididimales (Prochowska y col., 2015). Si bien el uso de vagina artificial permite la obtención de una muestra de buena calidad y a bajo costo, no puede ser utilizado ampliamente en situaciones clínicas, debido a que requiere de un gato entrenado. La electroeyaculación requiere de equipamiento especial, la necesidad de anestesiar al animal y es cuestionable desde el punto de vista ético, además de no estar permitida en numerosos países. La cateterización uretral permite la obtención de una buena muestra seminal, pero requiere también de la anestesia con altas dosis de $\alpha_{2}$ agonistas. Por último, la muestra puede obtenerse realizando cortes en la cola del 
epidídimo luego de la orquiectomía, pero se realiza usualmente en investigación, y no puede volver a repetirse en un mismo animal (Zambelli y col., 2008).

La biopsia y aspiración testicular son también métodos complementarios en el examen andrológico, que permiten distinguir entidades tales como la atrofia o degeneración testiculares, que al examen clínico o seminal no son posibles de ser confirmadas (Axne'r, 2008). Sin embargo, la biopsia es un método invasivo, que requiere anestesia general del animal, y existe el riesgo de complicaciones que pueden comprometer la fertilidad futura del animal. (Nelson y Couto, 2005).

El examen andrológico puede resultar dificultoso de realizar en los felinos domésticos, debido a su tendencia innata a experimentar stress durante la realización de estas maniobras semiológicas y complementarias de diagnóstico. Así, frecuentemente es necesaria la utilización protocolos de sedación o anestesia para poder llevarlos a cabo (Johnstone y Bancroft, 1988). Por lo tanto, la utilización de técnicas diagnósticas sensibles y no invasivas sería de gran utilidad para la evaluación de la funcionalidad reproductiva en esta especie. En este sentido, la ecografía es una técnica ampliamente utilizada en medicina veterinaria, que permite la evaluación, de manera inocua y en tiempo real, de diferentes órganos, siendo de gran utilidad en el diagnóstico andrológico. Además, tiene la ventaja de que permite controles repetidos en un mismo individuo. Es una técnica diagnóstica que utiliza ondas de ultrasonido, de frecuencias superiores a las audibles por el oído humano. Del haz ultrasónico, generado por el transductor, una parte se propaga a través de las diferentes estructuras del organismo, mientras que otro porcentaje se refleja a manera de eco y llega nuevamente al transductor, en donde se transforma en una pequeña onda de voltaje y, mediante un complejo proceso electrónico, se convierte en una imagen en la pantalla del ecógrafo, en una escala de grises. Aquellas estructuras que reflejan más los ultrasonidos se denominan hiperecoicas y su espectro va del blanco al gris claro, mientras que aquellas que los reflejan menos se conocen como hipoecoicas, y su espectro va del gris oscuro al negro. Aquella estructura que no refleja el 
ultrasonido y produce una imagen negra, se denomina anecoica. Así entonces, puede definirse la ecogenicidad como la capacidad de una estructura para reflejar los haces de ultrasonido que recibe, pudiendo ser más o menos heterogénea (Díaz Rodriguez y col., 2007).

En el gato doméstico, la evaluación ultrasonográfica andrológica se realiza principalmente a nivel testicular. Es posible evaluar tamaño, volumen y posición, así como también detectar la presencia de cambios en el parénquima testicular y alteraciones en epidídimo y conducto deferente, tales como dilataciones quísticas (Davidson y Baker, 2009). El testículo es ecogénico con una textura homogénea. Las túnicas parietal y visceral forman un delgado e hiperecoico eco periférico. El mediastino se aprecia como una estructura lineal, central y ecogénica, en el plano medio sagital y como un eco focal central en el plano de examen medio transverso. La cola del epidídimo es menos ecogénica que el parénquima testicular y, a veces puede, aparecer casi anecoica. La cola también tiene una textura ecográfica más densa que los testículos. El conducto deferente es difícil de seguir porque se hace pequeño (Matoon y Nyland, 2015).

A pesar de ser una herramienta ampliamente utilizada en el examen andrológico de diversas especies de compañía y de producción, en el gato doméstico no ha alcanzado tal grado de aplicación. Un mayor desarrollo de la misma contribuiría a la mejora en la eficiencia reproductiva y la evaluación en la eficacia de protocolos contraceptivos en esta especie.

En base a lo descrito anteriormente el objetivo general de esta Tesis Doctoral fue contribuir al control y a la mejora de la reproducción de felinos domésticos, mediante los siguientes objetivos específicos:

- Evaluar el efecto de la administración oral del derivado de indenopiridina RTI4587-073 (L) en la espermatogénesis felina. 
- Describir y comparar la ecogenicidad y heterogeneidad del parénquima testicular mediante análisis digital de imágenes ultrasonográficas en: a) gatos prepuberales, peripuberales y adultos y b) en testículos normales y con alterraciones en la espermatogénesis.

\section{Referencias}

1. Ackermann CL, Volpato R, Destro FC, et al. Ovarian activity reversibility after the use of deslorelin acetate as a short-term contraceptive in domestic queens. Theriogenology. 2012; 78: 817-822.

2. Agudelo C. Cystic endometrial hyperplasia-pyometra complex in cats. A review. Vet Q. 2005;27(4):173-82.

3. Aronson L, Cooper M. Penile spines of the domestic cat: their endocrine-behavior relations. Anat Rec. 1967; 157: 71-8

4. Asa C. Contraception in Dogs and Cats. Vet Clin North Am Small Anim Pract. 2018;48(4):733-742.

5. Axne'r. Updates on Reproductive Physiology, Genital Diseases and Artificial Insemination in the Domestic Cat. Reprod Dom Anim. 2008;43 (Suppl. 2), 144149

6. Axnér E, Linde Forsberg C. Sperm morphology in the domestic cat, and its relation with fertility: a retrospective study. Reprod Domest Anim. 2007;42(3):282-91.

7. Axnér E, Ström B, Linde-Forsberg C, Gustavsson I, Lindblad K, Wallgren M. Reproductive disorders in 10 domestic male cats. J Small Anim Pract. 1996;37(8):394-401. 
8. Bernstein P. The human-cat relationship. En: Rochlitz I The welfare of cats. Dordrecht, Holanda, Ed Springer, 2007, p. 47-89.

9. Bertschinger HJ, Trigg TE, Jochle W, Human A. Induction of contraception in some African wild carnivores by downregulation of LH and FSH secretion using the GnRH analogue deslorelin. Reproduction 2002;(Suppl 60):41-52.

10. Carter K, Chakraborty P, Bush M, Wildt D. Effects of electroejaculation and ketamine $\mathrm{HCI}$ on serum cortisol, progesterone, and testosterone in the male cat. J Andro. 1984; 15:431-437.

11. Cecchetto M, Salata P, Baldan A, Milani C, Mollo A, Fontaine C, Sontas H, Gelli D, De Benedictis G, Stelletta C, Romagnoli S. Postponement of puberty in queens treated with deslorelin. J Feline Med Surg. 2017; 1-7.

12. Davidson A, Baker T. Reproductive Ultrasound of the Dog and Tom. Top Companion Anim Med. 2009;24(2):64-70.

13. Díaz-Rodríguez N, Garrido-Chamorro, Castellano-Alarcón J. Ecografía: principios físicos, ecógrafos y lenguaje ecográfico. SEMERGEN. 2007;33(7):362-9.

14. Faya M, Carranza A, Priotto M, Abeya M, Diaz J, Gobello C. Domestic queens under natural temperate photoperiod do not manifest seasonal anestrus. Anim Reprod Sci. 2011; 129: 78-81.

15. Favre R, Bonaura MC, Praderio R, Stornelli M, de la Sota R, Stornelli M. Effect of melatonin implants on spermatogenesis in the domestic cat (Felis silvestris catus). Theriogenology. 2014;82(6):851-6.

16. Feldman E, Nelson R. En: Canine and feline endocrinology and reproduction. 2da. Edición. Philadelphia, USA, Ed. WB Saunders Co, 1996, p. 785.

17. França L, Godinho C. Testis morphometry, seminiferous epithelium cycle length, and daily sperm production in domestic cats (Felis catus). Biol Reprod. 2003;68(5):1554-61. 
18. Further E, Roos J, Niewiadomska Z, Maenhoudt C, Fontbonne A. Contraceptive implants used by cat breeders in France: a study of 140 purebred cats. J Feline Med Surg. 2020;1-9.

19. Garcia Romero G, Fernández P, Gimeno E, Barbeito C, Gobello C. Effects of the GnRH antagonist acyline on the testis of the domestic cat (Felis catus). Vet J. 2012;193(1):279-82.

20. Gimenez F, Stornelli M, Tittarelli C, Savignone C, Dorna I, de la Sota R, Stornelli M, 2009. Suppression of estrus in cats with melatonin implants. Theriogenology. 2009;72:493-499.

21. Gobello, C. 2019. Manual de Fisiología Reproductiva Veterinaria. 3ra ed. FCVUNLP. Pp 120.

22. Greenberg M, Lawler D, Zawistowski S, Jochle W, 2013. Low-dose megestrol acetate revisited: a viable adjunct to surgical sterilization in free roaming cats? Vet J 196, 304-308.

23. Griffin B. Prolific cats: the impact of their fertility on the welfare of the species. Comp Contin Edu Pract Vet. 2001; 23: 1058-69.

24. Goericke-Pesch S, Georgiev P, Antonov A, Wherend A. Clinical efficacy of a GnRH-agonist implant containing $4.7 \mathrm{mg}$ deslorelin, Suprelorin, regarding suppression of reproductive function in tomcats. Theriogenology. 2011; 75: 803810.

25. Goericke-Pesch S, Wehrend A, Georgiev P. Supression of Fertility in Adults Cats. Reprod Dom Anim. 2014; 49 (Suppl. 2), 33-40.

26. Jana K, Samanta P. Clinical evaluation of non-surgical sterilization of male cats with single intra-testicular injection of calcium chloride. BMC Vet Res. 2011;21;7:39. 
27. Johnston S, Root Kustritz M, Olson P. Prevention and termination of feline pregnancy. En Canine and Feline Theriogenology. Philadelphia, WB Saunders, 2001, p. 447-452.

28. Johnston I, Bancroft B. The effects of different anesthetics on blood steroid concentrations in domestic tom-cats. Vet J. 1988; 65:382-385.

29. Johnstone I, Bancroft B, McFarlane J. Testosterone and androstenedione profiles in the blood of domestic tom-cats. Anim Reprod Sci. 1984; 7:363-375.

30. Kutzler M, Wood A, 2006. Non-surgical methods of contraception and sterilization. Theriogenology 66, 514-525.

31. Levy J, Miller L, Crawford C, Ritchey J, Ross M, Fagerstone K. GnRH inmunocontraception in male cats. Theriogenology. 2004; 62:1116-1130.

32. Levy J, Gale D, Gale L, 2003. Evaluation of the effect of a long-term trap-neuterreturn and adoption program on a free-roaming cat population. J Am Vet Med Assoc 222, 42-46.

33. Loretti A, Ilha M, Ordas J. Martin de las Mulas J. Clinical, pathological, and immunohistochemical study of feline mammary fibroepithelial hyperplasia following a single injection of depot medroxyprogesterone acetate. J Feline Med Surg. 2005;7:43.

34. Mattoon J, Nyland T. Prostate and Testes. En Mattoon JS y Nyland T Small Animal Diagnostic Ultrasound. 3era Ed. Saint Louis, Estados Unidos, Ed Elsevier, 2015, p. 260-276.

35. Munson L. Contraception in felids. Theriogenology. 2006; 66:126-134.

36. Munson L, Bauman J, Asa C, Jöchle W, Trigg T. Efficacy of the GnRH analogue deslorelin for suppression of oestrous cycles in cats. J Reprod Fertil Suppl. 2001; 57: $269-273$. 
37. Murray J, Mosteller J, Loberg J, Andersson M, Benka V. Methods of fertility control in cats. Owner, breeder and veterinarian behaviour and attitudes. J Feline Med Surg. 2015; 17:790-799.

38. Nelson R, Couto G. Anormalidades de la fertilidad masculina. En Nelson R Couto G Medicina interna de animales pequeños, $3^{\circ} \mathrm{Ed}$. Buenos Aires, Argentina. Ed Intermédica. 2005, p. 957-971.

39. O’Brien S, Johnson W, Driscoll C, Pontius J, Pecon-Slattery J, Menotti-Raymond M. State of cat genomics. Trends Genet. 2008, 24(6):268-79.

40. Oliveira E, Fagundes A, Melo C, Nery L, Rêvoredo R, Andrade T, OliveiraEsquerre K, Kastelic J, Silva V Jr. Intratesticular injection of a zinc-based solution for contraception of domestic cats: a randomized clinical trial of efficacy and safety.Vet J. 2013;197(2):307-10.

41. Pet Secure. A Guide to Worldwide Pet Ownership. https://www.petsecure.com.au/pet-care/a-guide-to-worldwide-pet-ownership/

42. Prochowska S, Niżański W, Ochota M, Partyka A. Characteristics of urethral and epididymal semen collected from domestic cats. A retrospective study of 214 cases. Theriogenology. 2015;84(9):1565-71

43. Pukazhenthi B, Wildt D, Howard J. The phenomenon and significance of teratospermia in felids. J Reprod Fertil Suppl 2001; 57:423-433.

44. Risso A, Valiente C, Corrada Y, García Romero G, Blanco P, de la Sota P, Diaz J, Gobello C. The GnRH antagonist acyline prevented ovulation, but did not affect ovarian follicular development or gestational corpora lutea in the domestic cat. Theriogenology 2010; 73:984-987.

45. Romagnoli S, Baldan A, Righetti C, et al. Semen quality and interval to sterility in tom cats treated with a $9.4 \mathrm{mg}$ deslorelin implant. J Feline Med Surg. 2017;19(2):194-199. 
46. Root Kustritz. Applied Small Animal Andrology. En P. Lorton P, Chenoweth J Animal Andrology. Croydon, Reino Unido. Ed CABI, 2014, p. 177-196.

47. Sánchez B, Pizarro M, García P, Flores J. Histological study of Leydig cells in the cat from birth to sexual maturity. J Reprod Fert. 1993; 47:349-53.

48. Schmidt P. Feline breeding management. Small Anm Pract. 1986; 16: 435-51.

49. Statista. Number of dogs and cats kept as pets worldwide in 2018. https://www.statista.com/statistics/1044386/dog-and-cat-pet-populationworldwide/

50. Tsutsui T, Murao I, Kawakami E. Androgen concentration in the blood and spermatogenic function of tom cats during the breeding season. J Vet Sci. 1990; $52: 801-806$.

51. Wallace J, Levy J, 2006. Population characteristics of feral cats admitted to seven trap-neuter-return programs in the United States. J Feline Med Surg 8, 279-284.

52. Wehrend A, Hospes R, Gruber A, 2001.Treatment of feline mammary fibroadenomatous hyperplasia with a progesterone-antagonist. Vet Rec 148, 346347.

53. Zambelli D, Prati F, Cunto M, Iacono E, Merlo B. Quality and in vitro fertilizing ability of cryopreserved cat spermatozoa obtained by urethral catheterization after medetomidine administration. Theriogenology. 2008;69(4):485-90

54. Zasloff R. A new appreciation for feline friends. Compend Contin Educ Pract Vet. 1996; 18: 4-14. 


\section{CAPÍTULO I}

\section{EFECTO DEL DERIVADO DE INDENOPIRIDINA RTI-4587-073 (L) EN EL TESTÍCULO FELNO}

\section{Introducción}

El gato doméstico (Felis catus) es una especie extremadamente prolífica. Se reproduce durante toda su vida una vez alcanzada la pubertad, y durante todo el año si es mantenido en ambientes interiores o en latitudes menores a $35^{\circ}$ (Faya y col., 2011). Por este motivo, usualmente se requiere de métodos contraceptivos, que al igual que en el resto de los mamíferos, están destinados principalmente a la hembra. Con este fin, son usados frecuentemente los progestágenos, provocando muchas veces, serios efectos secundarios y trastornos reproductivos (Munson, 2006). Si bien se han evaluado enfoques tanto hormonales como no hormonales, la espermatogénesis ha mostrado ser un proceso más complejo de prevenir que la ovulación. Además, la gran mayoría de los protocolos contraceptivos masculinos que se han evaluado, han mostrado un tiempo variable para producir azoospermia y un tiempo impredecible de retorno a la fertilidad (Bowen, 2008). Por lo tanto, todavía es necesario el desarrollo de protocolos farmacológicos seguros, rápidos y eficientes para controlar la reproducción indeseada en el macho felino. Lograr infertilidad en el macho, contribuiría a preservar la salud reproductiva de la hembra.

Las indenopiridinas, que inicialmente fueron desarrolladas como antihistamínicos, son un grupo de compuestos que mostraron tener efectos antiespermatogénicos en ratas (Hodel y Suter, 1978), equinos (Pozor y col., 2013) y caninos (Chang y col., 2002), sin presentar efectos secundarios, como así tampoco toxicidad ni mutagenicidad (Fail y col., 2000; 
Mruk, 2008). Estudios en animales de laboratorio han demostrado que el sitio de acción es la célula de Sertoli, resultando en una disrupción en la adhesión entre estas y las células germinales (Hild et al., 2001, 2007b; Koduri et al., 2008).

Mientras que en monos las indenopiridinas provocaron infertilidad reversible con oligoastenozoospermia (Hild y col., 2007a), en ratas se describió infertilidad irreversible (Hild y col., 2004). En caballos y perros, indujeron inhibición de la espermatogénesis de manera rápida y transitoria, con un incremento en el número de células germinales inmaduras en los eyaculados (Chang et al., 2002; Hodel and Suter, 1978; Pozor et al., 2013, 2014). Histológicamente, los túbulos seminíferos se vaciaron de espermátides y espermatocitos (Pozor y col., 2013). Si bien los efectos testiculares de las indenopiridinas las convierten en una opción prometedora como contraceptivo masculino no esteroideo, tanto el efecto, como la seguridad clínica y la tolerancia no han sido estudiados aún en felinos.

El compuesto RTI-4587-073, es un nuevo derivado de indenopiridina, mezcla racémica de L y D isómeros. El isómero L, es el que particularmente posee potentes propiedades antiespermatogénicas (Pozor y col., 2013) y, por lo tanto, el que se seleccionó para este estudio. Así, el objetivo de este capítulo fue describir los efectos ultrasonográficos, histomorfométricos y hormonales en el testículo felino, de una dosis oral del compuesto RTI-4587-073 (L). Secundariamente, evaluar la seguridad clínica del tratamiento.

\section{Materiales y métodos}

\section{Diseño experimental y protocolo farmacológico}

En este estudio se incluyeron 60 testículos, provenientes de 30 gatos machos, mestizos, de entre 1,5 y 5 años de edad. Los mismos nacieron y se criaron en nuestra colonia experimental. A partir de los 40 días de vida, se destetaron y alimentaron con alimento 
balanceado y agua ad libitum. Todos los animales se alojaron sueltos en habitaciones de 3 x 4 metros, con enriquecimiento ambiental. Además, los gatos se socializaron por alumnos entrenados para este fin.

Los animales recibieron, al día 0, 12,5 mg/kg PO de RTI-4587-073 (L), y aleatoriamente se hemiorquiectomizaron, dos veces: día $-14(\mathrm{n}=8), 6$ horas $(\mathrm{n}=6), 12$ horas $(\mathrm{n}=8)$, día 1 $(\mathrm{n}=6)$, día $7(\mathrm{n}=8)$, día $14(\mathrm{n}=6)$, dia $21(\mathrm{n}=6)$, día $35(\mathrm{n}=6)$ o día $42(\mathrm{n}=6)$. La dosis calculada se disolvió en $2 \mathrm{ml}$ de solución salina y se administró mediante una sonda nasoesofágica luego de una leve sedación. La dosis y el esquema de administración se realizó de acuerdo a estudios en otros mamíferos (Hild y col., 2001; Pozor y col., 2013).

Previo a cada hemiorquiectomía, los animales se pesaron, se recolectaron muestras de materia fecal y los testículos se examinaron clínica y ultrasonográficante, de manera que cada animal recibió dos evaluaciones. También se evaluaron, para cada animal, la aparición de efectos secundarios, tales como disminución del apetito, vómitos u otros signos digestivos, cambios en el peso corporal o en el comportamiento general y sexual. Este estudio fue revisado y aprobado por el Comité Institucional de Cuidado y Uso de Animales de Laboratorio (CICUAL) de la Facultad de Ciencias Veterinarias de la Universidad Nacional de La Plata, Argentina, y los experimentos se condujeron bajo las guías establecidas por The Guide for The Care and Use of Laboratory Animals, USA.

\section{Ultrasonografias}

El examen ultrasonográfico de los testículos se realizó mediante un equipo ultrasonográfico, con un transductor lineal de 14 MHz (Toshiba Nemio XG, Japón). Los parámetros ultrasonográficos se seleccionaron a modo de obtener la mejor calidad de imagen posible y se mantuvieron durante todo el estudio. Las imágenes ultrasonográficas fueron obtenidas en los planos sagital y transversal. En cada evaluación, se estudiaron la ecogenicidad y la heterogeneidad testicular. 


\section{Recolección de material fecal, extracción de metabolitos y determinaciones hormonales}

Las muestras fecales se recolectaron previo a las hemiorquiectomías y se conservaron a $20^{\circ} \mathrm{C}$ hasta su procesamiento. Los esteroides fecales se extrajeron siguiendo los métodos descriptos por Faya y col. (2013) y los niveles de T (ng/ml) se determinaron mediante electroquimioluminiscencia (Elecsys Testo II, Roche Diagnostics, Mannheim, Alemania). Los coeficientes de variación intra e interensayo fueron $<10 \%$ y la sensibilidad de 0,025 $\mathrm{ng} / \mathrm{ml}$. Los datos fueron expresados en base a peso húmedo.

\section{Hemiorquiectomías}

Todos los animales se hemiorquiectomizaron dos veces, de acuerdo a García Romero y col. (2012), de manera que se obtuvieron 60 testículos. Brevemente, se premedicaron con sulfato de atropina (John Martin; 0,04 mg/kg SC), maleato de acepromacina (Acedan, Holliday; 0,03 mg/kg SC) y butorfanol (Torbutol Plus, Fort Dodge; 0,2 mg/kg IM). Para la inducción se utilizó tiopental sódico (Pentovet TM, Richmond; $8 \mathrm{mg} / \mathrm{kg}$ IV). Luego de la introducción del traqueotubo, la anestesia se mantuvo con isofluorano y oxígeno en sistema cerrado. Cada testículo se extrajo a través de una incisión longitudinal en el escroto, mediante la técnica a cielo abierto y cada cordón espermático se ligó con vicryl 0,3 previó a la escisión. Luego de la cirugía, se administró ketoprofeno (Ketofen, Fort Dodge; $1 \mathrm{mg} / \mathrm{kg} \mathrm{SC}$ ) y luego oralmente cada 24 horas durante 4 días. Posteriormente, todos los animales fueron dados en adopción responsable.

\section{Evaluación macro y microscópica testicular}

Inmediatamente luego de la cirugía, los testículos se midieron (largo y ancho; cm), se pesaron (g) y se calcularon el volumen testicular $\left(\mathrm{cm}^{3}\right.$, Lin y col., 2009) y el índice gonadosomático (\%; França y Godinho, 2003). 
Utilizando una hoja de bisturí, se realizaron secciones en la cola del epidídimo, para recuperar espermatozoides epididimales, que se examinaron bajo un aumento de 100x en un microscopio de campo claro, previa tinción con Giemsa (Valiente y col., 2014).

Posteriormente, las gónadas se colocaron en fijador Bouin durante 24 horas y luego en alcohol $70^{\circ}$ hasta ser procesadas con la técnica histológica de rutina e incluidas en parafina. Se obtuvieron cortes de $5 \mu \mathrm{m}$ que se montaron, desparafinaron en xylol, rehidrataron con soluciones graduadas de etanol y finalmente tiñeron con hematoxilina y eosina. Las imágenes histológicas se obtuvieron desde un microscopio óptico (Olympus BX50, Tokio, Japón) con el objetivo 10x, a través de una cámara de video conectada (Omax A35180U3, China) y se digitalizaron en formato TIFF color de 24 bits.

Para cada animal, se seleccionaron 20 perfiles tubulares redondos, de los cuales se determinó, mediante planimetría, el diámetro tubular $(\mu \mathrm{m})$ y la altura del epitelio germinal $(\mu \mathrm{m})$, utilizando el programa Image J National Institutes of Health, Bethesda, Maryland, USA). El volumen $\left(\mathrm{cm}^{3}\right)$ de los diferentes componentes del tejido testicular se determinó mediante estereología, colocando una grilla de 441 puntos sobre fotografías histológicas tomadas a 400x. Para este propósito, se seleccionaron aleatoriamente 15 secciones por testículo (6615 puntos). Los puntos se clasificaron como: espermatogonia, espermatocito primario, espermatocito secundario, espermátide redonda, espermátide elongada, espermatozoide, célula de Sertoli, célula de Leydig, compartimento intertubular y detritos celulares. Finalmente, el volumen de cada elemento se calculó de acuerdo a lo descripto por Carranza y col. (2015).

\section{Análisis estadístico}

La normalidad de los datos se comprobó mediante el test de Shapiro-Wilks. Las variables hormonales, macroscópicas y microscópicas testiculares, se compararon entre los diferentes puntos de tiempo mediante el test de Kruskal-Wallis, seguido por el test de 
Dunn-Bonferroni. Los datos se expresaron como la media \pm SEM. El nivel de significancia se fijó en $\mathrm{P}<0,05$.

\section{Resultados}

Los parámetros macroscópicos testiculares, incluidos peso $(\mathrm{P}>0,1)$, volumen $(\mathrm{P}>0,1)$ y el índice gonadosomático $(\mathrm{P}>0,1)$, así como también el peso corporal $(\mathrm{P}>0,1)$ no se vieron afectados por el tratamiento con RTI 4587-073 (L) en ninguno de los momentos de evaluación (Tabla 1). Si bien los espermatozoides epididimales mostraron morfología normal en todos los casos, durante las primeras 24 hs luego del tratamiento se observaron células germinales inmaduras y multinucleadas (Figura 1; A, B).

La histología testicular no presentó alteraciones al día -14 (Figura 2; A). A las 6 hs pos tratamiento se observó una severa desorganización de la citoarquitectura del epitelio seminífero, que alcanzó un máximo a las 24 hs, presentando vacuolizaciones y células germinales inmaduras y líquido en el lumen tubular (Figura 2; C). Durante las primeras 24 hs gran cantidad de túbulos seminíferos mostraron un proceso de desprendimiento celular, con oclusión total o parcial del lumen tubular por detritus celulares y líquido ( $\mathrm{P}<0,01$; Figura 2; D; Tabla 2). Estas alteraciones desaparecieron gradualmente hacia el final del estudio (Figura 2; F, H, I), y no pudieron ser evidenciadas mediante ecografía, ya que las propiedades ultrasonograficas testiculares se mantuvieron normales durante todo el estudio (Matoon y Nyland, 2015).

Durante las primeras 24 hs, el diámetro tubular $(\mathrm{P}<0,01$, Figura 3), se incrementó en detrimento del intersticio ( $\mathrm{P}<0,01$; Tabla 2), para luego disminuir a los valores pre tratamiento y alcanzar un valor máximo al día 35. Finalmente, mostró una tendencia a volver a los valores pretratamiento hacia el final del estudio. 
La altura del epitelio germinal no se pudo medir durante las primeras $24 \mathrm{hs}$, debido a la gran desorganización de la citoarquitectura tubular (Figura 4). Presentó un mínimo al día 14 pos tratamiento, para rápidamente recuperarse, alcanzar un máximo al día 21 , que se mantuvo hasta el final del estudio. Si bien el volumen ocupado por las espermatogonias no se modificó $(\mathrm{P}>0,1)$, el volumen del resto de los componentes del epitelio germinal disminuyó significativamente (Tabla 2). Esta disminución fue más marcada en el caso de los espermatocitos secundarios $(\mathrm{P}<0,01)$, espermatides redondas $(\mathrm{P}<0,01)$, elongadas $(\mathrm{P}<0,01)$, así como también de espermatozoides $(\mathrm{P}<0,01)$, los cuales reaparecieron al final del estudio al día 42. Por el contrario, el volumen ocupado por las células de Sertoli se incrementó 24 hs luego del tratamiento, para decrecer significativamente hasta el día 14, cuando empezó a retornar a los valores pretratamiento ( $\mathrm{P}<0,01$; Tabla 2).

Por otro lado, si bien el volumen de las células de Leydig disminuyó a la primera evaluación postratamiento ( $\mathrm{P}<0,01$; Tabla 2), la concentración de $\mathrm{T}$ fecal no varió durante dicho periodo $(\mathrm{P}>0,01)$.

Finalmente, durante el periodo de este estudio, este derivado de indenopiridina no provocó efectos secundarios en ninguno de los animales, ni a nivel general, digestivo o comportamental. 
Tabla 1. Parámetros morfométricos de los 30 gatos a los que se les administró, al día 0 , una dosis única de $12.5 \mathrm{mg} / \mathrm{kg}$ RTI-4587-073(1) PO y se los hemiorquiectomizó dos veces al día $-14(\mathrm{n}=8), 6 \mathrm{~h}(\mathrm{n}=6), 12 \mathrm{~h}(\mathrm{n}=8)$, día $1(\mathrm{n}=6)$, día $7(\mathrm{n}=8)$, día $14(\mathrm{n}=6)$, día 21 (n=6), día 35 (n=6) o día $42(n=6)$.

\begin{tabular}{|c|c|c|c|c|c|c|c|c|c|}
\hline Parámetro & $d-14$ & h 6 & h 12 & h 24 & d 7 & d 14 & $\mathrm{~d} 21$ & d 35 & $\mathrm{~d} 42$ \\
\hline Peso corporal (kg) & $4,83 \pm 0,28$ & $5,35 \pm 0,35$ & $4,90 \pm 0,49$ & $4,40 \pm 0,20$ & $4,74 \pm 0,28$ & $4,48 \pm 0,16$ & $4,65 \pm 0,35$ & $4,93 \pm 0,19$ & $4,47 \pm 0,32$ \\
\hline Peso testicular (g) & $1,95 \pm 0,12$ & $1,76 \pm 0,26$ & $1,85 \pm 0,24$ & $1,93 \pm 0,04$ & $1,87 \pm 0,35$ & $1,87 \pm 0,34$ & $1,77 \pm 0,21$ & $1,89 \pm 0,47$ & $1,92 \pm 0,55$ \\
\hline Volumen testicular $\left(\mathrm{cm}^{3}\right)$ & $2,69 \pm 1,43$ & $2,54 \pm 0,40$ & $2,10 \pm 0,29$ & $2,76 \pm 0,29$ & $2,67 \pm 0,97$ & $1,85 \pm 0,92$ & $2,28 \pm 0,62$ & $2,43 \pm 0,66$ & $2,54 \pm 0,68$ \\
\hline Índice gonadosomático (\%) & $0,08 \pm 0,01$ & $0,08 \pm 0,08$ & $0,08 \pm 0,01$ & $0,09 \pm 0,00$ & $0,08 \pm 0,01$ & $0,08 \pm 0,01$ & $0,08 \pm 0,01$ & $0,08 \pm 0,01$ & $0,08 \pm 0,01$ \\
\hline
\end{tabular}


Figura 1. Células germinales inmaduras (A) y multinucleadas (B) en semen epididimal, durante las primeras 24 hs pos tratamiento con RTI-4587-073 (L) (Giemsa, 1000X).

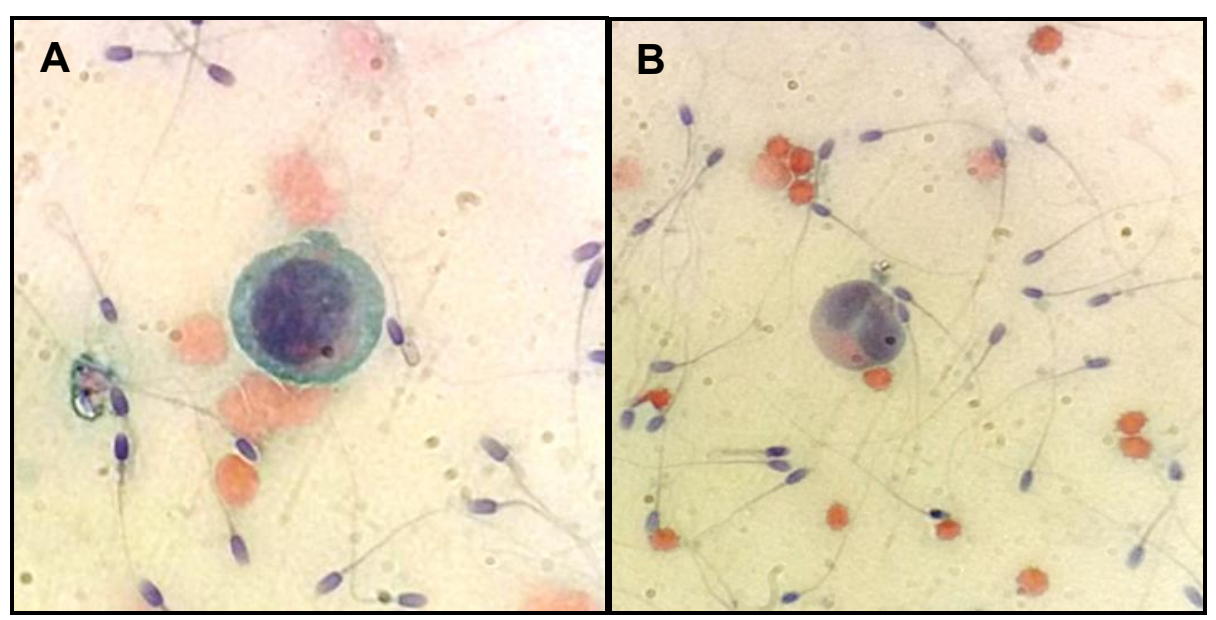

Figura 2. Túbulos seminíferos de los 30 gatos de la Tabla 1, a través del estudio: día -14 (A), 6 hs (B), 12 hs (C), día 1 (D), día 7 (E), día 14 (F), día 21 (G), día 35 (H) y día 42 (I). Nótese el epitelio germinal normal con espermatozoides en el borde luminal (A), fluido ocupando la luz tubular (B), epitelio seminífero desprendiéndose al lumen y presencia de células multinucleadas (C), gran desorganización del epitelio con detritus ocluyendo la luz (D), el desprendimiento del epitelio ha finalizado, ha disminuido la cantidad de detritus ocupando el lumen, y aparecen vacuolas en el epitelio (E), epitelio germinal bajo, con borde luminal irregular y presencia de detritus en la luz (F), epitelio germinal en recuperación, con presencia de algunas vacuolas y lumen limpio $(\mathrm{G})$, epitelio germinal normal, con algunas vacuolas $(\mathrm{H})$, epitelio normal, con abundantes espermátides elongadas en el borde luminal (I) (H\&E, 400X). 

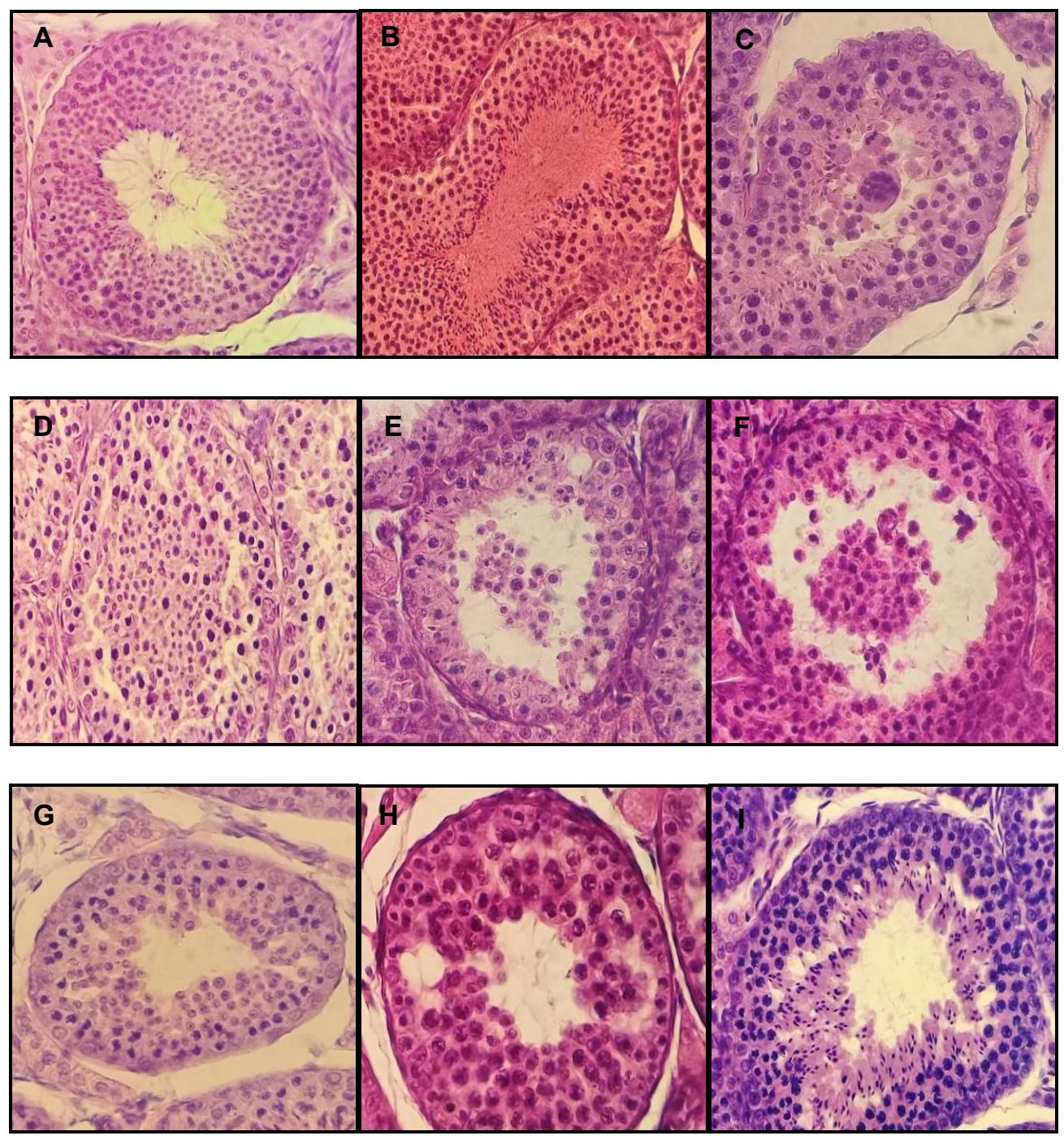
Figura 3. Diámetro tubular (media \pm SEM) de los 30 gatos del experimento de la Tabla 1. Aumentó durante las primeras 24 hs del estudio, alcanzó un valor máximo al día 35 y posteriormente mostró una tendencia a retornar a los valores iniciales $(\mathrm{P}<0,05)$.

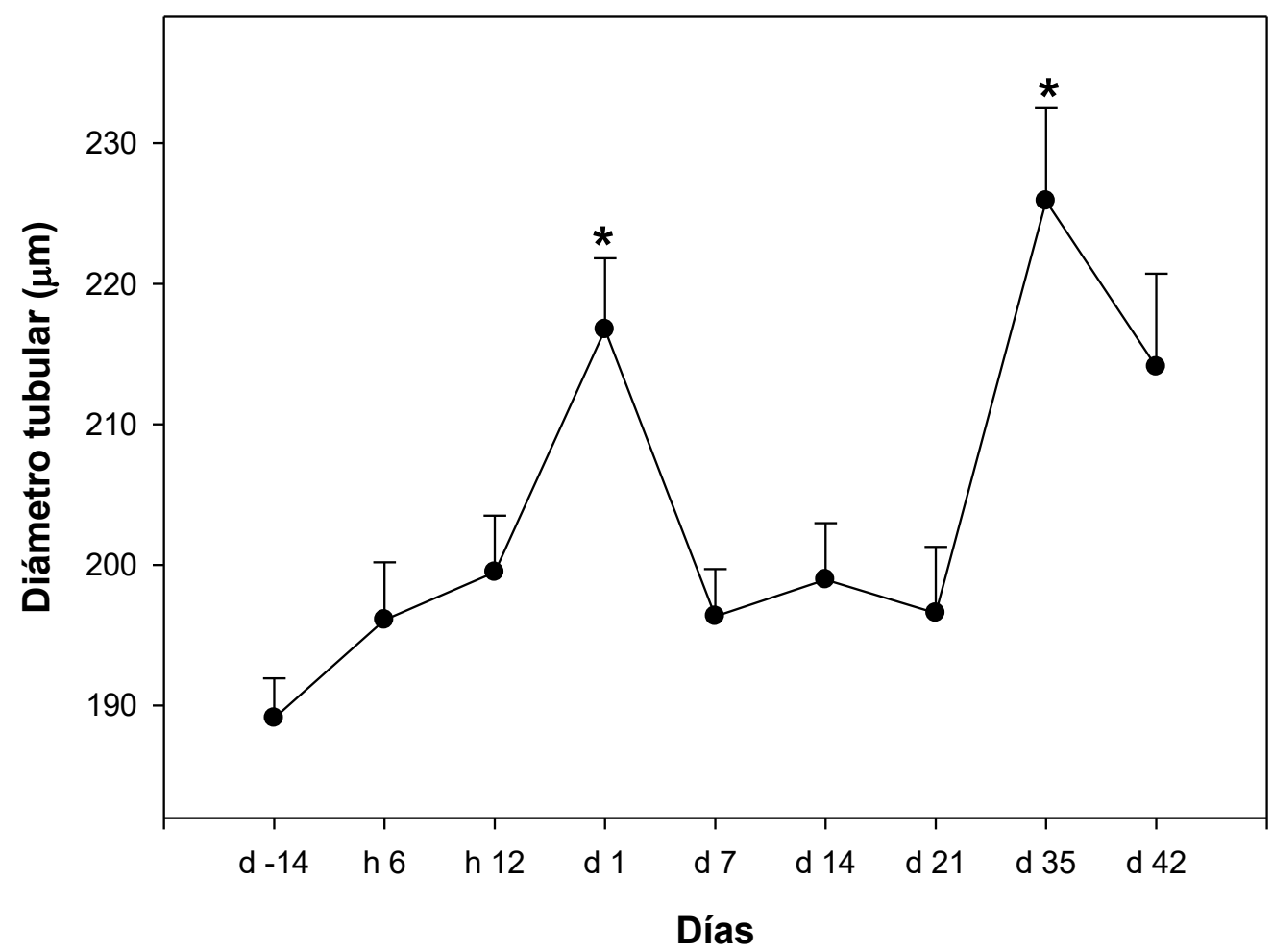


Figura 4. Altura del epitelio germinal (media $\pm \mathrm{SEM}$ ), de los 30 gatos de la Tabla 1. Durante las primeras 24 hs no pudo ser medido debido a la desorganización de la citoarquitectura tubular. Alcanzó un valor mínimo al día 14 para luego aumentar al día 21 y mantenerse hasta el final del estudio $(\mathrm{P}<0,05)$.

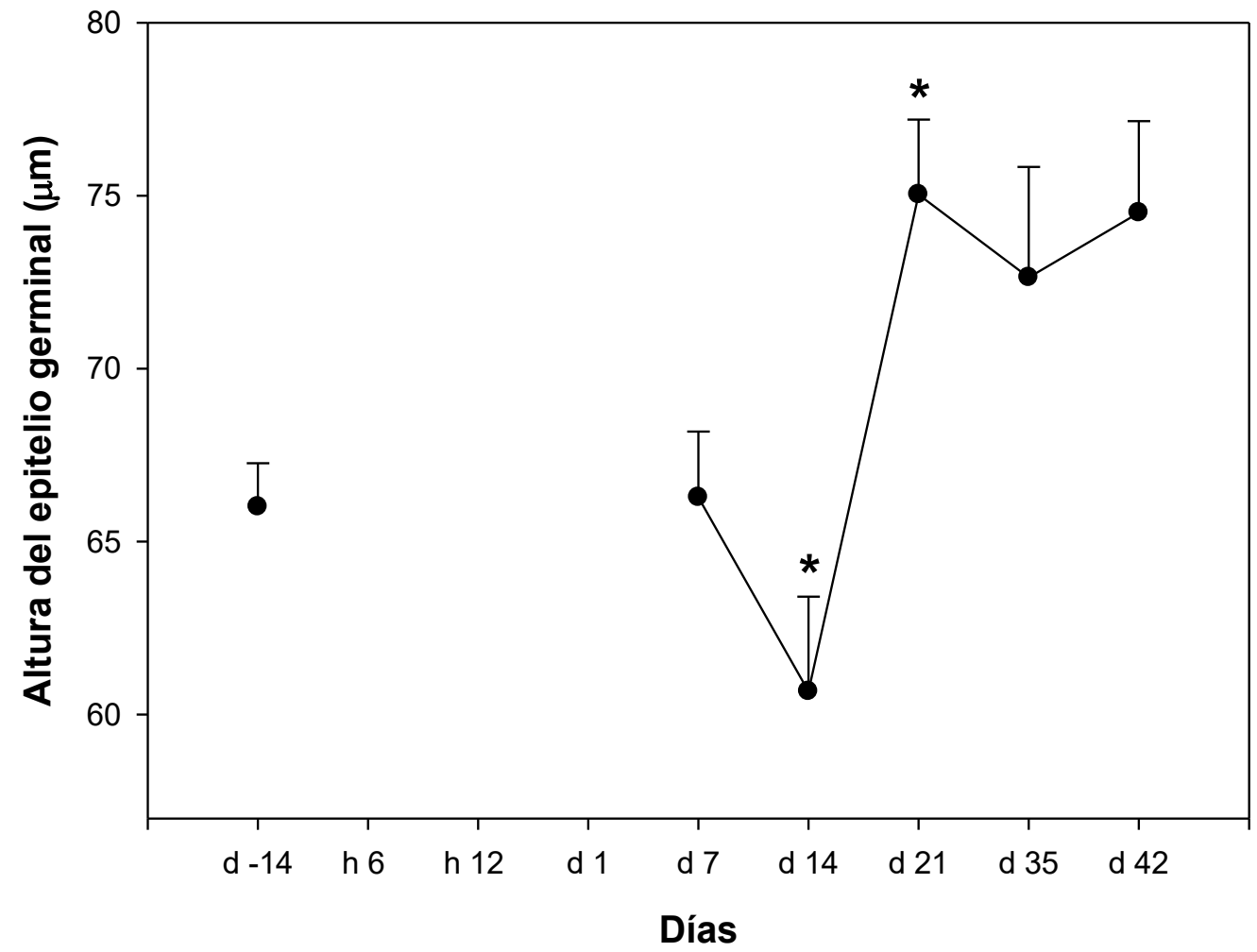


Tabla 2. Volumen (media $\pm \mathrm{SEM}$ ) de los diferentes componentes histológicos testiculares de los 30 gatos de la Tabla 1. Todos los componentes, excepto las espermatogonias, variaron a través del estudio $(\mathrm{P}<0,01)$. Letras diferentes en una misma fila, indican diferencias significativas $(\mathrm{P}<0,01)$.

\begin{tabular}{|c|c|c|c|c|c|c|c|c|c|}
\hline Parámetro $\left(\mathrm{cm}^{3}\right)$ & $d-14$ & h 6 & h 12 & h 24 & d 7 & d 14 & d 21 & d 35 & $\mathrm{~d} 42$ \\
\hline Célula de Sertoli & $0,15 \pm 0,11^{\mathrm{a}}$ & $0,22 \pm 0,04^{b}$ & $0,20 \pm 0,07^{\mathrm{b}}$ & $0,23 \pm 0,05^{\mathrm{b}}$ & $0,12 \pm 0,00^{\mathrm{a}}$ & $0,11 \pm 0,07^{\mathrm{a}}$ & $0,12 \pm 0,02^{\mathrm{a}}$ & $0,13 \pm 0,09^{\mathrm{a}}$ & $0,15 \pm 0,05^{\mathrm{a}}$ \\
\hline Espermatogonia & $0,11 \pm 0,05$ & $0,08 \pm 0,03$ & $0,07 \pm 0,02$ & $0,10 \pm 0,03$ & $0,08 \pm 0,05$ & $0,06 \pm 0,02$ & $0,07 \pm 0,04$ & $0,10 \pm 0,06$ & $0,07 \pm 0,05$ \\
\hline $\begin{array}{l}\text { Espermatocito } \\
\text { primario }\end{array}$ & $0,76 \pm 0,20^{\mathrm{a}}$ & $0,47 \pm 0,20^{\mathrm{b}}$ & $0,43 \pm 0,12^{\mathrm{b}}$ & $0,51 \pm 0,16^{\mathrm{b}}$ & $0,45 \pm 0,20^{\mathrm{b}}$ & $0,31 \pm 0,11^{\mathrm{b}}$ & $0,29 \pm 0,15^{b}$ & $0,51 \pm 0,15^{\mathrm{b}}$ & $0,46 \pm 0,09^{b}$ \\
\hline $\begin{array}{l}\text { Espermatocito } \\
\text { secundario }\end{array}$ & $0,00 \pm 0,01^{\mathrm{a}}$ & $0,00 \pm 0,00^{\mathrm{b}}$ & $0,00 \pm 0,00^{\mathrm{b}}$ & $0,00 \pm 0,00^{\mathrm{b}}$ & $0,00 \pm 0,00^{\mathrm{b}}$ & $0,00 \pm 0,00^{\mathrm{b}}$ & $0,00 \pm 0,00^{\mathrm{b}}$ & $0,00 \pm 0,00^{\mathrm{b}}$ & $0,00 \pm 0,00^{\mathrm{c}}$ \\
\hline Espermátide redonda & $0,55 \pm 0,30^{\mathrm{a}}$ & $0,39 \pm 0,15^{\mathrm{b}}$ & $0,25 \pm 0,05^{\mathrm{b}}$ & $0,39 \pm 0,19^{b}$ & $0,33 \pm 0,15^{\mathrm{b}}$ & $0,24 \pm 0,06^{\mathrm{b}}$ & $0,18 \pm 0,06^{\mathrm{b}}$ & $0,25 \pm 0,07 \mathrm{~b}$ & $0,34 \pm 0,09^{\mathrm{a}}$ \\
\hline Espermátide elongada & $0,45 \pm 0,28^{\mathrm{a}}$ & $0,14 \pm 0,08^{b}$ & $0,13 \pm 0,06^{\mathrm{b}}$ & $0,14 \pm 0,07^{\mathrm{b}}$ & $0,17 \pm 0,09^{\mathrm{b}}$ & $0,12 \pm 0,09^{\mathrm{b}}$ & $0,16 \pm 0,08^{\mathrm{b}}$ & $0,18 \pm 0,11^{\mathrm{b}}$ & $0,36 \pm 0,12^{\mathrm{a}}$ \\
\hline Espermatozoide & $0,02 \pm 0,01^{\mathrm{a}}$ & $0,00 \pm 0,00^{\mathrm{b}}$ & $0,00 \pm 0,00^{\mathrm{b}}$ & $0,00 \pm 0,00^{\mathrm{b}}$ & $0,03 \pm 0,00^{\mathrm{b}}$ & $0,01 \pm 0,01^{\mathrm{b}}$ & $0,00 \pm 0,00^{\mathrm{b}}$ & $0,00 \pm 0,00^{\mathrm{b}}$ & $0,01 \pm 0,01^{\mathrm{a}}$ \\
\hline Célula de Leydig & $0,21 \pm 0,06^{\mathrm{a}}$ & $0,04 \pm 0,03^{b}$ & $0,05 \pm 0,04^{\mathrm{b}}$ & $0,11 \pm 0,04^{\mathrm{b}}$ & $0,09 \pm 0,06^{\mathrm{b}}$ & $0,07 \pm 0,02^{\mathrm{b}}$ & $0,07 \pm 0,01^{\mathrm{b}}$ & $0,12 \pm 0,02^{\mathrm{a}}$ & $0,12 \pm 0,08^{\mathrm{a}}$ \\
\hline $\begin{array}{l}\text { Compartimiento } \\
\text { intertubular }\end{array}$ & $0,39 \pm 0,24^{\mathrm{a}}$ & $0,21 \pm 0,06^{\mathrm{b}}$ & $0,19 \pm 0,05^{\mathrm{b}}$ & $0,22 \pm 0,07^{\mathrm{b}}$ & $0,25 \pm 0,07^{\mathrm{b}}$ & $0,21 \pm 0,09^{b}$ & $0,22 \pm 0,08^{b}$ & $0,29 \pm 0,05^{\mathrm{a}}$ & $0,30 \pm 0,11^{\mathrm{a}}$ \\
\hline Detritus celular & $0,10 \pm 0,07^{\mathrm{a}}$ & $0,26 \pm 0,06^{\mathrm{b}}$ & $0,32 \pm 0,14^{\mathrm{b}}$ & $0,33 \pm 0,16^{\mathrm{b}}$ & $0,20 \pm 0,08^{\mathrm{c}}$ & $0,18 \pm 0,06^{\mathrm{c}}$ & $0,09 \pm 0,01^{\mathrm{a}}$ & $0,09 \pm 0,02^{\mathrm{a}}$ & $0,05 \pm 0,03^{\mathrm{a}}$ \\
\hline
\end{tabular}




\section{Discusión}

El uso de contraceptivos en el macho felino es muy limitado, debido a la falta de opciones efectivas y seguras. Las indenopiridinas han mostrado poseer efecto antiespermatogénico en diversas especies de mamíferos y las diferencias interespecie que se han observado, justifican su estudio en la especie felina. Este es el primer estudio que describe el efecto de este grupo de compuestos en el macho felino.

En concordancia con los trabajos en ratas (Hild y col., 2001; Koduri y col., 2008) y monos (Hild y col., 2007a), pero no en equinos (Pozor y col., 2014), el tratamiento con RTI 4587-073 (1), no afectó los niveles de testosterona en el macho felino. Mientras que la supresión de esta hormona y, por lo tanto, del comportamiento sexual, es un efecto deseable en el gato doméstico, los cambios en los niveles de testosterona y sus efectos fenotípicos son una desventaja en felinos silvestres, ya que se alteraría la jerarquía social y los caracteres sexuales secundarios. Contrariamente, el volumen ocupado por las células de Leydig decreció durante las primeras evaluaciones pos tratamiento. Debería tenerse en cuenta que, en este estudio, la medición de testosterona fecal no pudo detectar las posibles variaciones transitorias que pudo haber sufrido la testosterona sérica. En concordancia con los reportes en equinos utilizando el mismo protocolo farmacológico (Pozor y col., 2014), el volumen testicular no varió durante el transcurso de este estudio.

La rapidez de los efectos histológicos es uno de los efectos más interesantes de este protocolo antiespermatogénico. Efectos similares fueron descriptos previamente en monos, caballos, perros y ratas (Chang et al., 2002; Hild et al., 2001, 2007a; Pozor et al., 2014).

La vacuolización del epitelio germinal y la descamación celular hacia el lumen tubular causando una severa desorganización del epitelio, son hallazgos histológicos comunes asociados con el daño en las células de Sertoli luego de la exposición testicular a agentes tóxicos (Johnson, 2015; Vidal and Whitney, 2014). Las células gigantes multinucleadas, 
halladas tanto en el epitelio como en semen, surgen de la fusión de espermátides degeneradas con puentes intercelulares anormales (Vidal and Whitney, 2014). Este tipo de células también fue observado en ratas, caballos y perros tratados con indenopiridinas (Chang et al., 2002; Hild et al., 2001; Pozor et al., 2013).

Las indenopiridinas, producen alteraciones en las proteínas de unión de las células de Sertoli con las células germinales, lo que provoca un desprendimiento prematuro de estas últimas (Koduri y col., 2008). Las uniones de las células de Sertoli cumplen un rol esencial en la conformación de la barrera hematotesticular, necesaria para un normal desarrollo de la espermatogénesis. Debido a esto, han sido considerado un blanco para el desarrollo de contraceptivos masculinos (Lee y col., 2009). En este estudio, el daño en las células de Sertoli podría explicar, al menos en parte, el incremento en su volumen y el aumento en el diámetro tubular, asociado con la producción de líquido tubular el día 1 pos tratamiento (Vidal y Whitney, 2014).

Tal como se esperaba, acompañando los hallazgos histológicos severos, la mayor parte de los componentes del epitelio germinal se vieron afectados por el tratamiento con indenopiridina. La mayor disminución se produjo a nivel de espermatocitos y espermátides, evidenciando una severa pérdida de las capas más apicales del epitelio.

Previo al tratamiento, los parámetros histomorfométricos al dia -14 coincidieron con aquellos reportados previamente como normales para la especie (Franca and Godinho, 2003; Siemieniuch and Wocławek-Potocka, 2007). El incremento inicial en el diámetro tubular, ha sido previamente asociado con el aumento de la secreción por parte de las células de Sertoli luego de la exposición a agentes tóxicos (Vidal and Whitney, 2014). A su vez, el aumento observado al día 35 puede ser explicado por la recuperación en la espermatogénesis en dicho momento (Meisami et al., 1994).

La altura del epitelio germinal disminuyó drásticamente luego del tratamiento, hasta alcanzar únicamente dos capas celulares al día 14, para luego recuperarse a valores incluso mayores que aquellos pretratamiento, tan solo una semana posterior. La presencia 
de espermatogonias durante todo el estudio, garantizó la recuperación de la espermatogénesis, y, por lo tanto, la reversibilidad del protocolo farmacológico utilizado. Las indenopiridinas han provocado efectos tanto reversibles (en perros, monos y caballos; Chang et al., 2002; Hild et al., 2007a; Pozor et al., 2013) como irreversibles (en ratas; Hild et al., 2004). Sorpresivamente, una dosis tan baja como $2,5 \mathrm{mg} / \mathrm{kg}$, fue la que provocó efectos irreversibles en roedores de laboratorio (Hild y col. 2004), lo que sugiere un efecto especie-específico. En el gato doméstico, la reversibilidad del efecto ocurrió aproximadamente en el periodo de un ciclo espermático (Franca and Godinho, 2003). De manera similar, en caballos y perros tratados con indenopiridinas, la recuperación de la espermatogénesis se vio a las 6 o 7 semanas pos tratamiento, respectivamente (Chang et al., 2002; Pozor et al., 2014).

Teniendo en cuenta los cambios histológicos rápidos y severos, así como su reversibilidad, sería interesante probar la fertilidad in vivo, durante el pico del efecto y luego de la recuperación de la espermatogénesis, de modo de poder desarrollar un protocolo de dosis únicas o seriadas en felinos.

En concordancia con estudios en otras especies (Fail y col., 2000), en este estudio no se observaron efectos adversos, tales como pérdida de peso corporal o alteraciones digestvas, sugiriendo que este grupo de compuestos no tendría efectos tóxicos en esta especie.

Finalmente, se concluye que RTI-4587-073 (L) representa una opción contraceptiva oral no esteroidea rápida, efectiva, reversible y segura en el gato macho, debido a que interrumpió severamente la espermatogénesis durante las primeras 24 hs pos tratamiento, y para luego recuperarse tras aproximadamente, un ciclo espermático. Estudios adicionales, inlcuyendo dosis repetidas y vigilancia toxicológica de posibles efectos adversos a largo plazo, deberían llevarse a cabo antes de que puedan ser utilizados ampliamente. 


\section{Referencias}

1. Bowen, R. Male contraceptive technology for nonhuman male mammals. Anim. Reprod. Sci. 2008. 105; 139-143.

2. Carranza A, Faya M, Fernandez P, Barbeito C, Gobello C. Histologic effect of a postnatal slow-release GnRH agonist on feline gonads. Theriogenology. 2015. $25 ; 1097-1100$.

3. Chang C, Fung H, Lin Y, Kuo C, Chien C. Indenopyridine hydrochloride induced testicular spermatogenesis failure with high seminal alkaline phosphatase levels in male dog. Biol. Pharm. Bull. 2002. 25; 1097-1100.

4. Fail P, Anderson S, Cook C. 28-day toxicology test: indenopyridine RTI 4587056 in male Sprague-Dawley rats. Reprod. Toxicol. 2000. 14; 265-274.

5. Faya M, Carranza A, Priotto M, Abeya M, Diaz J, Gobello C. Domestic queens under natural temperate photoperiod do not manifest seasonal anestrus. Anim. Reprod. Sci. 2011. 129; 78-81.

6. Faya M, Carranza A, Miotti R, Ponchón T, Furlan P, Gobello C. Fecal estradiol17 beta and testosterone in prepubertal domestic cats. Theriogenology. 2013. 80; $584-586$.

7. Franca L, Godinho C. Morphometry, seminiferous epithelium cycle length, and daily sperm production in domestic cats (Felis catus). Biol. Reprod. 2003. 68; $1554-1561$.

8. García Romero G, Barbeito C, Fernandez P, Gimeno E, Gobello C. Unilateral orchidectomy in mature cats is not followed by compensatory hypertrophy. Reprod. Domest. Anim. 20126 (Suppl. 47); 226-228.

9. Hild S, Reel J, Larner J, Blye, R. Disruption of spermatogenesis and Sertoli cell structure and function by the indenopyridine CDB-4022 in rats. Biol. Reprod. 2001. 65; 1771-1779. 
10. Hild S, Attardi B, Reel J. The ability of a gonadotropin-releasing hormone antagonist, acyline, to prevent irreversible infertility induced by the indenopyridine, CDB-4022, in adult male rats: the role of testosterone. Biol. Reprod. 2004. 71; 348-358.

11. Hild S, Marshall G, Attardi B, Hess R, Schlatt S, Simorangkir D, Ramaswamy S, Koduri S, Reel J, Plant T. Development of 1-CDB-4022 as a non steroidal male oral contraceptive: induction and recovery from severe oligospermia in the adult male cynomolgus monkey (Macaca fascicularis). Endocrinology. 2007a. 148; $1784-1796$.

12. Hild S, Reel J, Dykstra M, Mann P, Marshall, G. Acute adverse effects of the indenopyridine CDB-4022 on the ultrastructure of Sertoli cells, spermatocytes, and spermatids in rat testes: comparison to the known Sertoli cell toxicant Di-npentylphthalate (DPP). J. Androl. 2007. 28; 621-629.

13. Hodel C, Suter K, 1978. Reversible inhibition of spermatogenesis with an indenopyridine (20-438). Arch. Toxicol. 1978. (Suppl. 1); 323-326.

14. Johnson K. Testicular histopathology associated with disruption of the Sertoli cell cytoskeleton. Spermatogenesis. 2015. 19; e979106.

15. Koduri S, Hild S, Pessaint L, Reel J, Attardi. Mechanism of action of 1-CDB4022, a potential nonhormonal male contraceptive, in the seminiferous epithelium of the rat testis. Endocrinology. 2008. 149; 1850-1860.

16. Lee P, Wong E, Mruk D, Cheng C. Testicular cell junction: a novel target for male contraception. Curr. Med. Chem. 2009. 16; 906-915.

17. Lin C, Huang W, Chen K, 2009. Measurement of testicular volume in smaller testes: how accurate is conventional orchidometer? Androl. 2009. 30; 685-689.

18. Mattoon J, Nyland T. Prostate and Testes. En Mattoon JS y Nyland T Small Animal Diagnostic Ultrasound. 3era Ed. Saint Louis, Estados Unidos, Ed Elsevier, 2015, p. 260-276. 
19. Meisami E, Najafi A, Timiras P. Enhancement of seminiferous tubular growth and spermatogenesis in testes of rats recovering from early hypothyroidism: a quantitative study. Cell Tissue Res. 1994. 275; 503-511.

20. Mruk D. New perspectives in non-hormonal male contraception. Trends Endocrinol. Metab. 2008.19; 57-64.

21. Munson L., 2006. Contraception in felids. Theriogenology. 2006. 1; 126-134.

22. Pozor M, Macpherson M, Mc Donnell S, Nollin M, Roser J, Love C, Runyon S, Thomas B, Troedsson M. Indenopyride derivative RTI-4587-073(1): a candidate for male contraception in stallions. Theriogenology. 2013. 80; 1006-1016.

23. Pozor M, Zambrano G, Roser J, Hess R, Runyon S, Runcan E, Thomas B, Dymock D, Macpherson M, Troedsson M, Kelleman A. Acute and chronic effects of a contraceptive compound RTI-4587-073(1) on testicular histology and endocrine function in miniature horse stallions. Reprod. Domest. Anim. 2014. 49; $392-402$.

24. Siemieniuch M, Wocławek-Potocka I. Morphological features of the seminiferous epithelium in cat (Felis catus, L. 1758) testes. J. Reprod. Dev. 2007. $53 ; 1125-1130$.

25. Valiente C, Arauz S, De la Sota P, Gobello C. Ejaculation training, seminal alkaline phosphatase and preservation through cooling in a milk-based extender in domestic cats. J. Feline Med. Surg. 2014. 16; 312-316.

26. Vidal J, Whitney K, 2014. Morphologic manifestations of testicular and epididymal toxicity. Spermatogenesis. 2014. 3; e979099. 


\section{CAPÍTULO II}

\section{ANÁLISIS DIGITAL ULTRANOSOGRÁFICO DE TESTÍCULOS FELINOS NORMALES Y ANORMALES}

\section{Introducción}

En el gato macho, los estudios sobre los desórdenes reproductivos son mucho más escasos que en el resto de los animales domésticos. Esto puede ser explicado, en parte, por la dificultad de realizar el examen andrológico en esta especie, no sólo por su pequeño tamaño corporal, sino también a su tendencia innata a experimentar stress. Las publicaciones sobre esta temática son muy escasas y provenientes de casos clínicos terminales de infertilidad (Axner y col., 1996). Los estadios iniciales de infertilidad, son generalmente factibles de ser revertidos terapéuticamente, pero al no estar asociados a manifestaciones evidentes, son de difícil diagnóstico (Pozor y col., 2017).

La única prueba precisa para la evaluación de la estructura testicular es el examen histopatológico. No obstante, la biopsia, resulta un procedimiento invasivo. Además, la muestra debe ser fijada, procesada y evaluada por profesionales entrenados, lo que puede tomar periodos prolongados hasta la obtención de resultados (Pozor y col., 2017). Por lo tanto, es necesario el desarrollo de métodos diagnósticos sensibles y no invasivos para la evaluación gonadal en esta especie. En este sentido, la ecografía testicular es utilizada ampliamente en el examen andrológico en animales domésticos, permitiendo la evaluación en tiempo real, de manera no invasiva y sin requerirse usualmente de sedación o anestesia (Kealy y col., 2011). De esta manera, es posible diagnosticar diversas 
afecciones que no pueden ser detectadas clínicamente cuando se encuentran en estadios iniciales.

En la práctica clínica, las imágenes ultrasonográficas usualmente se evalúan subjetivamente en términos de ecogenicidad y heterogeneidad (Moxon y col., 2015). El ojo humano es capaz de diferenciar entre 10 a 12 tonos de gris en una imagen (Matoon y Nyland, 2015). Sin embargo, las imágenes ultrasonográficas están compuestas por unidades denominadas píxeles, cuya intensidad se mide en una escala que va desde 0 (negro absoluto) a 255 (blanco absoluto). Utilizando programas de análisis de imágenes, es posible determinar un promedio de la intensidad de pixeles de una región, así como también el desvío standard de la intensidad de pixeles, que representan la ecogenicidad y la heterogeneidad de un tejido, respectivamente (Giffin y col.,2009). Así, es posible cuantificar estas dos variables, y transformar la ecografía en una herramienta cuantificable objetivamente.

Ha sido reportada la relación entre la ecogenicidad y heterogeneidad testicular y parámetros histomorfométricos en bovinos, ovinos y equinos (Brito y col., 2012; Giffin y col., 2009-2015; Pozor y col., 2017). Así mismo, en humanos, bovinos y ovinos se han publicado estudios en los cuales se mide la ecotextura testicular en función de la edad y llegada a la pubertad (Hamm y Fobe, 1994; Evans, y col., 1996; Giffin y col., 2014; Brito y col., 2012).

Hasta el momento no se han estudiado, en el gato doméstico, las características ultrasonográficas testiculares, analizadas digitalmente, ni en condiciones normales ni patológicas. Por lo tanto, el objetivo de este estudio fue describir y comparar la ecogenicidad y heterogeneidad testicular, en condiciones normales y anormales, utilizando un modelo farmacológico de arresto espermatogénico. Para esto, se utilizó un potente antagonista de GnRH, acyline, cuyos efectos deletéreos sobre la espermatogénesis felina ya fueron descriptos (García Romero y col., 2012). 


\section{Materiales y métodos}

\section{Animales}

Se utilizaron 7 gatos machos enteros, mestizos, entre 1 y 5 años de edad, nacidos y criados en nuestra colonia experimental. A partir de los 40 días de vida, se destetaron y alimentaron con alimento balanceado y agua ad libitum. Todos los animales se alojaron sueltos en habitaciones de $3 \times 4$ metros, con enriquecimiento ambiental. Además, los gatos se socializaron por alumnos entrenados para este fin.

Este estudio fue revisado y aprobado por el Comité Institucional de Cuidado y Uso de Animales de Laboratorio (CICUAL) de la Facultad de Ciencias Veterinarias de la Universidad Nacional de La Plata, Argentina, y los experimentos se condujeron bajo las guías establecidas por The Guide for The Care and Use of Laboratory Animals, USA.

\section{Protocolo farmacológico}

Los animales recibieron una dosis semanal de $330 \mu \mathrm{g} / \mathrm{kg} \mathrm{SC}$, durante 4 semanas. La dosis y frecuencia de administración fueron seleccionadas de acuerdo a estudios previos realizados en la especie (García Romero y col., 2012).

\section{Ultrasonografias}

Una semana previa y una semana posterior a la primera y última aplicación del disruptor, los animales se evaluaron mediante ultrasonografía en modo B utilizando un transductor lineal de $14 \mathrm{MHz}$ (Toshiba Nemio XG, Japón). Los parámetros ultrasonográficos (ganancia: 100; profundidad: $2 \mathrm{~cm}$ ) fueron seleccionados para obtener la máxima calidad de imagen, y se mantuvieron constantes durante todo el estudio. Las imágenes fueron tomadas en los planos longitudinal y transversal (jpg de 640 x 480 pixeles) y en las secciones longitudinales, se realizó el análisis digital utilizando el software Image J (National Institutes of Health, Bethesda, Maryland, USA) para lo cual se seleccionaron 6 
regiones de interés (RDI, $1 \mathrm{~mm}^{2}$ ) entre el mediastino y la cápsula testicular (12 RDI/gato). Dentro de cada RDI se cuantificaron la ecogenicidad y la heterogeneidad del parénquima testicular, como la intensidad media de pixeles (IMP) y el desvío estándar (SD) de la IMP, respectivamente (Giffin y col., 2014; Pozor y col., 2017).

\section{Orquiectomías}

Una semana posterior a la última aplicación del disruptor, todos los gatos se orquiectomizaron, y luego se entregaron en adopción responsable. Brevemente, se premedicaron con sulfato de atropina (John Martin; 0,04 $\mathrm{mg} / \mathrm{kg} \mathrm{SC}$ ), maleato de acepromacina (Acedan, Holliday; $0,03 \mathrm{mg} / \mathrm{kg} \mathrm{SC}$ ) y butorfanol (Torbutol Plus, Fort Dodge; 0,2 mg/kg IM). Para la inducción se utilizó tiopental sódico (Pentovet TM, Richmond; $8 \mathrm{mg} / \mathrm{kg} \mathrm{IV).} \mathrm{Luego} \mathrm{de} \mathrm{la} \mathrm{introducción} \mathrm{del} \mathrm{traqueotubo,} \mathrm{la} \mathrm{anestesia} \mathrm{se}$ mantuvo con isofluorano y oxígeno en sistema cerrado. Cada testículo se extrajo a través de una incisión longitudinal en el escroto, mediante la técnica a cielo abierto y cada cordón espermático se ligó con vicryl 0,3 previó a la escisión. Luego de la cirugía, se administró ketoprofeno (Ketofen, Fort Dodge; $1 \mathrm{mg} / \mathrm{kg}$ SC) y luego oralmente cada 24 horas durante 4 días.

\section{Examen macroscópico y microscópico}

Inmediatamente luego de la escisión de los testículos, estos se midieron (largo y ancho; $\mathrm{cm})$, pesaron (g) y se calculó el volumen ( $\mathrm{cm}^{3}$; Linn y col., 2009).

Posteriormente, las gónadas se colocaron en fijador Bouin durante 24 horas y luego en alcohol 70 grados hasta ser procesadas con la técnica histológica de rutina e incluidas en parafina. Se obtuvieron cortes de $5 \mu \mathrm{m}$ que se montaron, desparafinaron en xylol, rehidrataron con soluciones graduadas de etanol y finalmente tiñeron con hematoxilina eosina. Las imágenes histológicas se obtuvieron desde un microscopio óptico (Olympus 
BX50, Tokio, Japón) con el objetivo 10x, a través de una cámara de video conectada (Omax A35180U3, China) y se digitalizaron en formato TIFF color de 24 bits.

El análisis de las imágenes histológicas se llevó a cabo mediante planimetría (Image J, National Institutes of Health, Bethesda, Maryland, USA). Para ello, se seleccionaron 10 perfiles tubulares redondos, de los cuales se determinó el diámetro tubular $(\mu \mathrm{m})$, el diámetro de la luz $(\mu \mathrm{m})$ y la altura del epitelio germinal $(\mu \mathrm{m}$,$) . En los túbulos, se$ identificó la célula germinal más avanzada, para calcular el porcentaje de túbulos seminíferos con los diferentes tipos de células germinales. Finalmente se calculó la relación túbulo/intersticio y la relación lumen/intersticio (Pozor y col., 2017).

\section{Análisis estadístico}

La normalidad de los datos fue comprobada mediante el test de Shapiro-Wilks. Los valores pre (Pre) y postratamiento (Pos) de ecogenicidad, heterogeneidad y volumen testicular, se compararon mediante un test de Student pareado. Las variables ecográficas e histomorfométricas se correlacionaron mediante el test de correlación de Pearson. Los datos se expresaron como la media \pm SEM. El nivel de significancia estadística se fijó en $\mathrm{P}<0,05$ (SPSS, Inc., Chicago, IL, USA).

\section{Resultados}

El volumen testicular $\left(\mathrm{cm}^{3} ; 1,00 \pm 0.09\right.$ vs. $\left.0,85 \pm 0.1 ; \mathrm{P}<0,05\right)$ y la ecogenicidad $(\mathrm{P}<0,01)$, pero no la heterogeneidad ( $\mathrm{P}>0,05)$, disminuyeron en el grupo Pos (Figura 1).

Por otro lado, el tratamiento con acyline provocó un deterioro histológico leve, con una disminución del $34 \%$ y $18 \%$ en la altura del epitelio germinal y el diámetro tubular, respectivamente, comparado con testículos felinos normales (Figura 2; França y Godinho, 2003). 
Las correlaciones entre los parámetros macro y microscópicos con los ultrasonográficos se presentan en la Tabla $\mathbf{1}$.

Figura 1. Ecogenicidad (color sólido) y heterogeneidad (punteado), pre (Pre) y postratamiento (Pos), de los gatos que recibieron una dosis semanal de $330 \mu \mathrm{g} / \mathrm{kg} \mathrm{SC}$, durante 4 semanas. Letras diferentes indican diferencias significativas entre los grupos $(\mathrm{P}<0,05)$.

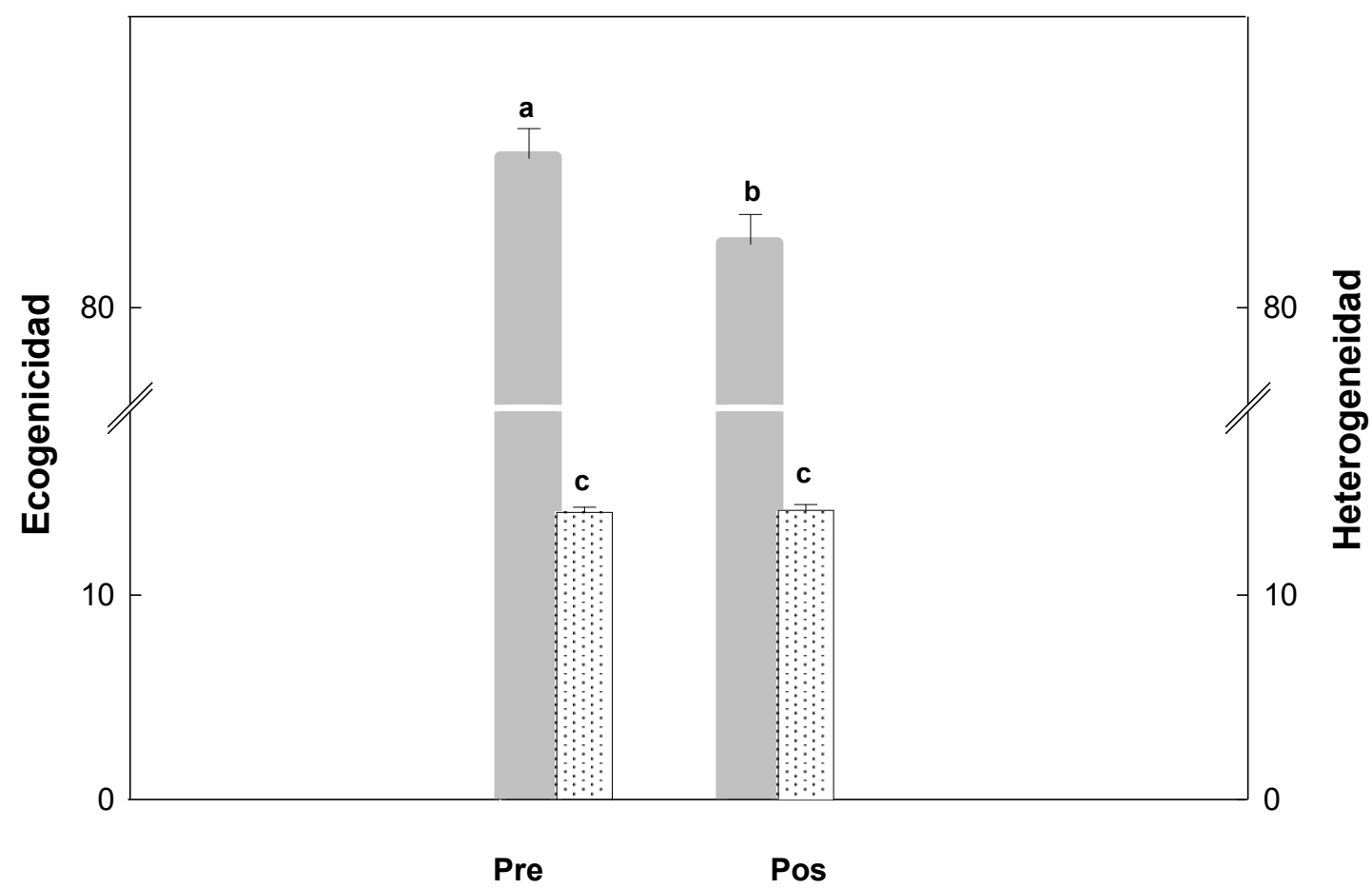


Figura 2. Túbulos seminíferos de uno de los gatos de la Figura 1, una semana posterior a última aplicación de acyline. Se observa una disminución en el diámetro tubular y de la altura del epitelio germinal.

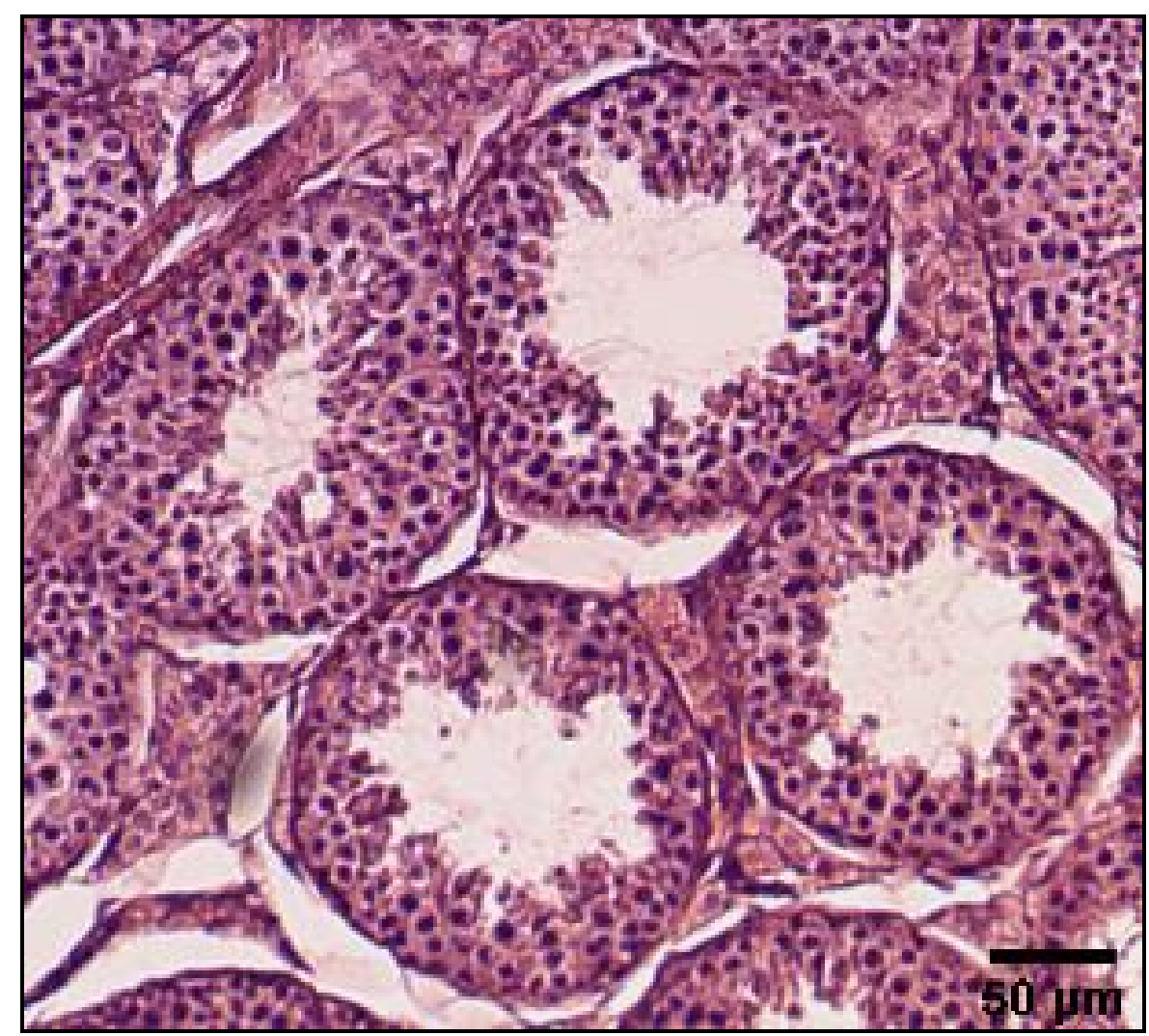


Tabla 1. Coeficientes de correlación de Pearson entre variables macro y microscópicas y ultrasonográficas testiculares de los animales de la Fig. 1.

\begin{tabular}{lcccc}
\hline Características macro y & Ecogenicidad & $P$ & Heterogeneidad & $p$ \\
microscópicas & & & & \\
\hline Volumen testicular $\left(\mathrm{cm}^{3}\right)$ & 0.08 & $>0,1$ & 0.00 & $>0,1$ \\
Índice gonadosomático (\%) & 0.23 & $>0,1$ & 0.04 & $>0,1$ \\
Diámetro tubular $(\mu \mathrm{m})$ & -0.11 & $>0,1$ & -0.21 & $>0,1$ \\
Diámetro luminal $(\mu \mathrm{m})$ & -0.11 & $>0,1$ & -0.21 & $>0,1$ \\
Altura epitelio $(\mu \mathrm{m})$ & 0.05 & $>0,1$ & 0.22 & $>0,1$ \\
Espermatogonia (\%) & -0.35 & $>0,1$ & 0.31 & $>0,1$ \\
Espermatocito primario (\%) & -0.07 & $>0,1$ & -0.11 & $>0,1$ \\
Espermátide redonda (\%) & 0.22 & $>0,1$ & 0.27 & $>0,1$ \\
Espermátide elongada (\%) & 0.13 & $>0,1$ & 0.25 & $>0,1$ \\
Espermatozoide (\%) & 0.09 & $>0,1$ & -0.34 & $>0,1$ \\
Relación túbulo/intersticio & -0.35 & $>0,1$ & -0.46 & $>0,1$ \\
Relación lumen/intersticio & 0.06 & $>0,1$ & -0.20 & $>0,1$ \\
\hline
\end{tabular}

\section{Discusión}

Hasta el momento, no han sido publicados trabajos sobre análisis digital de ultrasonografías testiculares en el gato doméstico. Así, en este estudio, se evaluó esta técnica como una herramienta diagnóstica no invasiva para el estudio de la función reproductiva del gato doméstico. 
Para evaluar la ecotextura testicular de gatos adultos con alteraciones en la espermatogénesis, se utilizó un modelo farmacológico de deterioro espermatogénico. Tal como previamente fue reportado (García Romero y col., 2012), el tratamiento con el antagonista de $\mathrm{GnRH}$, acyline, produjo un daño tubular leve, que podría simular casos de subfertilidad que, de ser diagnosticados, son factibles de ser tratados. Si bien puede asumirse que lesiones más severas, como degeneración o atrofia testiculares, podrían aportar resultados más evidentes, estas alteraciones son irreversibles.

Si bien a simple vista, el parénquima testicular no evidenció diferencias luego de la aplicación del antagonista, el análisis digital de los ultrasonogramas detectó los cambios tisulares que se produjeron. Así, en comparación con los valores previos al tratamiento, la ecogenicidad resultó significativamente menor luego de la última aplicación del disruptor. De manera similar, en bovinos, la ecogenicidad testicular disminuyó drásticamente luego de haber sido sometidos a stress térmico (Arteaga y col., 2005) y en equinos maduros, testículos inguinales y abdominales mostraron ser menos ecogénicos que testículos escrotales normales (Pozor y col., 2017).

Por otro lado, la heterogeneidad no mostró diferencias entre los valores pre y postratamiento. Probablemente, sean necesarios cambios más profundos en el parénquima testicular para que puedan verse reflejados en la heterogeneidad. Además, se ha propuesto que otros componentes del parénquima testicular ejercen mayor influencia en la heterogeneidad que los túbulos seminíferos (Pozor y col., 2017). Así, se ha demostrado que la heterogeneidad está directamente asociada con la composición bioquímica del parénquima testicular, la cual, a su vez, varía durante condiciones patológicas o a través del desarrollo (Ahmadi y col., 2013).

El análisis histológico de los testículos tratados con el disruptor, mostró una disminución del diámetro tubular y la altura del epitelio germinal con respecto a los valores normales reportados previamente para la especie (França y Godinho, 2003). Sin embargo, ninguna de las variables histomorfométricas estudiadas, mostró correlación con los parámetros 
ultrasonográficos analizados. En concordancia con estos resultados, en equinos con testículos retenidos abdominales, no se halló correlación entre los parámetros histológicos y ultrasonógraficos (Pozor y col., 2017). La evaluación de un mayor número de animales, con mayores variaciones histomorfométricas probablemente sea necesaria para poder detectar este tipo de asociaciones más detalladas.

Mediante el análisis digital de ultrasonográfico se detectaron cambios en la ecogenicidad, pero no en la heterogeneidad, en un modelo de deterioro testicular. Si bien el análisis digital de imágenes ultrasonográficas podría convertirse en una herramienta diagnóstica útil en la evaluación de la función reproductiva del gato doméstico, es necesario llevar a cabo más investigaciones, en un mayor número de animales, antes de que pueda ser ampliamente utilizado en el examen andrológico.

\section{Referencias}

1. Ahmadi B, Mirshahi A, Giffin J, Oliveira M, Gao L, Hahnel A, Bartlewski P. Preliminary assessment of the quantitative relationships between testicular tissue composition and ultrasonographic image attributes in the ram. Vet J. 2013 ;198(1):282-5.

2. Arteaga A, Barth A, Brito L. Relationship between semen quality and pixelintensity of testicular ultrasonograms after scrotal insulation in beef bulls. Theriogenology. 2005;64(2):408-15.

3. Axnér E, Ström B, Linde-Forsberg C, Gustavsson I, Lindblad K, Wallgren M. Reproductive disorders in 10 domestic male cats. J Small Anim Pract. 1996;37(8):394-401. 
4. Brito L, Barth A, Wilde R, Kastelic J. Testicular ultrasonogram pixel intensity during sexual development and its relationship with semen quality, sperm production, and quantitative testicular histology in beef bulls. Theriogenology 2012;78(1):69-76.

5. França L, Godinho C. Testis morphometry, seminiferous epithelium cycle length, and daily sperm production in domestic cats (Felis catus). Biol Reprod. 2003;68(5):1554-61.

6. Evans A, Pierson R, Garcia A, McDougall L, Hrudka F, Rawlings N. Changes in circulating hormone concentrations, testes histology and testes during sexual maturation in beef bulls. Theriogenology 1996;46(2):345e57.

7. Garcia Romero G, Fernández P, Gimeno E, Barbeito C, Gobello C. Effects of the GnRH antagonist acyline on the testis of the domestic cat (Felis catus). Vet J. 2012;193(1):279-82.

8. Giffin J, Bartlewski P, Hahnel A. Correlations among ultrasonographic and microscopic characteristics of prepubescent ram lamb testes. Experimental Biology and Medicine 2014; 239: 1606-1618.

9. Giffin J, Hahnel A, Bartlewski PM. Retinoic acid treatment alters germ cell heterogeneity and testicular echotexture in prepubescent ram lambs. Reprod Fertil Dev. 2015;29(2):244-253.

10. Giffin J, Franks S, Rodriguez-Sosa J, Hahnel A, Bartlewski P. A study of morphological and haemodynamic determinants of testicular echotexture characteristics in the ram. Exp Biol Med (Maywood). 2009;234(7):794-801.

11. Hamm B, Fobbe F. Maturation of the testis: ultrasound evaluation. Ultrasound Med Biol. 1995;21(2):143-47.

12. Lin C, Huang W, Chen K. Measurement of testicular volume in smaller testes: how accurate is the conventional orchidometer? J Androl. 2009;30(6):685-689. 
13. Mattoon J, Nyland T. Prostate and Testes. En Mattoon JS y Nyland T Small Animal Diagnostic Ultrasound. 3era Ed. Saint Louis, Estados Unidos, Ed Elsevier, 2015, p. 260-276.

14. Moxon R, Bright L, Pritchard B, Bowen I, de Souza M, da Silva L, England G. Digital image analysis of testicular and prostatic ultrasonographic echogencity and heterogeneity in dogs and the relation to semen quality. Anim Reprod Sci. 2015;160:112-9.

15. Pozor M, Morrissey H, Albanese V, Khouzam N, Deriberprey A, Macpherson M, Kelleman A. Relationship between echotextural and histomorphometric characteristics of stallion testes. Theriogenology. 2017;99:134-145. 


\section{CAPÍTULO III}

\section{ANÁLISIS DIGITAL ULTRASONOGRÁFICO DURANTE EL DESARROLLO TESTICULAR FELINO}

\section{Introducción}

En el gato doméstico, ocurren una serie de cambios durante el desarrollo testicular que han sido detalladamente descriptos (Sánchez 1993; Sieminuch y Wockławek-Potocka, 2007; Triptavanatta y col., 2015). En el período neonatal, los túbulos seminíferos carecen de luz, están compuestos sólo por células de Sertoli y una o dos espermatogonias. Progresivamente, el parénquima testicular va desarrollando lobulillos, los túbulos seminíferos van aumentando de diámetro, adquiriendo luz y el epitelio seminífero comienza a estratificarse para, finalmente, adquirir las características de un testículo maduro, con producción de espermatozoides (Sánchez 1993).

La ultrasonografía es una técnica no invasiva que permite la visualización de diferentes estructuras y órganos, tanto en animales como en humanos. Recientemente, el análisis digital de la ecotextura testicular se ha convertido en una alternativa a métodos diagnósticos invasivos, siendo posible cuantificar la ecogenicidad y heterogeneidad de un tejido. Una imagen ultrasonográfica está compuesta por unidades llamadas pixeles, cuya intensidad de color se mide en una escala de 0 (negro absoluto) a 255 (blanco absoluto). Utilizando programas de análisis de imágenes, es posible determinar un promedio de la intensidad de pixeles de una región, así como también el desvío standard de la intensidad de pixeles, que representan la ecogenicidad y la heterogeneidad de un tejido, respectivamente (Giffin y col.,2009) 
Estudios en humanos (Hamm y Fobe, 1994) y bovinos (Brito y col., 2012) han demostrado que la ecogenicidad testicular aumenta con la edad hasta la madurez sexual. Así mismo, en rumiantes se han reportado los cambios tisulares que se producen en el testículo durante el desarrollo puberal pueden ser detectados mediante el análisis digital de imágenes ultrasonográficas (Evans y col., 1996; Brito y col., 2012; Giffin y col., 2014).

Aunque todos estos estudios sugieren que el análisis digital de imágenes ultrasonográficas es un método válido para evaluar la función testicular, su utilidad no ha sido aún estudiada en el gato doméstico. Por lo tanto, el objetivo de este capítulo fue describir y comparar la ecogenicidad y heterogeneidad del parénquima testicular mediante análisis digital de imágenes ultrasonográficas en gatos prepuberales, peripuberales y adultos. Y, secundariamente, correlacionar los parámetros ultrasonográficos con parámetros histomorfométricos testiculares.

\section{Materiales y métodos}

\section{Animales}

Se utilizaron 14 gatos machos, mestizos, entre 5 y 36 meses de edad, los cuales nacieron y se criaron en nuestra colonia experimental y se expusieron a un fotoperiodo positivo de 14 hs de luz y 10 hs de oscuridad. A partir de los 40 días de vida, se destetaron y alimentaron con alimento balanceado y agua ad libitum. Todos los animales se alojaron sueltos en habitaciones de $3 \times 4$ metros, con enriquecimiento ambiental. Además, los gatos se socializaron por alumnos entrenados para este fin.

Este estudio fue revisado y aprobado por el Comité Institucional de Cuidado y Uso de Animales de Laboratorio (CICUAL) de la Facultad de Ciencias Veterinarias de la 
Universidad Nacional de La Plata, Argentina, y los experimentos se condujeron bajo las guías establecidas por The Guide for The Care and Use of Laboratory Animals, USA.

\section{Ultrasonografias}

Los animales se evaluaron mediante ultrasonografía en modo B utilizando un transductor lineal de $14 \mathrm{MHz}$ (Toshiba Nemio XG, Japón). Los parámetros ultrasonográficos (ganancia: 100; profundidad: $2 \mathrm{~cm}$ ) fueron seleccionados para obtener la máxima calidad de imagen, y se mantuvieron constantes durante todo el estudio. Las imágenes fueron tomadas en los planos longitudinal y transversal (jpg de 640 x 480 pixeles) y en las secciones longitudinales, se realizó el análisis digital utilizando el software Image J (National Institutes of Health, Bethesda, Maryland, USA) para lo cual se seleccionaron 6 regiones de interés (RDI, $1 \mathrm{~mm}^{2}$ ) entre el mediastino y la cápsula testicular (12 RDI/gato). Dentro de cada RDI se cuantificaron la ecogenicidad y la heterogeneidad del parénquima testicular, como la intensidad media de pixeles (IMP) y el desvío estándar (DS) de la IMP, respectivamente (Giffin y col., 2014; Pozor y col., 2017).

\section{Orquiectomías}

Todos los gatos se orquiectomizaron, y luego se entregaron en adopción responsable. Brevemente, se premedicaron con sulfato de atropina (John Martin; 0,04 mg/kg SC), maleato de acepromacina (Acedan, Holliday; $0,03 \mathrm{mg} / \mathrm{kg}$ SC) y butorfanol (Torbutol Plus, Fort Dodge; 0,2 mg/kg IM). Para la inducción se utilizó tiopental sódico (Pentovet TM, Richmond; 8mg/kg IV). Luego de la introducción del traqueotubo, la anestesia se mantuvo con isofluorano y oxígeno en sistema cerrado. Cada testículo se extrajo a través de una incisión longitudinal en el escroto, mediante la técnica a cielo abierto y cada cordón espermático se ligó con vicryl 0,3 previó a la escisión. Luego de la cirugía, se administró ketoprofeno (Ketofen, Fort Dodge; $1 \mathrm{mg} / \mathrm{kg} \mathrm{SC}$ ) y luego oralmente cada 24 horas durante 4 días. 


\section{Examen macroscópico y microscópico}

Inmediatamente luego de la escisión de los testículos, estos se midieron (largo y ancho; cm), pesaron (g) y se calculó el volumen $\left(\mathrm{cm}^{3}\right.$; Linn y col., 2009) y el índice gonadosomático (\%; França y Godinho, 2003).

Posteriormente, las gónadas se colocaron en fijador Bouin durante 24 horas y luego en alcohol 70 grados hasta ser procesadas con la técnica histológica de rutina e incluidas en parafina. Se obtuvieron cortes de $5 \mu \mathrm{m}$ que se montaron, desparafinaron en xylol, rehidrataron con soluciones graduadas de etanol y finalmente tiñeron con hematoxilina eosina. Las imágenes histológicas se obtuvieron desde un microscopio óptico (Olympus BX50, Tokio, Japón) con el objetivo 10x, a través de una cámara de video conectada (Omax A35180U3, China) y se digitalizaron en formato TIFF color de 24 bits.

El análisis de las imágenes histológicas se llevó a cabo mediante planimetría (Image J, National Institutes of Health, Bethesda, Maryland, USA). Para ello, se seleccionaron 10 perfiles tubulares redondos, de los cuales se determinó el diámetro tubular $(\mu \mathrm{m})$, el diámetro de la luz $(\mu \mathrm{m})$ y la altura del epitelio germinal $(\mu \mathrm{m}$,$) . En los túbulos, se$ identificó la célula germinal más avanzada, para calcular el porcentaje de túbulos seminíferos con los diferentes tipos de células germinales. Finalmente se calculó la relación túbulo/intersticio y la relación lumen/intersticio (Pozor y col., 2017).

De acuerdo a las características histomorfométricas, los animales se clasificaron en tres grupos:

1. Prepuberal (Pre): diámetro tubular menor a $100 \mu \mathrm{m}$, epitelio germinal no estratificado.

2. Peripuberal (Peri): diámetro tubular entre 100 y $150 \mu \mathrm{m}$, epitelio germinal estratificado y espermátides y espermatozoides en al menos el $50 \%$ de los túbulos.

3. Pospuberal (Pos): diámetro tubular mayor a $150 \mu \mathrm{m}$, epitelio germinal estratificado y espermatides y espermatozoides en más del 50\% de los túbulos. 


\section{Análisis estadístico}

La normalidad de los datos se confirmó mediante el test de Shapiro-Wilks. Los valores de ecogenicidad y heterogeneidad de los 3 grupos (Pre, Peri y Pos) se compararon mediante un test de ANOVA seguido del test de Tukey. Las características ecográficas y los parámetros histomorfométricos testiculares, se correlacionaron mediante el test de correlación de Pearson. Los datos se expresaron como la media \pm SEM. El nivel de significancia estadística se fijó en $\mathrm{P}<0,05$ (SPSS, Inc., Chicago, IL, USA).

\section{Resultados}

De acuerdo a las características histomorfométricas, 6, 2 y 6 gatos fueron clasificasdos como Pre, Peri y Pos, respectivamente. El volumen testicular aumentó progresivamente y mostró diferencias entre los tres grupos. Por su parte, el índice gonadosomático, mostró diferencias entre los grupos Peri y Pos (Tabla 1).

Tanto la ecogenicidad $(\mathrm{P}<0,01)$ como la heterogeneidad $(\mathrm{P}<0,01)$ aumentaron a través de los tres grupos. Los animales del grupo Pre presentaron testículos menos ecogénicos con respecto a los grupos Peri y Mad. Igual comportamiento presentó la heterogeneidad (Figura 1).

Las correlaciones entre los parámetros macro y microscópicos con los ultrasonográficos se presentan en la Tabla 2. Debido a la ausencia de luz en los túbulos de los animales Pre, la altura del epitelio no pudo ser medida en este grupo.

Exceptuando la altura del epitelio germinal y la relación túbulo/intersticio, todas las variables mostraron estar correlacionadas con la ecogenicidad y la heterogeneidad.

Tabla 1. Parámetros testiculares macroscópicos (media \pm SEM) de los 14 gatos prepuberales (Pre), peripuberales (Peri) y pospuberales (Pos). Letras diferentes en una misma línea indican diferencias significativas entre los grupos $(\mathrm{P}<0,05)$. 


\begin{tabular}{lllll}
\hline Parámetro & Pre & Peri & Pos & P \\
\hline Volumen testicular $\left(\mathrm{cm}^{3}\right)$ & $0,15 \pm 0,03^{\mathrm{a}}$ & $81,87 \pm 5,89^{\mathrm{b}}$ & $94,67 \pm 3,62^{\mathrm{c}}$ & $<0,001$ \\
& & & & \\
Índice gonadosomático (\%) & $0,04 \pm 0,003^{\mathrm{a}}$ & $0,05 \pm 0,004^{\mathrm{a}}$ & $0,08 \pm 0,004^{\mathrm{b}}$ & $<0,001$ \\
\hline
\end{tabular}

Figura 1. Ecogenicidad (color sólido) y heterogeneidad (punteado) de los animales de la Tabla 1. Letras diferentes indican diferencias significativas entre los grupos $(P<0,05)$

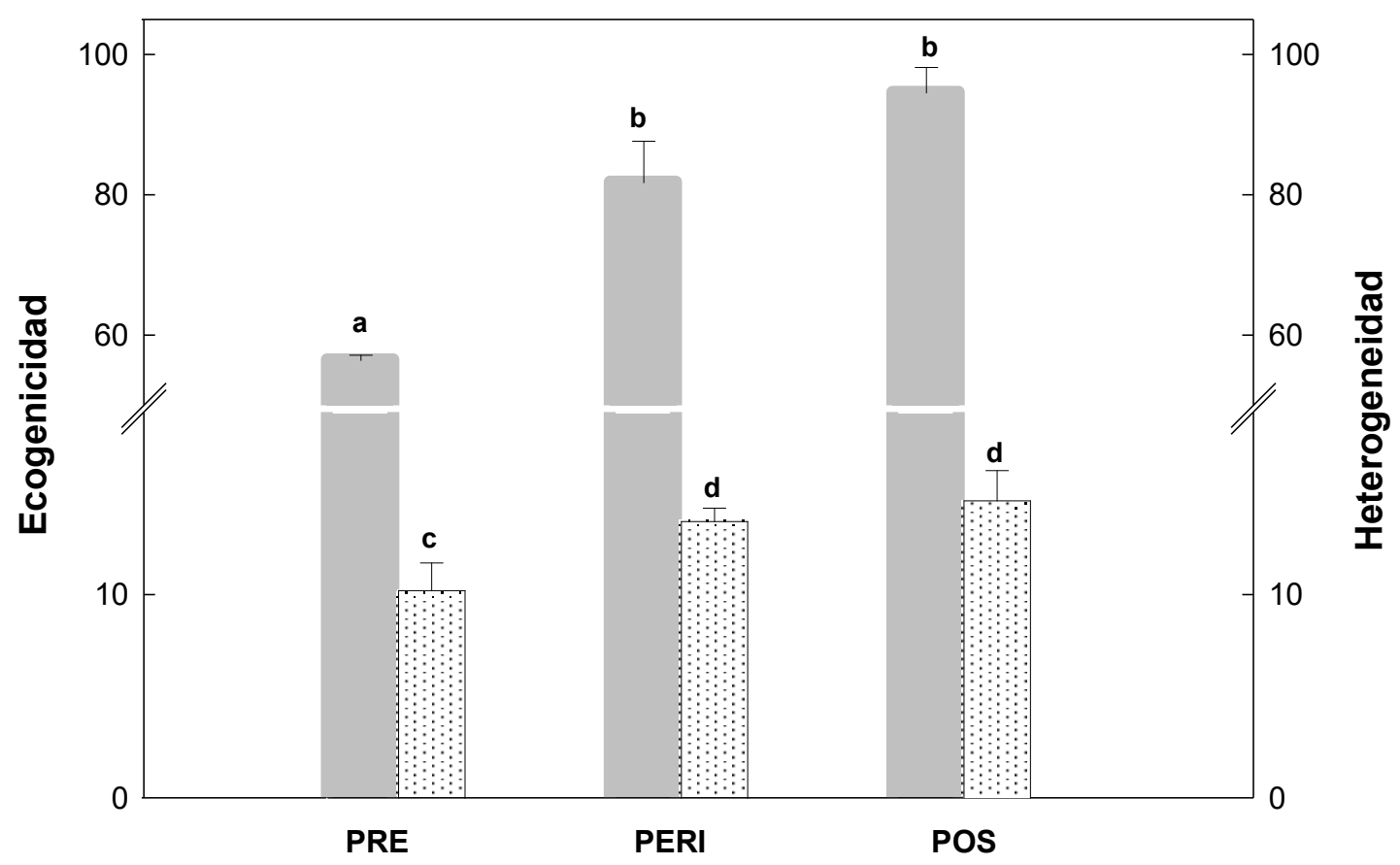


Tabla 2. Coeficientes de correlación de Pearson entre variables macro y microscópicas y ultrasonograficas testiculares de los animales de la Tabla 1.

\begin{tabular}{|c|c|c|c|c|}
\hline $\begin{array}{l}\text { Características macro y } \\
\text { microscópicas }\end{array}$ & Ecogenicidad & $\mathrm{P}$ & Heterogeneidad & $\mathrm{P}$ \\
\hline Volumen testicular $\left(\mathrm{cm}^{3}\right)$ & 0.59 & $<0.01$ & 0.73 & $<0.01$ \\
\hline Índice gonadosomático (\%) & 0.64 & $<0.01$ & 0.44 & $<0,05$ \\
\hline Diámetro tubular $(\mu \mathrm{m})$ & 0.75 & $<0.01$ & 0.75 & $<0.01$ \\
\hline Diámetro luminal $(\mu \mathrm{m})$ & 0.73 & $<0.01$ & 0.77 & $<0.01$ \\
\hline Altura epitelio $(\mu \mathrm{m})$ & 0.23 & $>0,1$ & 0.38 & $>0,1$ \\
\hline Espermatogonia (\%) & -0.81 & $<0.01$ & -0.84 & $<0.01$ \\
\hline Espermatocito primario (\%) & 0.19 & $>0,1$ & 0.17 & $>0,1$ \\
\hline Espermátide redonda (\%) & 0.62 & $<0.01$ & 0.61 & $<0.01$ \\
\hline Espermátide elongada (\%) & 0.68 & $<0.01$ & 0.74 & $<0.01$ \\
\hline Espermatozoide (\%) & 0.63 & $<0.01$ & 0.49 & 0.01 \\
\hline Relación túbulo/intersticio & 0.43 & 0.05 & 0.26 & $>0,1$ \\
\hline Relación lumen/intersticio & 0.61 & $<0.01$ & 0.49 & 0.01 \\
\hline
\end{tabular}




\section{Discusión}

Este es el primer estudio donde se describen y analizan objetivamente las características ultrasonográficas de testículo felinos durante su desarrollo puberal.

Como era de esperar, el volumen testicular aumentó progresivamente con el desarrollo reproductivo, y se correlacionó positivamente con las variables ultrasonograficas, de manera similar a lo que se describió en bovinos (Gabor y col., 1996). Por su parte, el índice gonadosomático también aumentó progresivamente hasta alcanzar los valores adultos reportados para la especie (França y Godinho, 2003), y se correlacionó positivamente con la ecogenicidad y la heterogeneidad testicular.

Coincidiendo con estudios en otras especies (Brito y col., 2012; Evans y col., 1996; Giffin y col., 2014; Hamm y Fobe, 1994), en el gato doméstico la ecogenicidad y la heterogeneidad aumentaron con el desarrollo reproductivo. En este estudio, ambas variables ecográficas se incrementaron hasta la pubertad, para luego mantenerse constantes.

Ha sido demostrado que la ecotextura testicular es afectada por los cambios histológicos que suceden durante el inicio de la espermatogénesis, dentro de los cuales los principales son el aumento en los diámetros tubular y luminal (Brito y col., 2012; Giffin y col., 20092014; Pozor y col., 2017). En este sentido, estas variables mostraron estar fuerte y positivamente correlacionadas con la ecogenicidad y heterogeneidad testicular en el gato doméstico. El incremento en el tamaño tubular y la formación del lumen también explica que las relaciones túbulo/intersticio y lumen/intersticio hayan mostrado estar correlacionadas positivamente con la ecotextura testicular.

Contrariamente a lo esperado, no se encontró relación entre la altura del epitelio germinal y las variables ultrasonograficas. En equinos dicha variable resultó positivamente correlacionada, con la ecogenicidad y la heterogeneidad (Pozor y col., 2017). Esta 
discrepancia puede ser debida a que en los gatos prepúberes, esta variable no pudo ser medida por la ausencia de luz, reduciéndose el número de testículos analizados.

Las relaciones entre el porcentaje de túbulos seminíferos con cada tipo celular con las variables ultrasonogáficas, arrojó resultados similares a los reportados en bovinos (Evans y col., 1996). Las correlaciones pasaron de ser fuertemente negativas para aquellos estadios celulares más inmaduros (espermatogonias) a positivos para las células más maduras (espermátides redondas, elongadas y espermatozoides).

Los hallazgos de este capítulo ponen de manifiesto cómo los cambios que suceden durante el desarrollo testicular afectan sus características ecográficas. De este modo, el análisis digital cuantitativo de imágenes ultrasonográficas en modo B podría constituirse en una herramienta útil en el diagnóstico de pubertad en felinos.

\section{Referencias}

1. Brito LF, Barth AD, Wilde RE, Kastelic JP. Testicular ultrasonogram pixel intensity during sexual development and its relationship with semen quality, sperm production, and quantitative testicular histology in beef bulls. Theriogenology 2012;78(1):69-76.

2. Evans AC, Pierson RA, Garcia A, McDougall LM, Hrudka F, Rawlings NC. Changes in circulating hormone concentrations, testes histology and testes during sexual maturation in beef bulls. Theriogenology 1996;46(2):345-57.

3. França LR, Godinho CL. Testis morphometry, seminiferous epithelium cycle length, and daily sperm production in domestic cats (Felis catus). Biol Reprod. 2003;68(5):1554-61. 
4. Giffin JL, Franks SE, Rodriguez-Sosa JR, Hahnel A, Bartlewski PM. A study of morphological and haemodynamic determinants of testicular echotexture characteristics in the ram. Exp Biol Med (Maywood). 2009;234(7):794-801.

5. Giffin JF, Bartlewski PM, Hahnel AC. Correlations among ultrasonographic and microscopic characteristics of prepubescent ram lamb testes. Experimental Biology and Medicine 2014; 239: 1606-1618.

6. Hamm B, Fobbe F. Maturation of the testis: ultrasound evaluation. Ultrasound Med Biol. 1995;21(2):143-47.

7. Lin CC, Huang WJ, Chen KK. Measurement of testicular volume in smaller testes: how accurate is the conventional orchidometer? J Androl. 2009;30(6):685-689.

8. Pozor M, Morrissey H, Albanese V, Khouzam N, Deriberprey A, Macpherson M L, Kelleman A A. Relationship between echotextural and histomorphometric characteristics of stallion testes. Theriogenology. 2017;99:134-45.

9. Sánchez B, Pizarro M, García P, Flores JM. Postnatal development of seminiferous tubules in the cat. J Reprod Fertil Suppl. 1993;47:343-48.

10. Sieminuch MJ, Wockławek-Potocka I. Morphological features of the seminiferous epithelium in cat (Felis catus). J. Reprod. Dev. 2007.; 53:11251130.

11. Tiptanavattana N, Radtanakatikanon A, Hyttel P, Holm H, Buranapraditkun S, Setthawong P, Techakumphu M, Tharasanit T. Determination phase at transition of gonocytes to spermatogonial stem cells improves establishment efficiency of spermatogonial stem cells in domestic cats. J Reprod Dev. 2015;61(6):581-8. 


\section{CONCLUSIONES FINALES}

- Una única dosis oral del derivado de indenopiridina RTI 4587-073 (L), provocó una rápida desorganización del epitelio seminífero y disminución de todos sus componentes celulares, excepto las espermatogonias. El retorno a la normalidad ocurrió en aproximadamente un ciclo espermático. No se presentaron efectos colaterales clínicos asociados con el tratamiento.

- El volumen ocupado por las células de Leydig disminuyó luego del tratamiento con el RTI 4587-073 (L). No obstante, este cambio no se vio reflejado en las concentraciones de testosterona fecal, que no variaron durante el estudio.

- Las indenopiridinas se vislumbran como una opción farmacológica no esteroidea efectiva y segura para el rápido control de la reproducción en esta especie.

- Mediante análisis digital de ultrasonografías testiculares modo $\mathrm{B}$, fue posible detectar cambios sutiles en la apariencia ecográfica en un modelo de daño testicular. La ecogenicidad, pero no la heterogeneidad, resultó menor en testículos con deterioro en la espermatogénesis que en aquellos normales.

- El análisis digital de imágenes ultrasonográficas en modo $\mathrm{B}$, permitió distinguir testículos pre púberes, de púberes y adultos. La ecogenicidad y la heterogeneidad aumentaron con la edad. Así mismo, mostraron estar fuertemente correlacionadas con parámetros testiculares macro y microscópicos. 
PUBLICACIONES 


\section{Effect of the indenopyridine RTI-4587-073 (1) on feline testicle \\ F. D'Francisco ${ }^{a, b}$, M. López Merlo ${ }^{a, b}$, R. Vercellini ${ }^{a, b}$, P. Blanco ${ }^{a, b}$, C. Barbeito ${ }^{a, b}$, C. Gobello ${ }^{\mathrm{a}, \mathrm{b}, \mathrm{*}}$}

-Faculy of Veterinary Sciesca, National Uninenity of Le Mana, Argetina

"National Research Council, Argotines

ARTICLE INFO

\section{Keyword:}

Felld

Coetriaceptice

Non-steroidal

Texis

\begin{abstract}
The aim of this study was to describe the seminal, histomorphological and hormonal effects of the oral indenopyridine RT-4587-073(1) on feline testicle. Clinical side effeets were also recorded. Sixty testicles of 30 adult cats that had been treated $(\mathrm{d} 0$ ) with FTh-4587-073(1) $12.5 \mathrm{mg} / \mathrm{kg}$ PO and randomly hemioechiectomixed twiee on: day $-14(n-8), 6 \mathrm{~h}(n-6), 12 \mathrm{~h}(n-8), 24 \mathrm{~h}$ $(n-6)$, day $7(n-8)$, day $14(n-6)$, day $21(n-6)$, day $35(n-6)$ or day $42(n-6)$ were studied. Before each hemiorchiectomy, fecal samples for testosterone (I) measurement were collected and the testes were grossly and ultrasound examined. This indenopyridine did not cause changes in testicular weight $(P>0.1)$, volume $(P>0.1)$, echostructure, gonadosomatic index $(P>0.1)$, fecal $\mathrm{T}$ concentrations $(P>0.1)$, nor clinical side effects. A severe disorganization of the cytoarchitecture of the seminiferous epithelium, sloughed cells and flubd, were observed in the $6 \mathrm{~h}$ samples up to a maximum at $24 \mathrm{~h}$. Tubular diameter $(P<0.01)$ increased twice, during the first $24 \mathrm{~h}$ and on $\mathrm{d} 35$. Germinal epithelium achieved its minimum height on $\mathrm{d} 14$ to rapidly recover thereafter. This treatment caused a significant decrease in the volume of all the semb. niferous cell components, except spermatogonias. All histotological parameters normalized by the end of the study. It was concluded that RT1-4587-073(1) severely disnupted spermatogenesis during the first $24 \mathrm{~h}$ after treatment returning to normality in approaimately one spermatic cycle without clinical side effects.
\end{abstract}

\section{Introduction}

Domestic felids (Felis catus) are extremely prolific breeders, they mate from early puberty up to death and, if kept indoors or at latitudes higher than $35^{\circ}$, throughout the year (Faya et al., 2011). Thus, contraception - reversible reproduction control - is often required for genetically valuable domestic or wild cats. As in most other mammalian species, feline contraception is mainly targeted towards females and progestins are commonly used provoking, sometimes, severe reproductive and general health side effects (Munson, 2006). Although both steroidal and non-steroidal approaches have been assessed in males, controlling spermatogenesis probed to be a more complex objective than preventing ovulation in females. Furthermore, most male contraceptive protocols have shown a variable lag time to achieve azoospermia as well as an unpredictable return to fertility (Bowen, 2008). Safe, rapid and efficient pharmaceutical compounds are still needed to temporally control the undesired reproduction in male felids. If tom cats were rendered temporarily sterile, female reproductive health could also be preserved.

The group of indenopyridine derivatives, which were originally developed as antihistamine drugs, has shown antispermatogenic

\footnotetext{
-Correspending author at: Labocatory of Reproductive Physiology, Faculty of Veterinary Sciences, National University of La Plata, 60 y 118 La Plata CC 296 (B 1900 AVW), Argentina.

E-mail addres: czobelloeffev.unlp.eduar (C, Gobello).
}

https://doLarg/10.1016/j.anireprosci.2019.03.014

Received 9 October 2018; Received in revised form 11 March 2019, Acoepted 26 March 2019

Available online 27 March 2019

0378-4320/ क 2019 Published by Elkevier B.V. 
effects in rats (Hodel and Suter, 1978), stallions (Pozor et al., 2013) and dogs (Chang et al., 2002) without overt side effects, toxicity nor mutagenic potential (Fail et al., 2000; Mruk, 2008). Studies in laboratory animals showed that the primary target of in* denopyridines is the Sertoli cell, resulting in disruption of Sertoli - germ cell adhesion (Hild et al., 2001, 2007b; Koduri et al., 2008).

While in monkeys indenopyridines induced reversible severe oligoasthenozoospermia (Hild et al., 2007a), irreversible infertility was described in rats (Hild et al., 2004). In horses and dogs indenopyridines induced a rapid (few days) and transient inhibition of spermatogenesis increasing the number of immature germ cells in ejaculates (Chang et al., 2002; Hodel and Suter, 1978; Pozor et al., 2013, 2014). Histologically the seminiferous tubuli appeared emptied of spermatides and spermatocytes (Pozor et al., 2013). Al. though the testicular effects described in these four species make indenopyridines a promising candidate for nonesteroidal, oral male contraception in felids, nothing is known about their effect, reversibility and tolerability in this species (Munson, 2006).

The compound RTl-4587.073, formerly called CDB-4022, is a new indenopyridine derivative, which is a mixture of L and Disomers. The toisomer exhibits a particularly strong anti- spermatogenic activity (Pozor et al., 2013) and, therefore, was chosen for this feline trial. Thus, the aim of this study was to describe the ultrasonographic, histomorphological and bormonal effects of oral indenopyridine RTl-4587.073(1) on feline testicle. Secondly, some epididymal semen characteristics and clinical side effects of the drug were also recorded in the treated cats.

\section{Material and methods}

\subsection{Experimental protocal}

Sixty testicles of 30, 1.5-5 years old, domestic short hair, fertile cats were included in this study. The males were born in our Institutional Colony, exposed to $14 \mathrm{~h}$ of light per day in three $4 \times 4 \mathrm{~m}$ enriched rooms, fed commercial food and water ad libitum. The animals were treated (day 0) with RTl.4587.073(1) $12.5 \mathrm{mg} / \mathrm{kg}$ PO and randomly hemiorchiectomized twice on: day $\cdot 14$ ( $n=8$ ), $6 \mathrm{~h}$ $(n=6)$, 12 h $(n=8)$, day $1(n=6)$, day $7(n=8)$, day $14(n=6)$, day $21(n=6)$, day $35(n=6)$ or day $42(n=6)$. The calculated dose was dissolved in $2 \mathrm{ce}$ of saline and administered by a naso-esophageal tube after mild sedation. The dose and dosing scheme were selected according to studies in other mammals (Hild et al., 2001; Pozor et al., 2013) and to our own pilot trials in cats.

Before each hemiorchiectomy, the felids were weighed, fecal samples were collected and the testes were grossly and ultrasound examined in a way that each animal had 2 random evaluation time points on the same days of surgeries. The appearance of clinical side effects, such as lack or diminished appetite, vomiting or other digestive signs, changes in body weight or sexual or general behavior, was also recorded in all the animals. This study was reviewed and approved by the Animal Care and Use Committee of the Veterinary School of the National University of La Plata and all experiments were conducted under the guidelines established in The Guide for The Care and Use of Laboratory Animals, USA.

\subsection{Utrasound evaluations}

Ultrasound examinations of the testes were undertaken by a single experienced evaluator using a real time B*mode ultrasound machine (Toshiba Nemio XG, Japón) with a $14 \mathrm{MHz}$ lineal transducer. All machine settings were established at the first examination according to best image quality and remained unaltered for all remaining examinations. Acoustic gel was applied to the transducer and coupled directly to the clipped scrotum with minimum pressure to obtain the images. The testes were imaged in the sagittal and transverse planes. Testicular dimensions were obtained from frozen images, using the ultrasound calipers and the total testicular volume was calculated as described by Lin et al. (2009). Ecogenicity and homogeneity of the parenchyma were also assessed at each time point.

\subsection{Fecal collection, extraction and harmane determinations}

Fecal samples were collected at the time points of hemiorchiectomies (see below) and frozen for testosterone (T) determination. Fecal steroids were extracted using the methods described by Faya et al. (2013) and T (ng/ml) was determined using electro. chemiluminescence immunoassay (Elecsys Testo II, Roche Diagnostics, Mannheim, Germany). Inter and intra*assay coefficients of variation of the assays were $<10 \%$ and sensitivity was $0.025 \mathrm{ng} / \mathrm{mL}$. All fecal data were expressed on a wet-weight basis

\subsection{Hemiorchiectomies}

All the cats were randomly hemiorchiectomized twice according to Garcia Romero et al. (2012) in a way that a total of 60 testes were obtained. Briefly, the animals were premedicated with atropine sulfate, (Atropine Sulfate, John Martin; $0.04 \mathrm{mg} / \mathrm{kg}$ SC), ace. promazine maleate (Acedan, Holliday; $0.03 \mathrm{mg} / \mathrm{kg} \mathrm{SC}$ ), and butorphanol (Torbutol Plus, Fort Dodge; $0.2 \mathrm{mg} / \mathrm{kg} \mathrm{DM}$ ), anesthesia was induced with sodium thiopental (Pentovet TM, Richmond; $8 \mathrm{mg} / \mathrm{kg} \mathrm{IV)} \mathrm{in} \mathrm{all} \mathrm{of} \mathrm{the} \mathrm{animals.} \mathrm{Once} \mathrm{the} \mathrm{cats} \mathrm{were} \mathrm{endotracheally}$ intubated, anesthesia was maintained with isoflurane and oxygen in a closed system. Each testis was removed through a longitudinal midscrotal incision using sterile surgical procedures and a closed tunic technique, finally the spermatic cord was ligated with 3.0 vicryl before transection. After surgery ketoprofen (Ketofen*, Fort Dodge; $1 \mathrm{mg} / \mathrm{kg}$ ) were injected SC (once) and then orally every $24 \mathrm{~h}$ during 4 additional days. Then, all the cats were placed foc adoption. 


\subsection{Gross and histological examination of the testes}

Immediately after surgical removal, the testes were measured (length, width and depth; $\mathrm{cm}$ ) and weighed (g) and gonadosomatic index (\%; Franca and Godinho, 2003) was also calculated.

Sperm was recovered by the epididymal tail sectioning using a scalpel blade. Spermatozoa morphology was evaluated by Giemsa stain, under $1000 \mathrm{X}$ magnification using bright field microscopy (Valiente et al., 2014).

The testes, were sectioned longitudinally, placed in Bouin's fixative for $12 \mathrm{~h}$ and then changed to alcohol 70 and processed routinely with paraffin embedding. After processing, $5 \mu \mathrm{m}$ serial sections were cut, mounted on slides, dried, deparaffinized in xylene, rehydrated in graded ethanol solutions and stained with hematoxylin and eosin. Histological images were obtained from a micro scope (Olympus BX50; 10X and 40X) through an attached video camera (Sony DXC 151) and digitalized in a 24 bit true color TIFF format. Twenty tubular profiles, which were round or nearly round, were chosen randomly and measured for each animal. The tubular diameter of seminiferous tubules $(\mu \mathrm{m})$ and the germinal epithelium beight $(\mu \mathrm{m})$ were measured by planimetry (lmage Pro Plus, Media Cybernetics, Silver Spring, MA, USA). The volume ( $\mathrm{cm} 3)$ of the different testicular tissue components was determined by stereology using a light microscopy and a 441 sintersection grid placed on $40 \mathrm{X}$ tissue pictures. For this, 15 fields were chosen ran domly (6615 points) for each testis. Points were classified as one of the following. spermatogonia, primary and secondary sperma. tocytes, round spermatids, elongated spermatids, spermatozos, Sertoli and Leydig cells, intertubular compartment, and cellular debris. Finally, the proportion of each element was calculated using the whole testicular volume as previously described by Carranza et al. (2015).

\subsection{Statistical analysis}

Normality of distribution of results was tested using a Shapiro - Wilk normality test. All hormonal, gross and microscopical variables were compared among time points by Kruskall.Wallis test followed by a Dunn's multiple comparisons test. In all the cases descriptive data were expressed as mean \pm SEM and $P$ values $>0.05$ were considered significant.

\section{Results}

Neither gross testicular parameters including weight $(P>0.1)$, volume $(P>0.1)$ and ganadosomatic index $(P>0.1)$ nor body weight ( $P>0.1$ ) were affected by RTl-4587.073 (1) treatment at the different evaluation time points (Table 1). Although epididymal spermatozoa morphology was normal in all the cases, giant multinucleated cells appeared in the semen samples during the first $24 \mathrm{~b}$ after treatment (Fig. 1).

Histological testicular structure was normal on day .14 (Fig. 2; A) and a severe disorganization of the cytoarchitecture of the seminiferous epithelium was observed as early as in the $6 \mathrm{~h}$ samples reaching a maximum impairment at $24 \mathrm{~h}$, with the presence of vacuolization, immature germ and multinucleated cells as well as intratubular fluid (Fig. 2; C). During the first $24 \mathrm{~h}$ several semi* niferous tubules were in the process of sloughing or had already sloughed material within the lumen occluding the tubules along with the fluid and cellular detritus $(P<0.01$; Fig. 2, C and D; Table 2). These abnormalities gradually disappeared up to the end of the study (Fig. 2, F, H, I) and could not be evidenced through their echostructure which was normal at all time points (Mattoon and Nyland, 1995).

Seminiferous tubular diameter $(P<0.01$; Fig. 3, Inset) increased in detriment to the interstitium $(P<0.01$; Table 2$)$ during the first $24 \mathrm{~h}$ and, then, reached its peak value on $\mathrm{d} 35$. Finally this diameter showed a tendency to return to initial values up to the end of the study.

Germinal epithelium height could not be measured during the first $24 \mathrm{~h}$ after treatment due to the major disorganization of its cytoarchitecture (Fig. 3). This epithelium presented its minimum height on day 14 to rapidly recover to reach peak values on day 2 I and, thereafter, it maintained that height (Fig. 3). Although the volume occupied by spermatogonia did not varied throughout the study $(P>0.1)$ the volume of the primary spermatocytes decreased during the same period $(P<0.01 ;$ Table 2$)$. This diminution was even more marked in the case of secondary spermatocytes $(P<0.01)$, round $(P<0.01)$ and elongated $(P<0.01)$ spermatids as well as luminal spermatozoa $(P<0.01)$ which reappeared just before the end of the study on day 42 . Conversely, the volume

Table 1

Morphometrie data of the 30 male eats which had been adninistered (d 0) a single PO dose of $12.5 \mathrm{mg} / \mathrm{kg}$ RTh-4587.073(1) and randomly hemiorchiectomixed twice on day $-14(n-8), 6 h(n=6), 12 \mathrm{~h}(n-8)$, day $1(n=6)$, day $7(n=8)$, day $14(n=6)$, day $21(n=6)$, day $35(n=6)$ or day $42(n=6)$.

\begin{tabular}{|c|c|c|c|c|c|c|c|c|c|}
\hline & $d-14$ & h 6 & h 12 & h 24 & $d 7$ & $d 14$ & $d 21$ & d 35 & $d 42$ \\
\hline Body weight (kg) & $4.83=0.28$ & $5.25 \pm 0.35$ & $4.90=0.49$ & $4.40 \pm 0.20$ & $4.74=0.28$ & $4.48 \pm 0.16$ & $4.65=0.35$ & $4.93 \pm 0.19$ & $4.47 \pm 0.32$ \\
\hline Testis weighth (g) & $1.95=0.12$ & $1.76 \pm 0.26$ & $1.85=0.24$ & $1.93 \pm 0.04$ & $1.87=0.35$ & $1.87 \pm 0.34$ & $1.77=0.21$ & $1.50 \pm 0.47$ & $1.92 \pm 0.55$ \\
\hline $\begin{array}{l}\text { Testicular velumen } \\
\qquad\left(\mathrm{cm}^{3}\right)\end{array}$ & $2.69=1.43$ & $2.54 \pm 0.40$ & $210=0.29$ & $2.76 \pm 0.29$ & $2.67=0.97$ & $1.85 \pm 0.92$ & $2.28=0.62$ & $2.43 \pm 0.66$ & $2.54 \pm 0.68$ \\
\hline $\begin{array}{c}\text { Conadisomitic } \\
\text { index (W) }\end{array}$ & $0.08=0.01$ & $0.08 \pm 0.08$ & $0.08=0.01$ & $0.00 \pm 0.00$ & $0.08=0.01$ & $0.08 \pm 0.01$ & $0.08=0.01$ & $0.08 \pm 0.01$ & $0.08 \pm 0.01$ \\
\hline
\end{tabular}




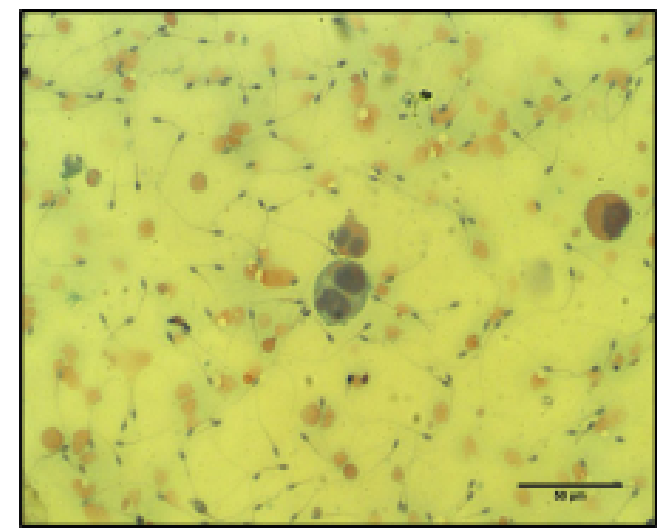

Fig. 1. Glant multinucleated cell (Giemsa stain, 1000X) found in epididymal sperm during the first $24 \mathrm{~h}$ after $\mathrm{kTH}-4587.073$ (1) administration in most of the male cats of Table 1 .

occupied by Sertoli cells increased $24 \mathrm{~h}$ after treatment to significantly decrease up to day 14 when it began to return to pretreatment volume $(P<0.01 ;$ Table 2$)$

Although, the volume occupied by Leydig cells decreased in the first post treatment observations $(P<0.01$; Table 2$)$, fecal T concentrations did not vary during the same period (data not shown; $P>0.1$ ). Finally, this indenopyridine did not cause general, digestive or behavioral side effects in any animal during the study period.

\section{Discussion}

Widespread use of contraceptives has been limited in male felids by safety concerns and the lack of effective choices. In spite that indenopyridines have shown antispermatogenic effects in several mammals, there are species differences which justify such study in the feline species. Up to the authors' knowledge, this is the first report that describes their effects in cats.

In line with most articles in rats (Hild et al., 2001; Koduri et al., 2008) and monkeys (Hild et al., 2007a) but unlike to those in horses (Pozor et al., 2014), T did not seem to be affected by RTl-4587.073 (I) treatment in these felids. While suppression of T and, therefore, libido would have been desirable in domestic cats, $\mathrm{T}$ dependent changes in behavior and phenotype are definitively a disadvantage for wild felids as they may alter their group hierarchy as well as their secondary sexual characteristics. Conversely, the volume occupied by Leydig cells was decreased in the post treatment observations. In this respect, it should be borne in mind that in this trial, fecal determinations could have masked transient serum $T$ variations that could have been evidenced in blood samples. In line with a horse report using the same pharmacological protocol (Pozor et al., 2014), total testicular volume did not change throughout the days of this feline trial.

The rapidity of histological effects was one of the most interesting findings of the present antispermatogenic protocol. Similar rapid effects of treatment with RTl-4587.073(I) on testicular tissue were previously described in monkeys, horses, dogs and rats (Chang et al., 2002; Hild et al., 2001, 2007a; Pozor et al., 2014).

Particularly, the seminiferous epithelium vacuolization and sloughing into the tubular lumen causing severe tubular dis. organization is a common histopathological observation associated with Sertoli cell injury after exposure to testicular toxicants (Johnson, 2015; Vidal and Whitney, 2014). The multinucleated giant cells found both in the epithelium and semen are thought to arise from fusion of degenerate spermatids with abnormal intercellular bridges (Vidal and Whitney, 2014). This kind of cells was also previously observed in rats, horses and dogs treated with bisdiamines (Chang et al., 2002; Hild et al., 2001; Pozor et al., 2013 ).

Specifically, indenopyridines alter Sertoli cells - germ cell adherents' junction proteins leading to a massive germ cell loss (Koduri et al., 2008). As Sertoli cell junctions are an essential component of the bloodøtestis barrier required for normal spermatogenesis they have been considered a target for male contraceptive development (Lee et al., 2009). In this study, the injury in Sertoli cells could, not only, explain the early increase in their own volume but also the augmentation of the whole tubular diameter associated with fluid production on day 1 (Vidal and Whitney, 2014).

As expected, in the presence of these severe histological findings almost all cellular components of the germinal epithelium were significantly affected by the indenopyridine treatment. Importantly, the major shortage of germinal cells occurred at the level of spermatocytes and spermatids evidencing a severe loss of the outer layers.

Before the treatment on day $\mathbf{. 1 4}$ all histomorphometric parameters were in line with those previously described for the species (Franca and Godinho, 2003; Siemieniuch and WoclawekaPotocka, 2007). The early increase in the seminiferous tubule diameter found in this study has also been associated with the tubular fluid production after Sertoli cells toxicant administration (Vidal and Whitney, 2014). The late augmentation of this diameter on day 35 could be explained as a rebound recovery of spermatogenesis at that time point (Meisami et al., 1994).

The whole height of the germinal epithelium rapidly decreased to two layers of cells on day 14 to recover to values even higher 

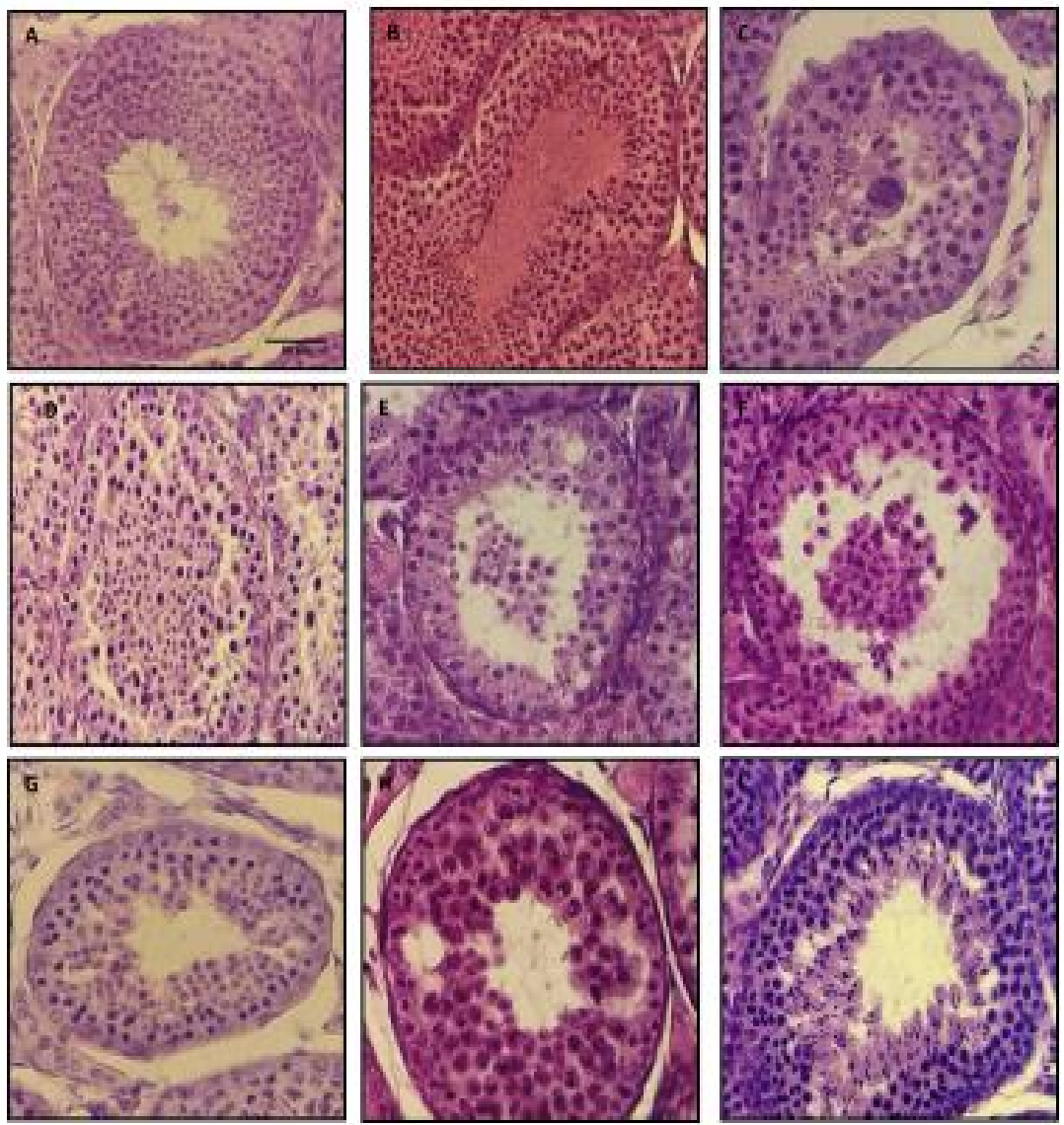

Fig. 2. Seminiferous tubules of the cats and experiment of Tabie 1 ar different time points $-14(\mathrm{~A}), 6 \mathrm{~h}(\mathrm{~B}), 12 \mathrm{~h}$ (C), day 1 (D), day 7 (E), day 14 (F), day 21 (G), day $35(\mathrm{H})$ and day 42 (I) All sections were stained with hemataxylin and eosin (40x).

Notice normal germinal epithelium and spematozon at the luminal border $(\mathrm{A})$, fluid in the lumen of a seminiferous tubule (B), seminiferous epithelium sloughing into the lumen with a giant multinucleated cell in the center (C), severe disarganization of the seminiferous epithelium with occluding detritus flling the lumen (D), epithelium slaughing is finishing and some vacuoles are appearing, luminal detritus is diminishing (E), thin geminal epthelium with frayed luminal border and some detritus in the lumen $(\bar{\eta})$, quite recovered germinal epithelium with still some vacuoles and a clean lumen (G), recovered germinal epithelium height with some vacuoles (H), fully recovered germinal epithelium with abundant elongated spermatids at the luminal bonder (1).

than the pretreatment ones a week later. The tubular presence of unaffected spermatogonias throughout the study period guaranteed the recovery of spermatogenesis and, therefore, the reversibility of this feline pharmacological protocol. Indenopyridines have variably produced either a reversible (in dogs, monkeys and horses; Chang et al.. 2002; Hild et al., 2007a; Poxor et al., 2013) or irreversible (in rats; Hild et al., 2009) effect on fertility. Surprisingly, the lowest dose $\cdot 2.5 \mathrm{mg} / \mathrm{kg}$ - among these trials, was the one which caused irreversible damage in laboratory rodents (Hild et al., 2004) which suggests a species • specific effect. In these domestic cats, reversibility of the geminal epithelium occurred at approximately one feline ppermatic cycle period (Franca and Godinho, 2003). Similarly, in indenopyridine treated horses and dogs, reversible spermatogenesis was noted 6 and 7 weeks after its admin. istration, respectively (Chang et al., 2002; Pazor et al., 2014).

Considering the rapid and severe histological changes as well as their reversibility it would be of interest in the future to in vivo test fertility during the peak indenopyridine effect and also after spermatogenic recovery so that rational, single or serial - doses protocols could be proposed for felids.

Finally and in keeping with publications in rodents (Fail et al., 2000) no observable adverse effects such as body weight lass or digestive problems were found in the treated animals, suggesting that this compound might not have general taxicity in felids.

It was concluded that RT-4587.073(1) represents a rapid, effective, reversible and safe non-steroid antispermatogenic oral protocol for male cat contraception as it severely disrupted spermatogenesis during the first $24 \mathrm{~h}$ after treatment returning to normality in approximately one spermatic cycle. Further refinement, including repented doses and surveillance for toxicological and long term adverse effects, of these indenopyridine derivatives should be carried out before their field implementation could be widely 
F. DPrasiona, et al.

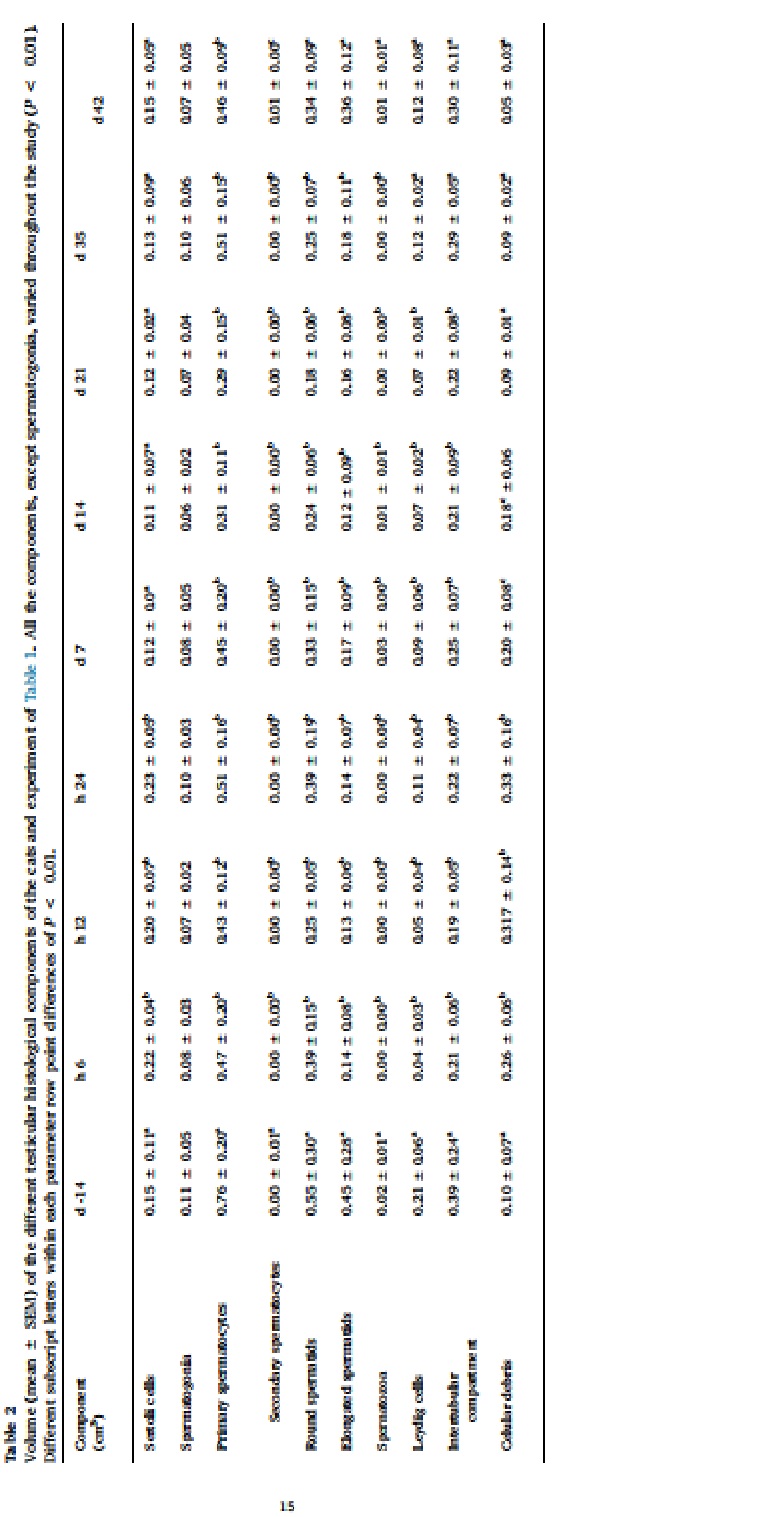




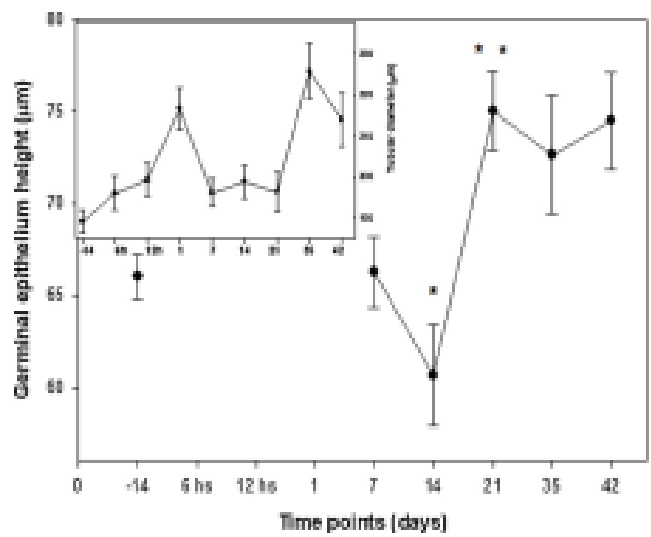

Fig. 3. Testicular germinal epithelium height and tubular diameter (mean \pm SEM; Inset) of the cats and experiment of Table 1. Germinal eplthelium height could not be measured during the first $24 \mathrm{~h}$ after treatment. Asterisks point differences of $P<0.05$.

recommended.

\section{Conflict of interest}

The authors do not have any financial noe personal relationships with other people or organizations that could inappropriately influence the study.

\section{Acknowledgments}

This work was partially supported by the Teaching Incentive Program of NULP (V233). RTI 4587 073(d) was kindly provided by the Research Triangle Institute, Research Triangle Park, NC, USA. FDF, MLM, RV are a Research Fellows, and PB, CB and CG are Career Scientists of CONICET, Argentina.

\section{References}

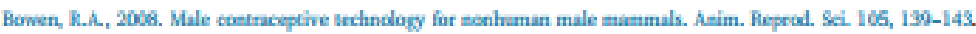

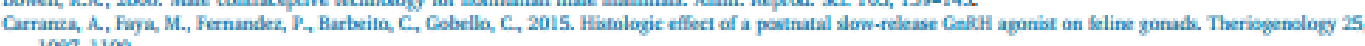
$10 \mathrm{n}-1100$.

Chang, CI, Fung, H.P. Lin, Y.P., Kua, CY, Chien, CW., 2000. Indesopyridine hydrocthoride indered teviteular spermatogenesis failure with hiph seminal alkaline phosphataise leveb in male dog. Kiol. Dharm. Bell. 25, $1097-1100$.

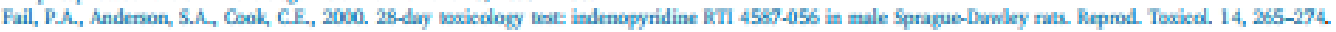

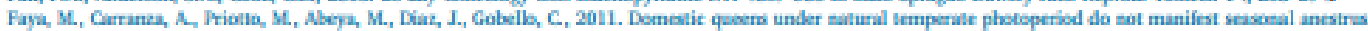
Maim. Beprod. Sci. 129, 78-81.

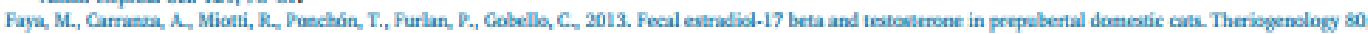
584-58\%.

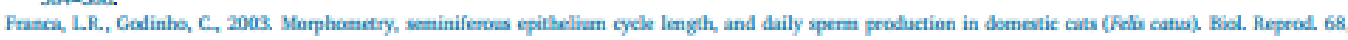
1554-1561.

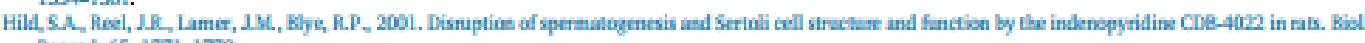
Beprod. $65,1771-1779$.

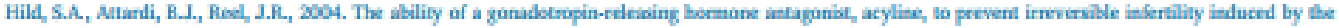

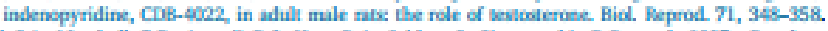

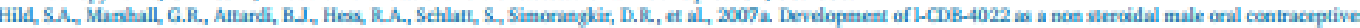

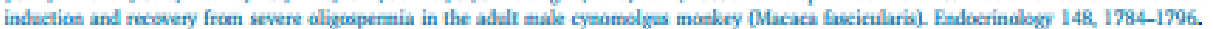

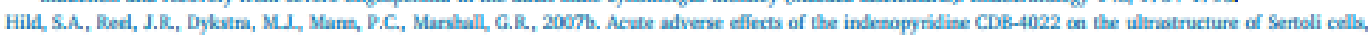

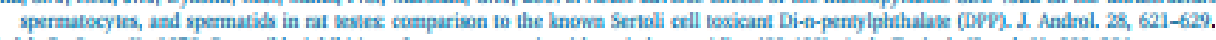

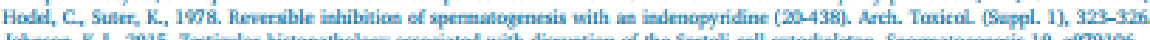

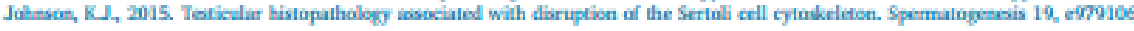

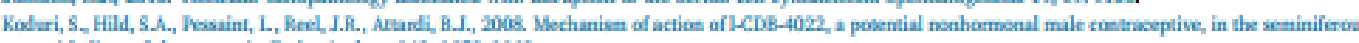
epitheliem of the rat testis. Endocrieology 149, 1850-1860.

Lee, N.P., Wong, EW., Mrak, D.D., Cheng, CY, 2000. Testicelar eell jusction: a sovel target for male cuntraception. Curr. Med. Ceem. 16, 906-915.

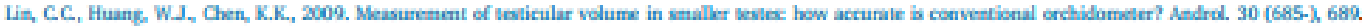

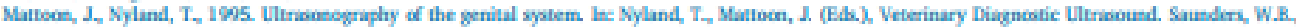
Philadelphia, pp 141-164.

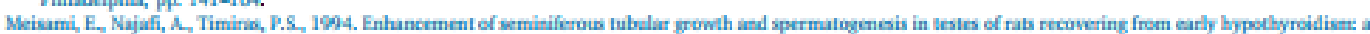
quantitative stady. Cell Tisse Ris. 275, 503-511.

Mruk, D.D, 2005. New perspectives in non-hormanal male cumtraceptios Trends Fedocrinal Metab. 19, 57-64.

Mensos, L, 2006. Cantracteption in felids. Theriogenolugy 1, 126-134.

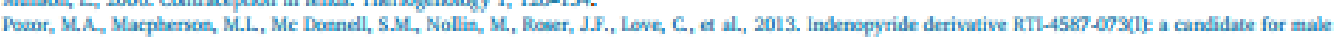
contraception in sallios. Theriogenolosy $80,1006-1016$ 


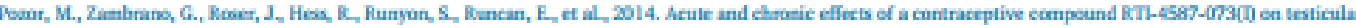
histology and endocrine function in miniature horwe sallioms. Bleprod. Domest. Anith, 49, $302-402$

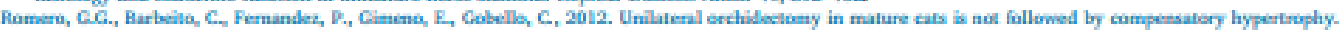
Bieprod. Domest. Anith. 6 (Suppl 47), 226-228.

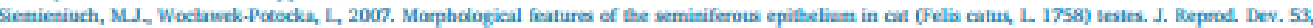

$1125-1130$.

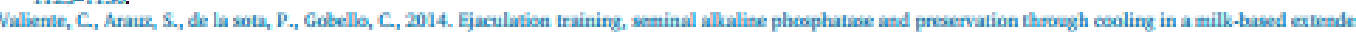

in domestic eats. J. Feline Med. Serg, 16, 312-316.

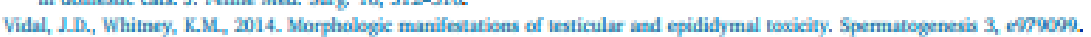




\title{
Feline testicular ultrasonogram differentiates pre vs. postpubertal and normal vs. disrupted spermatogenesis
}

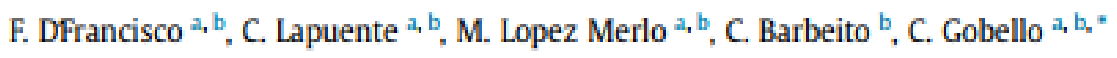

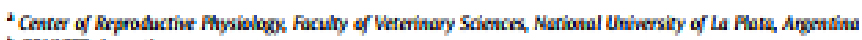 \\ - CONGCET, Argentina
}

A R TICLE I N F O

\section{Nricle history.}

Bectived 24 Fetruary 2020

Rectived in revised form

17 ) ye 2020

Accepted it Mugast 2020

Available online 16 August 2020

\section{Kenuerds}

Ruberty

Andrubgy

Ecograptry

Subsertility

Histulogy

Geminal epithelium

\begin{abstract}
A BSTRACT
The aims of this study were: to ultrasonograhically describe and compare testicular parenchyma echogenicity and beterogeneity using digital image analysis in: I) prepubertal (PREP) peripubertal (PERI) and mature (MAT) cats; II) Normal and abnormal mature felids. Secondary, the relationships between his. tomorphological and ultrasonographic attributes of the testes were also determined. D) Fourteen, PREP, PERl and MAT male cats were ultrasonographically examined and then castrated. II) Seven adult cats were ultrasonographically examined before and after a GnkH antagonist administration and then castrated. All the testes were grossly and histomorphometrically assessed. In the frozen digital images of the longitudinal ultrasound sections, 3 regions of interest (BOL, $1 \mathrm{~mm} 2)$ were selected. Within each ROO the echogenicity and the heterogeneity of the testicular parenctyma were digitally analyzed. In experiment 1 , testicular volume ( $0.15 \pm 0.0 \mathrm{vs} .0 .49 \pm 0.1 \mathrm{vx} .1 .65 \pm 0.1 ; \mathrm{P}<0.01)$ and gonadosomatic index $(0.04 \pm 0.0$ vs. $0.05 \pm 0.0$ vs. $0.08 \pm 0.0 ; \mathrm{P}<0.01)$, echogenicity $(56.54 \pm 0.75$ vs $81.87 \pm 5.88$ vs.94.67 \pm 3.62 $\mathrm{P}<0.01)$ and beterogeneity $(10.2420 \pm 1.3740 \mathrm{vs} .13 .65 \pm 0.65$ vs. $14.67 \pm 1.49 ; \mathrm{P}<0.01)$ augmented throughout PRE, PERL, and MAT. In experiment II, testicular volume ( $100 \pm 0.09 \mathrm{vs} .0 .85 \pm 0.09 ; \mathrm{P}<0.05$ ), echogenicity ( $87.74 \pm 1.53$ vs. $83.32 \pm 1.54 ; \mathrm{P} 0.01)$ but not heterogeneity $(14.09 \pm 0.26 \mathrm{vs} 14.19 \pm 0.29$; P > 0.05) decreased in the post GnRH antagonist aboormal testes. For both experiments, testicular volume, seminiferous tubular diameter, percentage of spermatids as the most mature cell type, and Iuminal//intertubular ratio were highly correlated $(\mathrm{P}<0.01)$ with their echotextural attributes. Computer. assisted image analysis of B mode ultrasonogram appears as a good indicator of pubertal development and mild alterations of spermatogenesis in felids.
\end{abstract}

0 2020 Elsevier lnc. All rights reserved.

\section{Introduction}

Domestic cats have been increasing in popularity as pets over their canine counterparts. Several explanations for this shift have been postulated including that cats cost less to keep, and are more feasible in urban settings. Domestic felids have also been extensively used as models for human diseases and for assisted repro. ductive technologies in wild endangered felids [1]. With the increasing interest in breeding cats the requests to determine puberty and to investigate cases of reproductive failure have become more frequent.

\footnotetext{
- Comesponding author. Center of Repreductive Ftysiobog, Faculty of Veserinary Sciences, National Lhiversity of La Plata, 60 y 118, L Plata, CC 296 (B 1900 NW Sciences, Notiona.

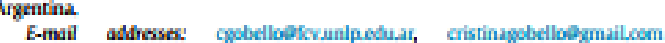
(C. Gobelo)
}

Sexual immaturity and testicular lesions, are causes of sub and infertility in domestic cats $[2,3]$. Both puberty and mild testicular lesions are difficult to clinically diagnose in this species. Although the most accurate test for diagnosis is testicular biopsy, this "gold standard procedure is invasive and, therefore, rarely performed in practice. Thus, sensitive, non-imvasive diagnostic methods are still required to contribute to the breeding soundness examination in this species.

Two-dimensional ultrasonography is a noe invasive diagnostic technique that has been widely used in the andrological exam of most mammalian species. Although, testicular parenchyma is commonly described as a tissue of medium heterogeneity and homogeneous echotexture [4] these appreciations are subjective. The present availability of high-frequency and resolution equip. ments has permitted the accurate evaluation of the cellular composition of a tissue. Additionally, digital image analysis sup. ports ultrasound findings to be a quantifiable tool. Thus, 
echogenicity ie. pixel intensity is described in terms of numerical values which range from 0 (absolute black) to 255 (absolute white) and heterogeneity as pixel standard deviation of echogenicity. which reflects the existence of interspersed hyper and hypoechoic areas in a tissue [5]. These quantitative evaluations have been mainly carried out in farm animals testes $[5-7]$ and there are also some reports in horses and dogs [8,9]. Although, fine tuning of this technique would contribute to the reproductive performance of this species, to date, no computer-assisted image analysis of testicular ultrasonograms appear to have been published in domestic cats.

Thus the aims of this study were twolold: to ultrasonograhically describe and compare testicular parenchyma echogenicity and heterogeneity using digital image analysis in: I) prepubertal, peripubertal and postpubertal cats and II) Normal and abnormal mature feline testes. Secondary, the relationships between histomorphological and ultrasonographic attributes of the gonads were also determined. In Experiment II, a pharmacological model of spermatogenic impairment was used. For this purpose, acyline, a potent gonadotrophin releasing hormone (GnRH) antagonist was selected as spermatogenic disruptor, based on previously described deleterious effects on feline spermatogenesis [10].

\section{Materials and methods}

2.1. Experiment I

2.1.1. Animals

Fourteen, 5-36 months of age, $2.5-4.7 \mathrm{~kg}$ body weight, prepubertal (PREP), peripubertal (PERI) and mature (MAT) healthy, crossbred male cats that were born in our institutional cat colony were included in this study. The animals were kept free in enriched $5 \mathrm{~m}^{2}$ rooms with $14 \mathrm{~h}$ of light/10 dark per day, fed premium commercial food and given water ad libitum. This study was reviewed and approved by the Animal Care and Use Committee of the Veterinary School of the National University of La Plata and all experiments were conducted under the guidelines established in The Guide for The Care and Use of Laboratory Animals, USA.

\subsubsection{Ultrusanographic evaluations}

Ultrasonographic evaluations were undertaken by a single experienced evaluator using a real time B-mode ultrasound machine (Toshiba Nemio XG, Japan) with a $14 \mathrm{MHz}$ lineal transducer in both testicles of each animal. All machine settings were established at the first examination according to best image quality and remained unaltered for all remaining examinations (Gain: 100, focal depth: $2 \mathrm{~cm}$ ). Acoustic gel was applied to the transducer and coupled directly to the clipped scrotum with minimum pressure to obtain the images. The testes were imaged in the longitudinal and transverse planes and dimensions were obtained from frozen images, using the ultrasound callipers. Total testicular volume was also calculated as described by Linn et al. (2009 [11]). In the frozen digital images (jpeg of $640 \times 480$ pixels) of the longitudinal sections, 3 regions of interest $\left(\mathrm{ROI}, 1 \mathrm{~mm}^{2}\right)$ were selected, between the central mediastinum and the testicular capsule (12 ROI/cat). Within each $\mathrm{ROI}$ the echogenicity and the heterogeneity of the testicular parenchyma were analyzed using Image J software (National Institutes of Health, Bethesda, Maryland, USA).

\subsubsection{Orchidectomies}

A routine open castration was performed [12]. For the surgery. the animals were pre-medicated with atropine sulfate, (Atropine
Sulfate, John Martin; $0.04 \mathrm{mg} / \mathrm{kg}$, subcutaneously), acepromazine maleate (Acedan, Holiday; $0.03 \mathrm{mg} / \mathrm{kg}$ subcutaneously) and butorphanol (Torbutol Plus, Fort Dodge; $02 \mathrm{mg} / \mathrm{kg}$, intramuscularly). Anesthesia was induced with sodium thiopental (Pentovet $\mathrm{TM}$, Richmond; $8 \mathrm{mg} / \mathrm{kg}$. intravenous). After the males were endotracheally intubated, anesthesia was maintained with isoflurane and oxygen in a closed system. After surgery ketoprofen (Ketofen, Fort Dodge; $1 \mathrm{mg} / \mathrm{kg}$ ) was injected subcutaneously (once) and then orally every $24 \mathrm{~h}$ for 4 additional days. After orchidectomy all the cats were placed for adoption.

\subsubsection{Gross, seminal and histological examination}

Immediately after surgical removal, the testes were weighed (g) Conadosomatic index ( $\boldsymbol{X}[13])$ was also calculated. The testes were sectioned longitudinally, placed in Bouin's fixative for $24 \mathrm{~h}$ and then changed to alcohol 70 and processed routinely with paraffin embedding. After processing. $5 \mu \mathrm{m}$ serial sections were cut, mounted on slides, dried, deparaffinized in xylene, rehydrated in graded ethanol solutions and stained with hematoxylin and eosin. All histological determinations were made by a single operator without knowledge of the age at which the animals were castrated.

Histological images were obtained from a microscope (Olympus BX50, Tokyo, Japan); $10 \mathrm{X}$ or $40 \mathrm{X}$ through an attached digital RCB video camera (Omax A35180U3, China) and digitalized in a 24 bit true color TIFF format. Ten round tubular profiles per testis were evaluated for mean tubular diameter $(\mu \mathrm{m})$, mean germinal epithelium height $(\mu \mathrm{m})$, as well as the identification of the most developed germ cell found in the seminiferous tubules of each cat. The percentages of tubular cross sections containing different identified most mature cell were recorded. The proportion of the tubularfintertubular and luminal/intertubular compartments were also calculated. Images were analyzed by planimetry (Image Pro Plus v60-Media Cybernetics, Silver Spring, MA, USA).

Peripubertal state (PERI) was defined when tubular diameter was $100-150 \mu \mathrm{m}$ and a multilayer germinal epithelium (up to the spermatide or spermatozoa stage) was present in more than $50 \%$ of the tubules. Lower and higher values were considered pre (PREP) and mature (MAT) states, respectively [14].

\subsection{Experiment II}

2.2.1. Animals and pharmacological protocol

Seven, 1-3 years old, $3.2-4.8 \mathrm{~kg}$, cross-bred fertile cats from our institutional cat colony were administered acyline (Contraception s Reproductive Health Branch Center for Population Research, NIH, Bethesda, MD, USA) $330 \mu \mathrm{g} / \mathrm{kg}$ SC once a week for 4 consecutive weeks. Acyline |acety]-D2Nal-D4CIPhe-D3PalSer-Aph (ac)-DAph (Ac)-Leu-Lys (Ipr)-Pro-D-Ala-Nh2] was provided in a lyophilized powder which was suspended in sterile distilled water (concentration, $2 \mathrm{mg} / \mathrm{mL}$ ). The antagonist dose and frequency of administration were selected according to our previous studies $[10,15]$. The animals were kept under the experimental conditions described for Experiment 1 . This study was reviewed and approved by the Animal Care and Use Committee of the Veterinary School of the National University of La Plata and all experiments were conducted under the guidelines established in The Cuide for The Care and Use of Laboratory Animals, USA.

\subsubsection{Follow up}

Testicular ultrasound evaluations were carried out one week before treatment (PRETR) and one week after the last antagonist administration (POSTR). Then all the cats were submitted to 


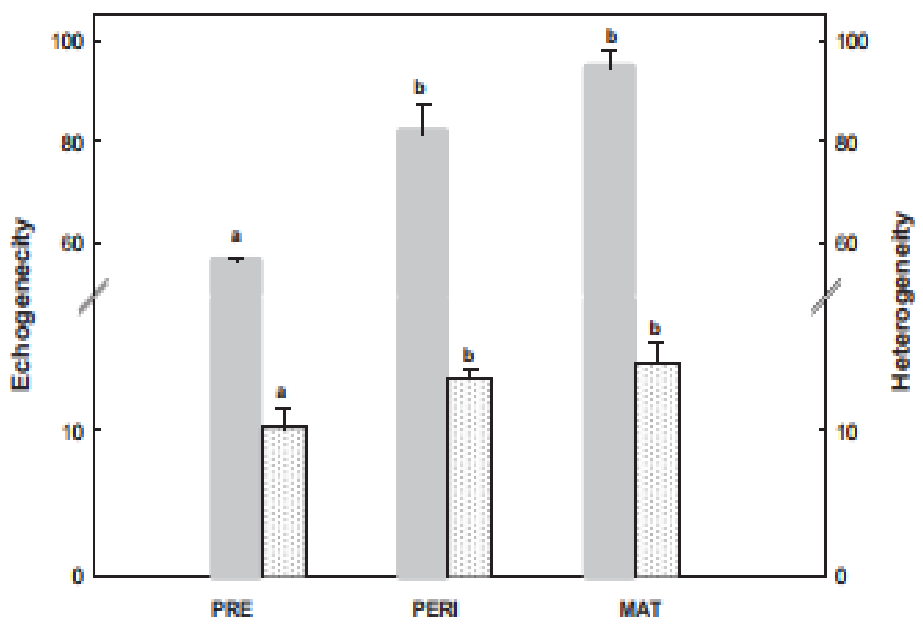

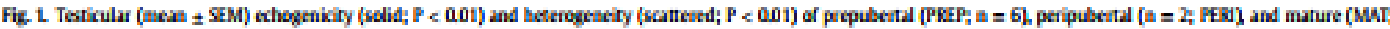

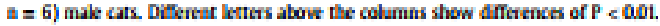

orchidectomies. Immediately after surgical removal, the testes were grossly and histologically assessed. All ultrasonographic and histological procedures were carried out as explained for Experiment $I$. The castrated cats were also placed for adoption.

\subsection{Statistical analysis}

Normality of obtained data of both experiments was confirmed by Shapiro-Wilk test. Gross testicular parameters and ROls echogenicity and heterogeneity values of the 3 groups (PREP vs. PERI vs. MAT) of Experiment I and the 2 groups (PRETR vs. POSTR) of Experiment II were compared by one way ANOVA followed by Tukey test and paired Student's t-test, respectively. For both experiments, echotextural parameters were correlated with gross and microscopic attributes of the testes by Pearson correlation test. Descriptive statistic was expressed as mean \pm SEM and the level of significance was set at P $<0.05$ (SPSS, Inc., Chicago, II, USA)

\section{Results}

In Experiment I, 6, 2 and 6 cats were histomorphometrically classified as PREP, PERL, and MAT, respectively. Testicular volume $(0.15 \pm 0.0$ vs. $0.49 \pm 0.1$ vs. $1.65 \pm 0.1 ; P<0.01)$ and gonadosomatic index $(0.04 \pm 0.0$ vs. $0.05 \pm 0.0$ vs. $0.08 \pm 0.0 ; P<0.01)$ increased with reproductive development, showing differences among the 3 groups. Both echogenicity ( $<<0.01$ ) and heterogeneity ( $P<0.01$ ) also augmented throughout PREP, PERI, and MAT (Fig. 1).

In Experiment II, acyline caused mild histological spermatogenic impairment with a diminution of $34 \mathrm{X}$ and $18 \mathrm{X}$ of normal germinal height and tubular diameter, respectively when compared to what has been reported for normal testes in this species [13]. In this experiment, testicular volume (cc; $1.00 \pm 0.09$ vs. $0.85 \pm 0.1$; $P<0.05)$ and parenchyma echogenicity ( $P-0.01$ ) but not heterogeneity ( $\mathrm{P}>0.05$; Fig. 2) decreased in POSTR. Correlations between gross (also Fig. 3) and histomorphological testicular

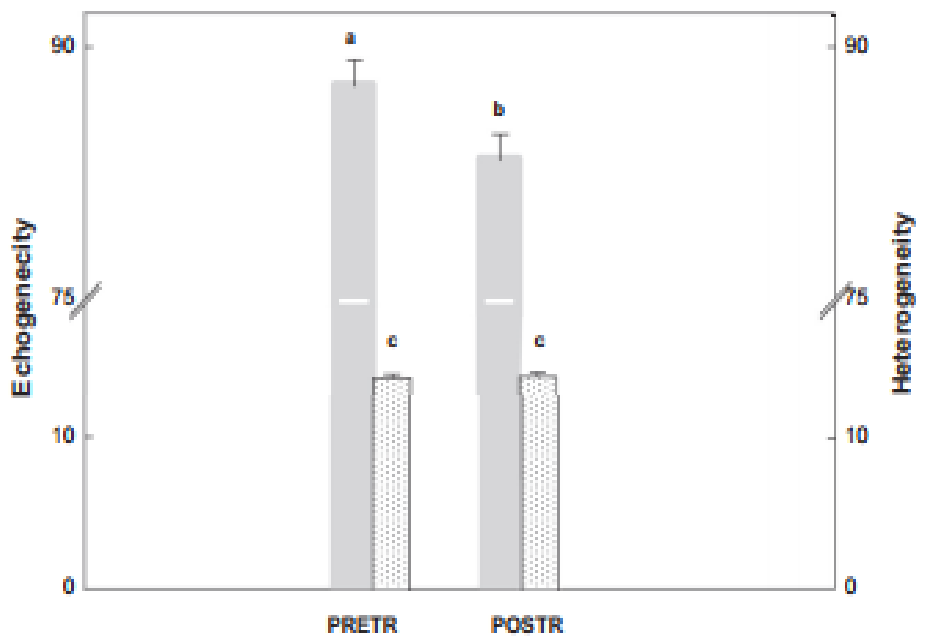

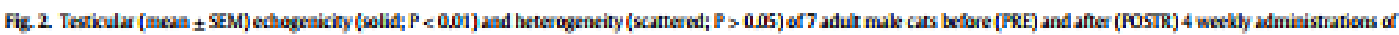

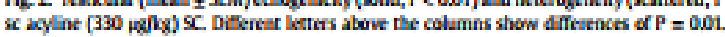




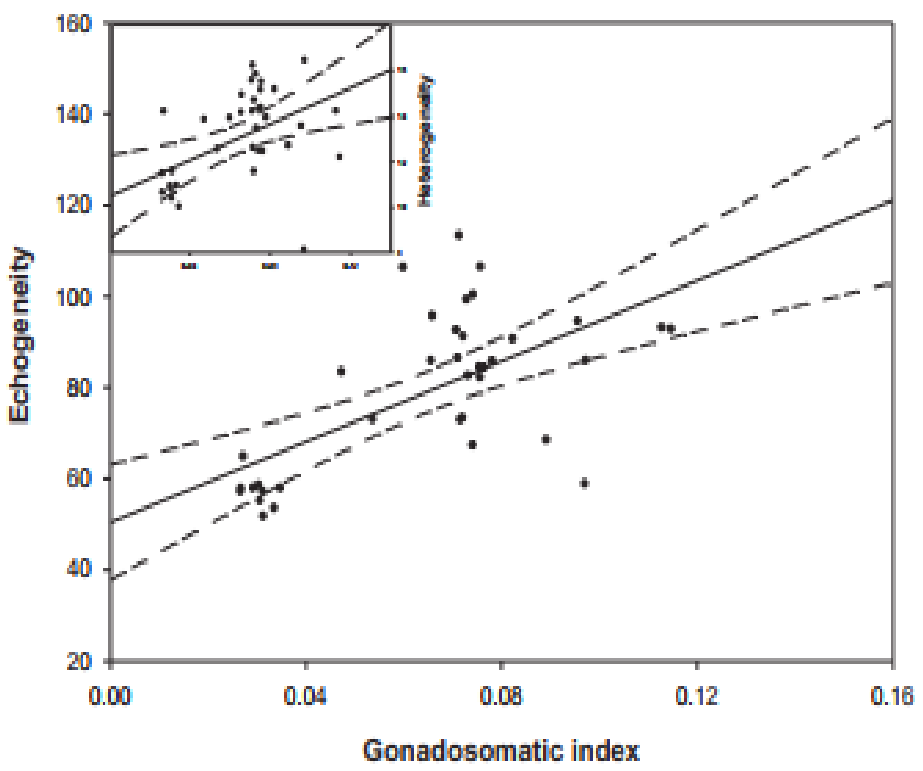

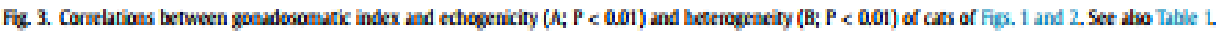

parameters with echotextural attributes of both experiments are shown in Table 1.

\section{Discussion}

Male cats are particularly difficult to andrologically examine not only because of their comparatively reduced body size but also for their innate tendency to experience stress requiring sedation or even anesthesia for minor maneuvers. Thus, in this study. computer-assisted image analysis of B mode ultrasonogram was evaluated as a non-invasive technique to contribute to the male cat breeding soundness examination.

As expected, in the growing cats of Experiment $L$, testicular volume and gonadosomatic index increased up to what has been previously described as adult values [13]. In line with reports in humans [16], ruminants $[5,17-19]$ and horses [9], in these cats, computer-assisted analysis of testicular ultrasonograms could differentiate pre from postpubertal state.

In domestic felids, the same as in other mammals, the onset of spermatogenesis during peripubertal development is accompanied by changes in testicular microstructure [14]. An increase of seminiferous tubule diameter and lumen as well as of the epithelial

Table 1

Correlarions betweten testicular gows and histomorplological with echosestural attrikutes of cats of Figa 1 and 2.

\begin{tabular}{|c|c|c|c|c|}
\hline Causs $\alpha$ micrescopic parametess & Echoyenicity & $p$ & Hestrogentity & $p$ \\
\hline Testicular volume $\left(c c^{4}\right)$ & 0.58 & 80.01 & 0.69 & $<0.01$ \\
\hline Cenadosiemaris index & 0.63 & s.01 & 0.46 & $<0.01$ \\
\hline Thular diameter ( $\mu \mathrm{m})$ & 0.69 & 0.01 & 0.71 & $<0.01$ \\
\hline Epintelim height $(\mu \mathrm{m})$ & 0.08 & $>0.1$ & 0.22 & $>0.1$ \\
\hline Spermategonia $(\mathbf{x})$ & -0.75 & 0.01 & -0.78 & $<0.01$ \\
\hline Primary spermutocyes (x) & 0.14 & $>a .1$ & 0.12 & $>0.1$ \\
\hline Roand spermuxids $(\boldsymbol{x})$ & 0.41 & 0.01 & 0.43 & a.01 \\
\hline Elonged spermatids (x) & 0.62 & 0.01 & 0.69 & $<0.01$ \\
\hline Spermatooua $(x)$ & 0.39 & 0.05 & 0.23 & $>0.1$ \\
\hline Tubular/intertubular tatio & 0.38 & 0.05 & 0.23 & $>0.1$ \\
\hline Luminalfimertubular ratio & 0.54 & 0.01 & 0.42 & a.01 \\
\hline
\end{tabular}

height, due to the appearance of more mature spermatogenic cell types, occur [19]. Thus, the increase in echogenicity is associated with these testicular changes leading to the onset of pubertal spermatogenesis $[5,17,20]$. Furthermore in agreement with a similar study in ram lambs, the seminiferous tubular diameter of the present study had the strongest correlation with testicular echotexture [5].

To investigate the echotextural characteristics of adult cats with impaired spermatogenesis, a suitable pharmacological model was used for Experiment IL. As previously reported [15], in these cats. the GnRH antagonist treatment reduced testicular volume causing mild seminiferous tubular deterioration which could mimic subfertility cases. In spite of these mild histomorphometric testicular changes, computer-assisted image analysis of B mode ultrasonogram could differentiate abnormal from normal spermatogenesis by a significant decrease in pixel intensity. Although it can be assumed than more severe lesions, e.g. testicular degeneration or atrophy, could be quantitatively more evident, the reproductive importance to these end stage lesions is much less clinically relevant. Similarly, in bulls echogenicity decreased in the first 2-3 weels after scrotal insulation, coincidently with the diminution in sperm motility and normal morphology [21]. In stallions, retained abdominal testes have also lower and less heterogeneous echogenicity than scrotal testes [9]. In domestic dogs, poor seminal quality has been associated with decreased parenchyma echogenicity [22 and future sperm motility was positively related to gonadal echogenicity [23].

Testicular spermatogenic cells are known to affect the grey-scale appearance of scrotal ultrasonograms [5] and changes in the composition of tubular cell population affect echotexture. Thus, in both experiments, the cytological and echotextural correlations shifted from negative with the less mature cell types -i.e. spermatogonias - to positive with the more mature cell types - i.e. elongated spermatids-in spermatogenesis evidencing a marked increase in echogenicity.

It was concluded that, in domestic cats, testicular parenchyma variations were accompanied by changes in their echotexture, thus, 
computer-assisted image analysis of B mode ultrasonogram appears as a good indicator of pubertal development and mild alterations of spermatogenesis. Further research in a larger number of animals needs to be carried out before computerized image anal. ysis of ultrasonograms may be widely used in clinical settings.

\section{Author statement}

Florencia D'Francisco: Analysis and initial interpretation of data, Writing- Original draft preparation. Cristina Cobello: Conceptualization, Methodology, Writing- Reviewing and Editing, General su. pervision, Funding. Mariana Lopez Merlo: Acquisition and interpretation of echographical data. Camila Lapuente: Investigation: Claudio Barbeito: Acquisition and interpretation of histologi. cal data.

\section{CRediT authorship contribution statement}

F. DFrancisco: Formal analysis, Writing - original draft. C. Lapuente: Methodology. M. Lopez Merlo: Methodology. C. Bar beito: Supervision, Software. C. Cobello: Conceptualization, Funding acquisition, Imvestigation, Supervision, Writing - review \& editing.

\section{Declaration of competing interest}

The authors declare that there is no conflict of interest that could be perceived as prejudicing the impartiality of the research reported.

\section{Acknowledgements}

This study was partially supported by the Incentive Program of Teaching and Research of the National University of La Plata V269. The authors thank the Contraception \& Reproductive Health Branch Center for Population Research, National Institute of Child Health \& Human Development, National Institutes of Health, USA, for providing acyline and Mr Ruben Mario for the histological assistance. FD'F, Cl. and MLM are a Research Fellows, and CG and CB are Career Scientists of CONICET, Argentina.

\section{References}

[1] Pira MR, Burrai GP, Miu F, Fakhi L, Zedda MT, Pau S, et al Stractare of preantral follicles, oxidative stanus and developmental competence of in virse marated cocyes after ovary storige at $4{ }^{-} \mathrm{C}$ in the domestic cat model Repred Bibl Endocribel 2018;16(1):76. limpre/Ndoi.org/10.1186/512968-018-0395-1.

12) Axnét E, Strón B, Linde-Forsbery C, Custawsen L, Lindblad K, Wallyren M Repreductive disondes in 10 demestic male cass / Small Anim Prat

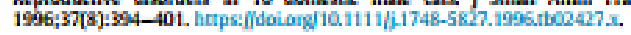

[3] Johtuston SD, Roor Kastrizz MV, Okion PN. Claical approach to the complaine of infertility in the male cat, ln: Canine and feline theriogenology. Philadelphia Sunders: 2001, a. 544-8

14] Nyland TG, Martoon 5 . Veterinary dingnosic ulmasound. Philadelphia:
Sunders; 1995. 357 pp.

[5] Gimin Jl, Franks SF, Rodrigare-Sosa JR, Hahnel A, Eartewski PM. A study of merphological and haemadymamic determinants of testicular echocesture

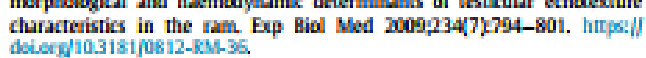

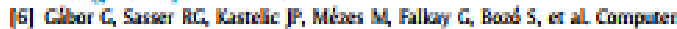

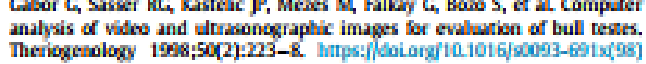
$00128-0$.

[7] Brito LF, Barth $A D$, Wide RE, Kastelic JP. Testicular ultrasonegram pixel intensity during serual development and is relarionship with semen quality, spermi production, and cuancintive terticulat bistology in bect bulk. Thes-

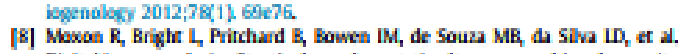
Digital imige analysis of testicular and prostaric ultrasonogaphic ectogencity and heterogeneity in dogs and the relation to semen qualify. Anim Beprod Sci 2015;160:112-2 hittpre.jdai.erg/10.1016.janireproici.2015.07.012.

[9] Paza M, Merrissey $H$, Nantese V, Kouzam N Deriberprey A Macphersen ML, es al. Reliationship between echocextural and histomorptometric characteristics of stallion testes. Theriogenology 2017;99:134-45.

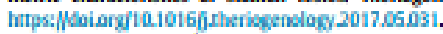

[10] Garci Romero G, Ferninder PE, Gimeno E, Barbeito C, Cobello C. Effects of the CakH anagenist acyline on the testis of the demestic cat (Felis canus). Ver )

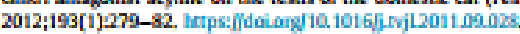

[11] Lin CC, Huang W], Chen KK. Mexarement of testicular volume in smallet testes: how aceurate is the conventicnal orchidometer? J Androl 2009;30(6):

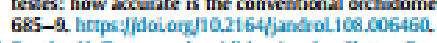

[12] Booche H. Testes and epididymies, In: Slatter D, editor. Texabook of small animal surgery. Philadelphia: Sunders RW; 1993. p. 1331-5.

[13] Franca LR, Codinho CL. Testis morphometry, seminiferous epinheliam cyck lenght, and daily sperm prodaction in domestic cass (Felis catus) Bol seprod 2003;63(5):1554-61. Antps:!doiang10. 10a5/pialreprod.102.010652.

[14] Sinchez B, Rizarro M, Garcia P, Fores JM. Poritnatal development of seminifcrous tubules in the cat.) heprod fentil suppi 1993,47:343-R

[15] Cobello C. Effects of Gnsith antragonists vs agoníss in domestic carnivores, a

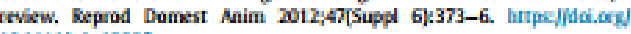
10.1111 /rea. 12025 .

[16] Hamm B, Fobbe F. Mruration of the testis: drraound evaluation. Utrasound Med Bial 1995:21(2)k143-7. Mntps://Woiarg/10.1016/50301-5629(94)000583.

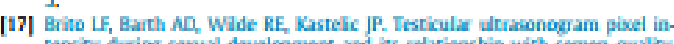
tensily during sexual development and its relationship with semen qualiny. sperm peoduction, and cuancitarive testicular histology in beef bulk. Theriogenologe 2012;78(1) the76.

[18] Chandolia BK, Bartiewsik PM, Omeke BC, Beand N, Rawlings NC, Pierson RA Ultrasonography of the developing reproductive triat in tam lambe effects of a GaRH agenist. Theriogenology 1997,4\& 11, 99e117.

[19] Evans AC, Pierson RA Garcia A, McDougall LM, Hrudla F, Rerwlings NC Changes in circulating hormone concentrintions, testes histology and testes during sexul maturation in beef bulls. Theriogenology 1995:46/2) 345e57.

[20] Bartiewsiki PM, Giflin JL, Olawole OA, Hahnel NC. Prespective ultrasenographic and endocrine predictars of spermarogenic enset in ram lambs. Anim Seprod

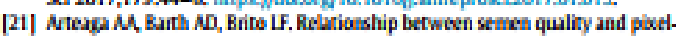
intensity of testicular ultrasoograms after scrocal itsulation in beef bulls.

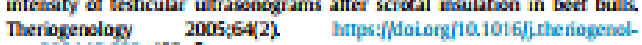
neriagenology, $208-5$.

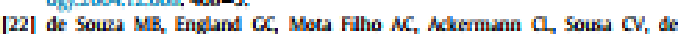
Carvilino $C G$, es al. Semen qualiny, testicular B-mode and Doppler ultasound, and serum testasterone cencentrations in dogs with estalished infertility.

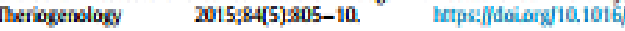
j.theriogenology.2015.06.015.

[23) England G, Bright L, Pritchard E, Bowen IM, de Sowa Mg, Silva L, et al Canine repreductive ultrasound examination for predicting finse sperm qualiry. Reprod Domest Anim 2017,52[Suppl 2)202-7. Irtps:(/foionglá.1111) rda.12825. 